\title{
Genotypic variation in drought response of silver birch (Betula pendula Roth)
}

\author{
Dissertation \\ zur Erlangung des Doktorgrades \\ der Mathematisch-Naturwissenschaftlichen Fakultäten \\ der Georg-August-Universität zu Göttingen
}

vorgelegt von

Stella Aspelmeier, geb. Landwehr aus Verl

Göttingen, den 17. September 2001 
D7

Referent: Prof. Dr. Ch. Leuschner Korreferent: Prof. Dr. M. Runge

Tag der mündlichen Prüfung: 30. Oktober 2001 


\section{Contents}

\begin{tabular}{ll}
\hline 1. Introduction & 7
\end{tabular}

2. Plant material and experimental setup 9

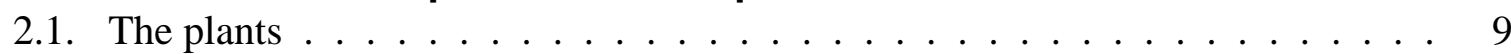

2.2. The experimental setup . . . . . . . . . . . . . . . . . 9

2.3. Weather conditions at the site of the experiment in 1999 and 2000 . . . . . . . 12

3. Methods 14

3.1. Analysis of isoenzyme systems of the birch clones . . . . . . . . . . . . . . . 14

3.2. Leaf water status parameters . . . . . . . . . . . . . . . 15

3.2.1. Measurement of leaf water potential . . . . . . . . . . . . . . . 15

3.2.2. Establishment of pressure-volume curves . . . . . . . . . . . . . . . 16

3.3. Leaf gas exchange parameters . . . . . . . . . . . . . . 17

3.3.1. Investigation of $\mathrm{CO}_{2}$ and $\mathrm{H}_{2} \mathrm{O}$ gas exchange under constant conditions . 17

3.3.2. Measurement of stomatal conductance and transpiration at ambient VPD 22

3.4. Chlorophyll content of the leaves . . . . . . . . . . . . 22

3.5. Carbon isotope ratio and nitrogen content of bulk leaf tissue . . . . . . . . . 24

3.6. Growth, biomass and allocation parameters . . . . . . . . . . . . 25

3.6.1. Determination of growth and senescence . . . . . . . . . . . 25

3.6.2. Investigation of biomass and allocation parameters . . . . . . . . . 25

3.7. Calculation of plasticity of the measured parameters . . . . . . . . . . . 26

3.8. Statistical analysis of the data . . . . . . . . . . . . . . . . 27

\begin{tabular}{ll}
\hline 4. Results & 28
\end{tabular}

4.1. Isoenzyme systems . . . . . . . . . . . . . . . . . . . 28

4.2. Leaf water status parameters . . . . . . . . . . . . . . . . . . . . . 29

4.2.1. Leaf water potential . . . . . . . . . . . . . . . . . 29

4.2.2. Parameters obtained from pressure-volume curves . . . . . . . . . . . 30

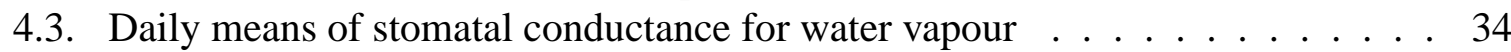

4.3.1. Stomatal conductance measured under constant conditions with low VPD 34

4.3.2. Stomatal conductance measured under natural conditions . . . . . . . . 36

4.4. Leaf gas exchange and photosynthesis . . . . . . . . . . . . . . . 37

4.4.1. Net photosynthesis and photosynthetic water-use efficiency at ambient

$\mathrm{CO}_{2}$ concentration and light saturation . . . . . . . . . . 37

4.4.2. Photosynthetic capacity, carboxylation efficiency, and compensating and saturating $\mathrm{CO}_{2}$ concentrations $\ldots \ldots \ldots \ldots 41$

4.5. Chlorophyll and nitrogen content of the leaves . . . . . . . . . . . . . . 43 
4.5.1. Chlorophyll content per unit leaf area . . . . . . . . . . . . . . . 43

4.5.2. Foliar nitrogen content and $\mathrm{C}: \mathrm{N}$ ratio . . . . . . . . . . . . . . 45

4.6. Carbon isotope composition of bulk leaf tissue . . . . . . . . . . . . . . . 47

4.7. Morphology of the leaves and fine roots . . . . . . . . . . . . . . . . 50

4.7.1. Morphology of the leaves . . . . . . . . . . . . . . 50

4.7.2. Morphology of the fine roots . . . . . . . . . . . . . . . 52

4.8. Growth and phenology . . . . . . . . . . . . . . . 54

4.9. Biomass and allocation . . . . . . . . . . . . . . . 56

5. Discussion 62

5.1. Order of appearance and plasticity of different leaf and plant level responses to drought - the strategy of Betula pendula . . . . . . . . . . . . . . 63

5.1.1. Leaf gas exchange, water potential, and water use efficiency . . . . . 63

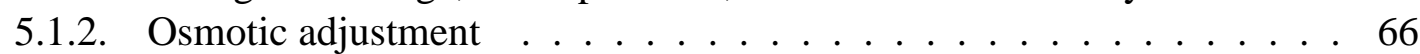

5.1.3. Chlorophyll and nitrogen content of the leaves . . . . . . . . . . . . 68

5.1.4. Morphology of leaves and fine roots . . . . . . . . . . . . . . . . . . 69

5.1.5. Biomass allocation . . . . . . . . . . . . . 71

5.1.6. The drought response of silver birch . . . . . . . . . . . . . . . 72

5.2. Similarities and differences between the four genotypes of silver birch . . . . . 73

5.2.1. Theoretical background on phenotypic plasticity . . . . . . . . . 73

5.2.2. Microenvironmental plasticity . . . . . . . . . . . . 75

5.2.3. Comparison of the four genotypes of silver birch $\ldots . . . . . .76$

\begin{tabular}{ll}
\hline 6. Summary & 83
\end{tabular}

\begin{tabular}{ll}
\hline A. Plasticity & 85
\end{tabular}

\begin{tabular}{ll}
\hline B. Multivariate analyses of variance & 88
\end{tabular} 


\section{List of Figures}

2.1. Long-standing climatic averages at weather stations near the places of origin of the investigated birch clones. . . . . . . . . . . . . . . . . 10

2.2. Mean soil water contents of the droughted (D99 and D99/D00) birch trees 1999

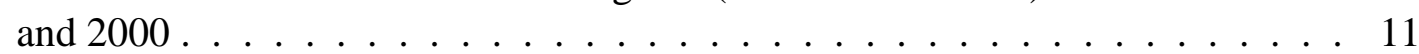

2.3. Climate data recorded at the weather station Göttingen in 1999 and 2000 . . . . 13

3.1. Example of a pressure-volume curve . . . . . . . . . . . . . . . 16

3.2. Calibration of the SPAD-502 chlorophyll meter for leaves of Betula pendula. . 23

4.1. Leaf water potentials $\left(\Psi_{\text {pre }}\right.$ and $\left.\Psi_{\min }\right)$ of the four birch clones during the summers of 1999 and $2000 \ldots \ldots \ldots \ldots$

4.2. Osmotic potentials at saturation and at the turgor loss point $\left(\Pi_{0}\right.$ and $\left.\Pi_{\mathrm{p}}\right)$ of the four birch clones during the summers of 1999 an 2000 $\ldots \ldots$. . . . . . . . 31

4.3. Apparent and relative osmotic adjustment of the four birch clones in early $\mathrm{Au}-$ gust 1999 and 2000. . . . . . . . . . . . . . . . . . . 32

4.4. Daily means of stomatal conductance $\left(g_{\mathrm{sw}}\right)$ of the four birch clones during the growing seasons 1999 and $2000 \ldots \ldots \ldots \ldots$

4.5. Daily means of stomatal conductance of the four birch clones during the grow-

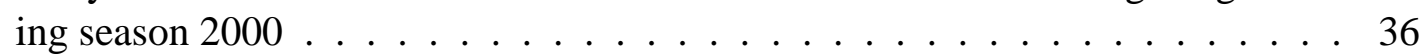

4.6. Daily means of net photosynthesis $\left(A_{\mathrm{amb}}\right)$ of the four birch clones during the growing seasons 1999 and $2000 \ldots \ldots \ldots \ldots$

4.7. Daily means of the water use efficiency (WUE) of the four birch clones during the growing seasons 1999 and $2000 \ldots \ldots \ldots \ldots$. . . . . . . . . . 39

4.8. Chlorophyll content of the birch leaves during the summers 1999 and 2000 . . 44

4.9. C:N ratio and nitrogen content per dry mass of the birch leaves during the summer of 2000 . . . . . . . . . . . . . . . . . . . . 45

4.10. Foliar nitrogen content per leaf area during the summer of 2000 . . . . . . . 46

4.11. $\delta^{13} \mathrm{C}$ values of bulk leaf tissue of the birch clones during the summer of 1999 . 47

4.12. $\delta^{13} \mathrm{C}$ values of bulk leaf tissue of the birch clones during the summer of 2000. . 48

4.13. Leaf-internal $\mathrm{CO}_{2}$ concentration as calculated from foliar $\delta^{13} \mathrm{C}$ values of the four birch clones during the growing seasons of 1999 and $2000 . \quad$. . . . . . . . 49

4.14. Average leaf areas of third and fourth leaves of the harvested trees 1999 and 200051

4.15. Relative contribution of five diameter classes to total finest root surface area (diameter $\leq 1.0 \mathrm{~mm}) 2000 \ldots \ldots \ldots \ldots \ldots$

4.16. Leaf-numbers of the birch trees in the growing seasons 1999 and 2000 . . . . . 55

4.17. Relative shoot and root biomass reduction of the droughted plants in comparison to the well watered ones 1999 and $2000 \ldots \ldots$. . . . . . . . . 56 
4.18. Living biomass and necromass, and percentage of necromass of the roots of the trees harvested in $2000 \ldots \ldots \ldots \ldots \ldots 7$

4.19. Average total leaf areas and fine root areas of the trees harvested in 2000 . . . . 58

4.20. Root:shoot ratios of the harvested trees 1999 and 2000 . . . . . . . . . . . . 59

4.21. Fine root:leaf dry mass ratios of the harvested trees 1999 and 2000 . . . . . . . 60

4.22. Fine root surface area:leaf area ratios of the harvested trees 1999 and 2000 . . . 61

5.1. Regressions of photosynthetic water use efficiency against $\delta^{13} \mathrm{C}$ values of bulk leaf tissue 1999 and $2000 \ldots \ldots \ldots \ldots$. . . . . . . . . . . 65

5.2. Reaction norms of chlorophyll contents, specific leaf areas, and fine root:leaf mass ratios in 1999 and $2000 \ldots \ldots \ldots$. . . . . . . . . . . . . . . . . . . . . 


\section{List of Tables}

2.1. Nutrients administered with each $500 \mathrm{ml}$ fertilizer solution of $2 \mathrm{~g}$ "Hakaphos blau" per liter water. $\ldots \ldots \ldots \ldots$. . . . . . . . . . . . . 10

2.2. Scheme of the different treatments of the four clones during the growth periods of 1999 and $2000 . \ldots \ldots \ldots \ldots 1 \ldots \ldots \ldots$

3.1. Scheme for the analysis of isoenzyme systems. . . . . . . . . . . 15

4.1. Genotypes of the four birch clones at six enzyme loci . . . . . . . . . . . . 28

4.2. Matrix of genetic distances between the four birch clones . . . . . . . . . . . 28

4.3. Moduli of tissue elasticity near full turgor $\left(\varepsilon_{\max }\right)$ of leaves of the birch clones throughout the growing seasons 1999 and 2000. . . . . . . . . . . . . 33

4.4. Net photosynthesis, stomatal conductance, intercellular $\mathrm{CO}_{2}$ concentration, and photosynthetic water use efficiency of the four birch clones after about 11 weeks of drought in 1999 and 2000. . . . . . . . . . . . . . . . . 40

4.5. Photosynthetic capacity per leaf area and per gram chlorophyll, carboxylation efficiency, and saturating $\mathrm{CO}_{2}$ concentration of the four birch clones in early August 1999 and 2000 . . . . . . . . . . . . . . . . . 42

4.6. Specific leaf area of the four birch clones in 1999 and 2000. . . . . . . . . . . . 51

4.7. Specific fine root surface area (SRA) and number of root-tips per mg dry weight of the fine roots of the four birch clones as obtained from harvests in 200052

5.1. Chronological order of response of different physiological and biochemical parameters to the water shortage . . . . . . . . . . . . . . 64

5.2. Ranking of relative plasticity of different generic groups of parameters measured in the summer of $2000 \ldots \ldots \ldots 71$

5.3. Microenvironmental plasticity as quantified by the coefficient of variation of 18 parameters measured in $2000 \ldots \ldots \ldots \ldots 76$

5.4. Significance of the influence of the treatment, the genotype, and the product of treatment $\mathrm{x}$ genotype on the variance of different parameters $\ldots . . . . .80$

5.5. Ranking of relative plasticity of 40 physiological, biochemical, morphological, production, and allocation parameters measured in the summer of 2000 . . . . 82

A.1. Relative plasticity of the four clones with regard to the water status parameters. 85

A.2. Relative plasticity of the four clones with regard to the water exchange parameters as calculated from measurements with the LI-1600 steady-state porometer.

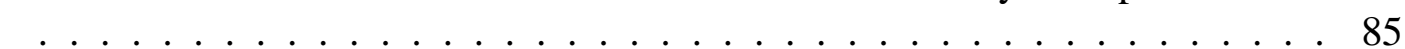

A.3. Relative plasticity of the four clones with regard to the daily means of gasexchange parameters as calculated from measurements with the LI-6400 system 86 
A.4. Relative plasticity of the four clones with regard to the gas-exchange parameters calculated from $\mathrm{CO}_{2}$ response curves in early August 1999 and $2000 . \quad$. . . 86

A.5. Relative plasticity of the four clones with regard to the nitrogen and chlorophyll contents and the carbon isotope composition of their leaves. . . . . . . . . . . 86

A.6. Relative plasticity of the four clones with regard leaf morphology. . . . . . . . 87

A.7. Relative plasticity of the four clones with regard fine root morphology . . . . . 87

A.8. Relative plasticity of the four clones with regard to patterns of allocation . . . . 87

B.1. Multivariate analysis of variance of the moduli of elasticity of bulk leaf tissue . 88

B.2. Multivariate analysis of variance of the maxima of stomatal conductance measured in 2000 . . . . . . . . . . . . . . . . 88

B.3. Multivariate analysis of variance of gas exchange parameters obtained from

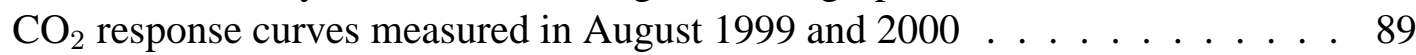

B.4. Multivariate analysis of variance of some leaf gas exchange parameters measured at constant low VPD in 1999 and 2000 . . . . . . . . . . . . . . . . 90

B.5. Multivariate analysis of variance of $\delta 13 \mathrm{C}$ values of bulk leaf tissue . . . . . . . 90

B.6. Multivariate analysis of variance of foliar chlorophyll contents . . . . . . . . . 91

B.7. Multivariate analysis of variance of specific and total leaf areas as calculated from harvests in August 1999 and $2000 \ldots$. . . . . . . . . . . . . 91

B.8. Multivariate analysis of variance of specific and total fine root areas and fine root:leaf area ratios as calculated from harvests in August 2000 . . . . . . . . . 92

B.9. Multivariate analysis of variance of root:shoot and fine root:leaf mass ratios as calculated from harvests in August 1999 and 2000 . . . . . . . . . . . . . . 92 


\section{Introduction}

The genus Betula belongs to the family Betulaceae and includes about 48 monoecious and anemophilous species with distributions in the temperate and arctic zones of the northern hemispere (KLEINSCHMIT 1998).

Silver birch (Betula pendula Roth.) is distributed in the temperate and boreal zones of Europe, and displays the widest physiological amplitude of all mid European broad-leaved tree species (ELLENBERG 1996). The trees are fast growing and exceptionally tolerant to spring frost, low temperatures in general, and nutrient deficiency, though their ecological amplitude is limited by shade intolerace and short life span (KLEINSCHMIT 1998). B. pendula is a species of early successional stages of forests in most parts of central Europe. ELLENBERG (1996) rates white birch susceptible to drought, although its ecogram groups this species among the few capable of growth at both the wet and the drought limit of forest growth (shallow soils on sun-exposed rocks), like Pinus sylvestris, with which it is often associated.

Several studies suggest increasing dominance of broad-niched, early-successional species as a result of a general northward migration of species, if predictions of global warming come true (PRENTICE et al. 1991; PRENTICE 1993; BAZZAZ 1996). Therefore, knowledge of the factors enabling these species to occupy such variant habitats is of predominant importance.

A high degree of ecological variation, i.e. a wide range of different habitats potentially occupied by a species (BAZZAZ 1996), can be achieved by different means: the species can show a high degree of genetic variability, comprising genotypes especially adapted to different habitats, or the genotypes can exhibit phenotypic plasticity, coding for the ability of the individual to express different phenotypes in different environments (GREGORIUS and KLEINSCHMIT 1999). Phenotypic plasticity is a heritable trait and thus subjected to evolution.

The ecological hypothesis of SCHLICHTING and LEVIN (1984) predicts that the pattern of selection on plasticity differs between habitats, leading to a habitat-correlated variation in reaction norm, i.e. plasticity. Provenance differences in drought sensitivity were observed for example in Fagus sylvatica (TOGNETTI et al. 1995; GARCÍA-PlAZAOLA and BECERRIL 2000), Pinus sylvestris (PALMROTH et al. 1999), and different species of Eucalyptus (TUOMELA 1997; Li 1998; LI et al. 2000; PITA and PARDOS 2001).

This study pursues two aims: first, to investigate the drought response of Betula pendula in a multi-level whole-tree approach and to try to elucidate the discrepancy of growth at the drought limit of forest growth on the one hand and high susceptibility to drought on the other. The second aim is to analyse variation in drought sensitivity and response between different clones of this species and to assess the phenotypic plasticity and possibly differing adaptive behaviour of genotypes from climatically different origins.

The use of clonal plants makes it possible to exactly replicate a given genotype in different environments, thus it is possible to study its inherent capacity for phenotypic plasticity 
(WU 1998). By this means, significant clonal variation in the plastic reactions and susceptibility of Betula pendula has been detected for example in response to different levels of ozone (HOLOPAINEN and KÄRENLAMPI 1997), or ozone and water availability (P̈̈ÄKKÖNEN et al. 1998a).

Four clones of silver birch from origins differing in amounts of precipitation in Austria, Germany, and Sweden were subjected to a prolonged drought period (about 3 months with soil water contents below 3 vol\%) in two subsequent summers.

Frequent measurements of different parameters of the water and $\mathrm{CO}_{2}$ gas exchange, chlorophyll contents and leaf water potentials, establishment of pressure-volume curves during each drought period, and repeated investigations of foliar carbon isotope composition and nutrient contents facilitate the analysis of not only pattern and extent of drought responses, but their time-course as well. Quantitative harvests of the above- and belowground biomasses of trees after each drought period and the survey of absorbing and transpiring surfaces render it possible to assess patterns of allocation. The influence of the genotype on drought-responses of different traits is calculated from a comparison of results obtained from drought-stressed plants with those measured at well-watered control trees and a drought-and-recovery treatment in the second year of investigation. Reaction norms are used to visualize variability of phenotypic plasticity between the genotypes. 


\section{Plant material and experimental setup}

\subsection{The plants}

Forty plants each of 4 different clones of Betula pendula were used in the experiment. The plants were propagated from tissue cultures in 1998 and then grown in fertile soil in green houses for 6 to 12 months until early spring 1999.

The Swedish provenance Bp-Swed. (local acronym COST 1) was propagated in cooperation with the Niedersächsische Forstliche Versuchsanstalt, Abteilung für Forstpflanzenzüchtung, Staufenberg, Germany. It originates from a tree selected by the Institute for Forest Tree Improvement in Ekebo, Svalöv, in Sweden (ca. $40 \mathrm{~km}$ north of Malmö). The local climate is suboceanic with moderately cold winters and mild summers with periodic water shortage occurring on sandy soils. The mean annual precipitation measured at the weather station Malmö is $553 \mathrm{~mm}$, the mean annual temperature is $7.9^{\circ} \mathrm{C}$ (see Fig. 2.1. MÜLLER 1996).

The East-German clone Bp-Germ. (local acronym SB390) was supplied by the Bundesforschungsanstalt für Forst- und Holzwirtschaft, Institut für Forstgenetik und Forstpflanzenzüchtung, in Waldsieversdorf, Germany (near Eberswalde, north-east of Berlin). The parent tree originates from a stand on sandy soil in Waldsieversdorf. The mean annual precipitation amounts to $581 \mathrm{~mm}$ and the mean annual temperature is $8.9^{\circ} \mathrm{C}$ (weather station Berlin-Dahlem, see MÜLLER 1996). The growth climate is suboceanic with moderately cold winters and warm summers with periodic water shortage.

Two Austrian clones (Bp-Aust.1 and Bp-Aust.2, local acronyms SB8 and SB7) were supplied by Vitro Plant Biotechnologie GmbH, Klosterneuburg, Austria. They originate from trees in Schneegattern (Vöklabruck, ca. $50 \mathrm{~km}$ north-east of Salzburg). The growth climate in this western part of the northern foothills of the Alps is oceanic with cold winters and warm summers with abundant rainfall. The annual precipitation amounts to $1278 \mathrm{~mm}$, with a mean annual temperature of $8.1^{\circ} \mathrm{C}$ (weather station Salzburg MüLLER 1996).

On April 1, 1999, the substrate was carefully washed off the roots of the plants and the trees were planted individually in large 451 pots filled with nutrient-poor, medium-grained quarzitic sand.

\subsection{The experimental setup}

The experiment was conducted at the Albrecht-von-Haller-Institut für Pflanzenwissenschaften of the University of Göttingen. The plants were placed outdoors in the experimental botanical garden, next to a mobile plexiglas roof equipped with a rain sensor, which automatically covered the plants when it rained. Thus, the birches grew under the local microclimate, but with complete control of soil water supply. The pots with the 4 genotypes and each two (1999) or 

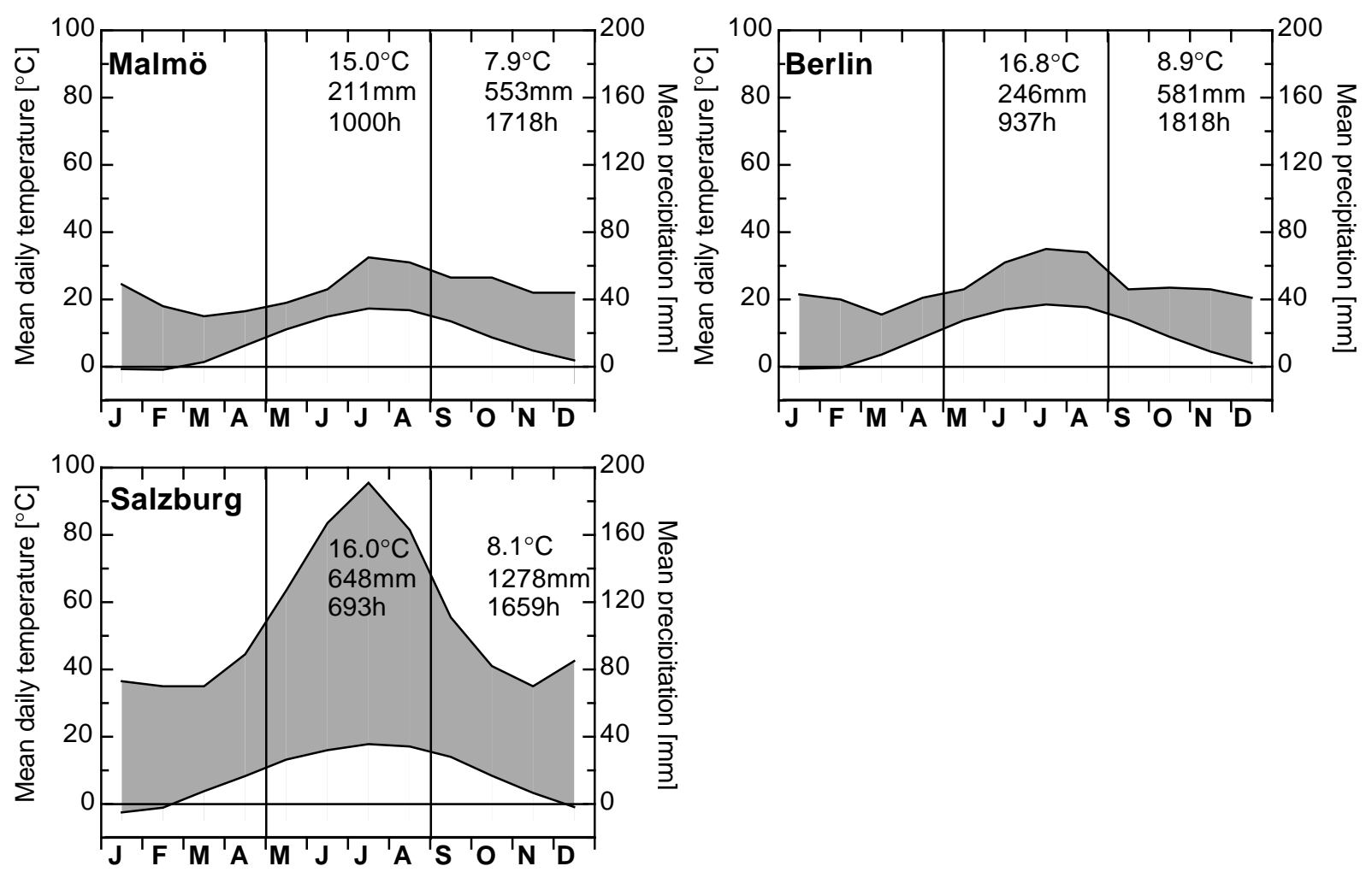

Figure 2.1.: Longstanding averages of climate parameters at the places of origin of the four investigated birch clones. The graphs show the average monthly temperature and precipitation. The numbers in the top right corner indicate the mean annual temperature, the annual precipitation, and the annual hours of sunshine. The numbers in the centre of the figure show the same parameters for the period from May to August, which is delimited by lines (MÜLLER 1996).

three (2000) different treatments (see Tab.2.2) were positioned in alternating order to minimize potential influences of environmental gradients at the experimental site.

From May to July of both 1999 and 2000, the plants were fertilized at intervals of 3 to 4 weeks, each pot with $500 \mathrm{ml}$ of the fertilizer solution described in Tab. 2.1. In both years, they were treated twice with a contact insecticide against aphids.

Table 2.1.: Nutrients administered with each $500 \mathrm{ml}$ fertilizer solution of $2 \mathrm{~g}$ "Hakaphos blau" per liter water.

\begin{tabular}{llllllllll}
\hline \multicolumn{1}{l}{ Macronutrients $[\mathrm{mM}]$} & \multicolumn{8}{l}{ Micronutrients $[\mu \mathrm{M}]$} \\
\hline $\mathrm{N}$ & $\mathrm{P}$ & $\mathrm{K}$ & $\mathrm{Mg}$ & $\mathrm{Fe}$ & $\mathrm{Mn}$ & $\mathrm{Cu}$ & $\mathrm{Zn}$ & $\mathrm{Mo}$ & $\mathrm{B}$ \\
\hline 6.04 & 1.40 & 3.20 & 0.50 & 9.00 & 9.00 & 3.00 & 2.30 & 1.00 & 9.00 \\
\hline
\end{tabular}

After planting the trees into 451 pots in April 1999, they were reguarly watered to field capacity until the end of May 1999. 
On June 1, 1999, 26 pots per clone were randomly selected for a drought treatment (treatment D99) that lasted for 12 weeks until early September. Water was withheld from these pots until they reached the target soil water content of $3 \mathrm{vol} \%$ (10\% of the soil water content at field capacity) at the end of June. A mobile TDR probe (time domain reflectometry probe, Trime FM2, IMKO GmbH, Ettlingen, Germany) was used to monitor the soil water content of all droughted plants at intervals of 2 to 3 days. Since the two probe sticks of this device are $16 \mathrm{~cm}$ long, the integrated water content of the uppermost $16 \mathrm{~cm}$ of soil in the pots, which were filled to a height of about $25 \mathrm{~cm}$ with sand, was measured. Three parallel measurements were made in each pot.

Water was then added to the pots in quantities that guaranteed a permanent water content of below $3 \mathrm{vol} \%$ in the experimental period from June to early September. At this level, distinct responses of the plants to the drought stress could be observed, but they did not shed their leaves or even die. Due to differences in plant size and associated water loss among the individuals, variable amounts of water had to be supplied to the pots to maintain comparable soil water contents. The mean soil water contents of the drought stressed treatments as measured regularly with the TDR probe are shown in Fig. 2.2 .

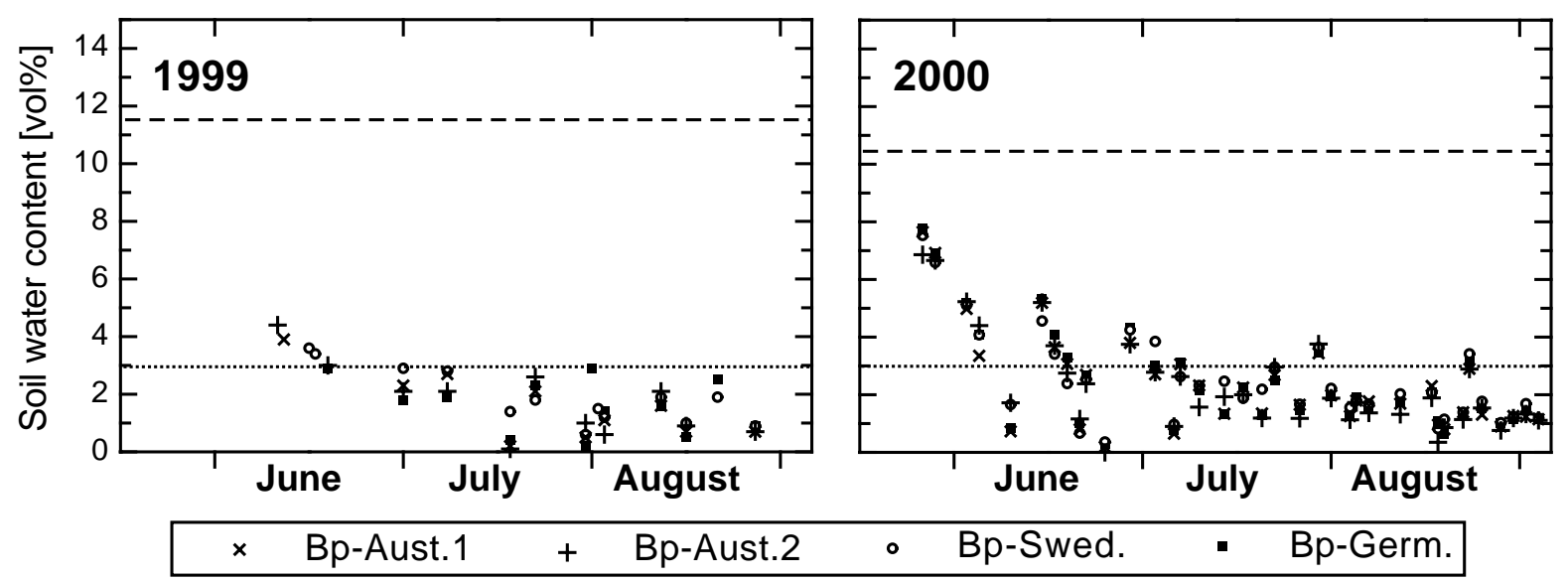

Figure 2.2.: Mean soil water contents of the droughted birch trees in the summers of 1999 (D99) and 2000 (D99/D00). The dashed lines indicate the spot checked soil water contents of the well watered plants.

The remaining 14 plants of each clone were watered to field capacity every or every other evening and represented the well-watered control treatment (W99). The water content of these pots was spot checked with the TDR probe before they were watered, it amounted to an average $11.6 \mathrm{vol} \%$.

From early September 1999 to mid May 2000, the mobile roof was turned off and all plants were subjected to natural rainfall. During the winter months, the pots were moved closer together and covered with leaves to prevent them from freezing.

On May 15th, 2000, the second drought cycle began. Water was again withheld from 11 of those 22 trees which had been subjected to a drought treatment in the summer of 1999 (4 trees per treatment and clone had been harvested in September 1999) until the target water content of $3 \mathrm{vol} \%$ was reached in early June. They were kept at a water content of below 
3 vol\% (controlled with a TDR probe) until the end of August (14 weeks, treatment D99/D00). The other 11 plants which had been droughted in 1999 were now treated like the controls and watered every or every other evening to field capacity in order to study recovery from the previous year's drought stress (treatment D99/W00, control treatment W99/W00). The water content of the W00 treatments was again spot checked with the TDR probe and averaged to $10.2 \mathrm{vol} \%$. A scheme of the different treatments of the four clones during the growth seasons of 1999 and 2000 is shown in Tab.2.2.

Table 2.2.: Scheme of the different treatments of the four clones during the growth periods of 1999 and 2000.

\begin{tabular}{lll}
\hline treatment / year & 1999 & 2000 \\
\hline control (W99/W00) & humid & humid \\
repeated stress (D99/D00) & dry & dry \\
stress and recovery (D99/W00) & dry & humid \\
\hline
\end{tabular}

\subsection{Weather conditions at the site of the experiment in 1999 and 2000}

Climate data recorded by the weather station Göttingen during the two years of the experiment are shown in Fig. 2.3. The trees were subjected to natural rainfall from early September 1999 to May 2000. During the seasons of field measurements from May to September 1999 and 2000 they were watered as described in the previous section, as indicated by lines in Fig. 2.3 . Both temperature and the amount of sunshine hours, however, were changed only negligibly by the plexiglas roof, for it was automatically moved away from the plants when the rainfall stopped (the rain sensors of the roof are heated to ensure fast reactions). Although the mean temperatures during the months of field measurements were similar in both years, differences in the numbers of sunny hours and cloudy days are striking. While in 1999 this period was mostly sunny, with no more than 9 days with an average cloud cover of more than $80 \%, 26$ days were defined "cloudy" in July 2000. 

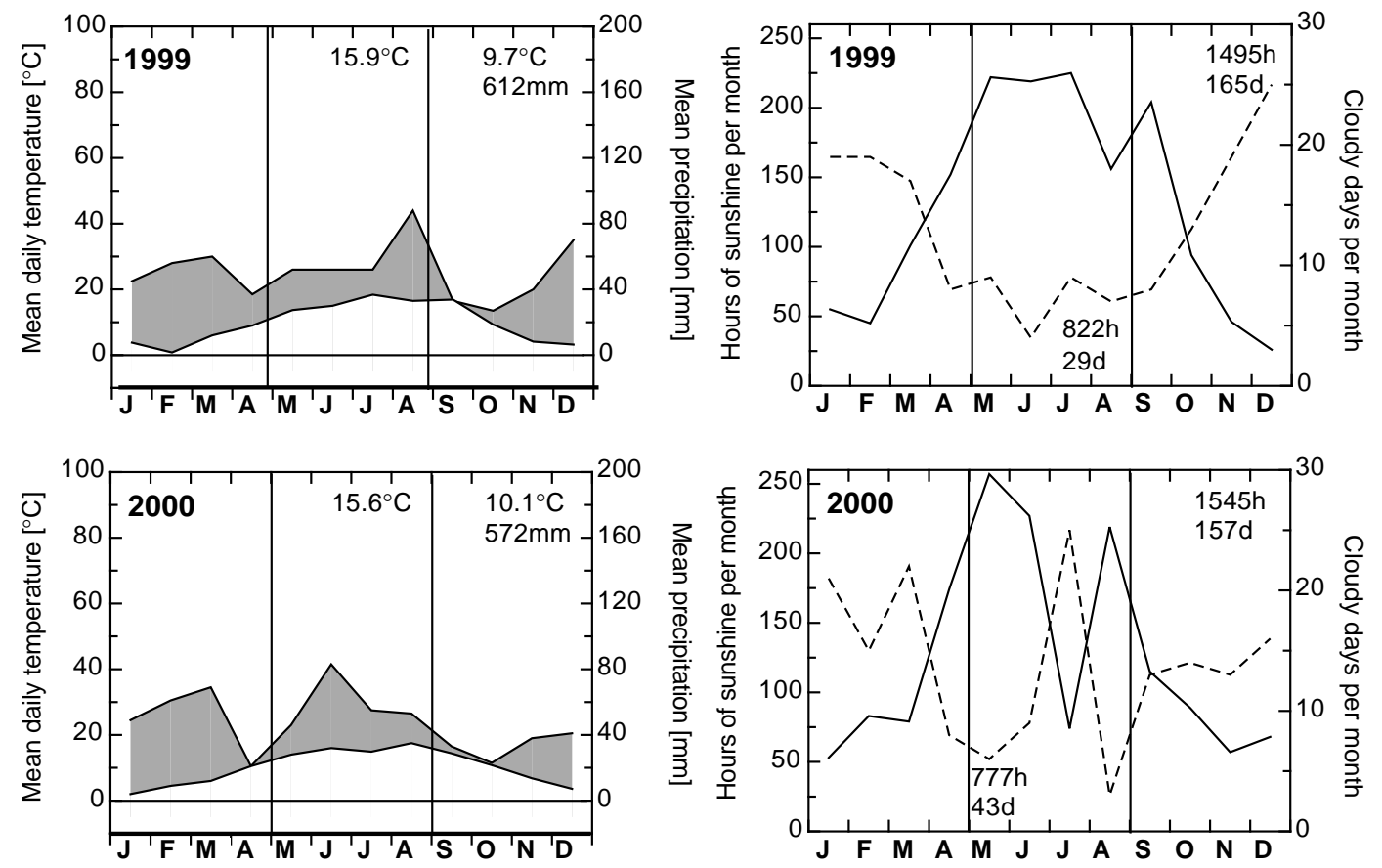

Figure 2.3.: Climate data as recorded by the weather station Göttingen in 1999 and 2000. The two graphs on the left show the average monthly temperature and precipitation. The numbers in the top right corner indicate the mean annual temperature and the annual precipitation, the ones in the figure centre the average temperature for the period of investigation from May to August (delimited by lines). The two graphs on the right indicate the monthly hours of sunshine (solid lines) and the number of cloudy days (daily average of cloud cover $>80 \%$ ) per month (dashed lines). The numbers in the top right corner show the annual sums of these parameters, the numbers on the left bottom the same parameters added up for the investigated time period from May to August (Witterungs Report Daten 1999/2000). 


\section{Methods}

\subsection{Analysis of isoenzyme systems of the birch clones}

To genetically characterize and distinguish the four examined birch clones, an analysis of 6 isoenzyme systems of the trees was carried out by the Arbeitsgemeinschaft Forstgenetik und Forstpflanzenzüchtung (ISOGEN), Göttingen. Punctual mutations of DNA can cause differences in the structures of variants of isoenzymes. If the electric charge and/or the spatial structure of the enzymes are changed, the different isoenzymes can be separated during electrophoresis in an electric field, dependent on different carrier media, e.g. starch, and variable $\mathrm{pH}$. The different variants of one enzyme are then made visible at their distinct positions with the help of enzyme-specific dyes (FERET and BERGMANN 1976; CHELIAK and PITEL 1984; LIENGSIRI et al. 1990).

\section{Extraction and electrophoresis of isoenzymes}

Dormant buds of one tree of each clone were sampled and analysed for the enzyme systems Leucin-Aminopeptidase (LAP), Glutamatoxalacetat-Transaminase (GOT), Isocitrat-Dehydrogenase (IDH), 6-Phosphogluconat-Dehydrogenase (6-PGDH), Menadionreductase (MNR) and Phosphoglucose-Isomerase (PGI).

The samples of bud-tissue were homogenised in $35 \mu \mathrm{l}$ of $0.07 \mathrm{M}$ Tris-HCl-buffer with a $\mathrm{pH}$ of 7.5. To stabilize the activity of the enzymes and to protect them from phenoles and heavy metals, $500 \mathrm{mg}$ sugar, $300 \mathrm{mg}$ PVP, $15 \mathrm{mg}$ DTT, and $5 \mathrm{mg}$ EDTA were dissolved in each $10 \mathrm{ml}$ of extraction buffer. The extracts were applied to a starch gel, which was then subjected to a horizontal electrophoresis. To analyse the isoenzymes 6-PGDH, MNR, and IDH, a Tris-citric acid buffer with pH 7.4 was used, while the analysis of the enzyme systems GOT, LAP, and PGI was carried out using the buffer system Ashton \& Braden pH 8.1 (see Tab. 3.1).

\section{Data analysis}

To quantify the genetic differences between the four clones, the genetic distances $d_{0}$ (GREGORIUS 1974) between them were calculated. If the examined gene-loci of two individuals (= clones) are identical, $d_{0}$ is 0 ; if they do not have an allel in common, $d_{0}$ becomes 1 . The cluster-analysis was carried out using the UPGMA-cluster-algorithm described by SOKAL and ROHLF (1981) based on the genetic distance. 
Table 3.1.: Scheme for the analysis of isoenzyme systems.

\begin{tabular}{llllll}
\hline isoenzyme & buffer system & gel & gelbuffer (A) & electrode buffer (B) & conditions \\
\hline GOT & Ashton \& & 23 g starch & $0.05 \mathrm{M}$ Tris & $0.19 \mathrm{M}$ boronic & constant \\
LAP & Braden & $4 \mathrm{~g}$ sugar & $9 \mathrm{mM}$ citric acid & acid & $75 \mathrm{~mA}$ \\
PGI & pH 8.1 & & $\begin{array}{l}190 \mathrm{ml} \text { buffer A } \\
\text { and } 10 \mathrm{ml} \text { buffer B }\end{array}$ & $\begin{array}{l}0.042 \mathrm{M} \\
\text { lithium hydroxide }\end{array}$ & 4 hours \\
\hline 6-PGDH & Tris Citro & $23 \mathrm{~g}$ starch & $70 \mathrm{ml} \mathrm{buffer} \mathrm{B}$ & $0.15 \mathrm{M}$ Tris & constant \\
MNR & pH 7.4 & $8 \mathrm{~g}$ sugar & and $130 \mathrm{ml} \mathrm{H} \mathrm{H}_{2} \mathrm{O}$ & $0.043 \mathrm{M}$ citric acid & $180 \mathrm{~mA}$ \\
IDH & & & & & 5.5 hours \\
\hline
\end{tabular}

\subsection{Leaf water status parameters}

\subsubsection{Measurement of leaf water potential}

The pressure chamber technique (SCHOLANDER et al.|1965), with which the pressure potential $\Psi_{P}$ of the xylem can be measured, was used to examine the leaf water potentials of the birch trees. The pressure potential is usually negative and when a leaf is excised from a transpiring plant, this tension causes the water retained in the xylem to recede into the leaf and into the mesophyll, thus causing an equalization of the water potentials of the apoplast and the symplasm. By applying increasing air pressure to the leaf, the water can be forced back to the cut end of the xylem. Since both the osmotic potential and the matrical potential of the apoplast are typically negligible (TYREE and JARVIS 1982), and since the water content of the leaf does usually not change during the measurement, theory holds that the pressure that is necessary to force the water back just to the sectional plane is approximately equal to the reciprocal value of the leaf water potential.

With this method, the daily maxima ( $\Psi_{\text {pre }}$, measured before dawn) and minima of leaf water potential ( $\Psi_{\min }$, measured between 12:00 and 13:30 solar time) were measured four to five times from early June to late August of each 1999 and 2000. This was done on bright, sunny days and in the early mornings following such days. Measurements were conducted on single, fully expanded leaves (third and fourth leaves, counted from the terminal bud of a twig), which were cut from the trees and immediately investigated with a pressure chamber by PMS Instruments (Corvallis, Oregon, USA). The time between cutting of a leaf and the beginning of a measurement was usually less than 30 seconds to prevent unnecessary loss of water from the leaves after they had been excised. The leaf was fixed into the chamber with the petiole standing out, so the section could be investigated with a magnifying lens. The pressure was raised by less than $0.3 \mathrm{MPa}$ per second while the cut end of the xylem was being observed. As soon as liquid became visible at the sectional plane, the pressure was noted. Five leaves of different trees of each treatment and each clone were investigated with this technique before dawn and in the early afternoon. It was possible to measure the water potentials of all treatments and clones in about $11 / 2$ hours, so all varieties could be investigated on the same days. 


\subsubsection{Establishment of pressure-volume curves}

Further parameters of the leaf water status were calculated from pressure-volume curves, which were generated using the overpressurization technique in a pressure chamber (TYREE and HAMMEL 1972; TYREE and JARVIS 1982). In both summers, pressure-volume analysis was carried out four times. Four twigs per treatment and clone were analysed in parallel on all sampling occasions (except in June 1999, when only three twigs were studied).

Four twigs from 4 different trees with 4 to 6 each leaves were collected at about 19:00 in the evening, recut under water, and left overnight in the refrigerator for resaturation in beakers filled with water and sealed in plastic bags. On the next day, the saturation mass $\left(F W_{\text {sat }}\right)$ of the twigs was obtained and immediately afterwards they were wrapped in plastic foil to prevent transpiration during the measurement and placed in pressure chambers. After measuring the initial $\Psi$ value, 12 pressure levels from 0.4 to $3.3 \mathrm{MPa}(0.4,0.7,1.0,1.3,1.6,1.9,2.2,2.5,2.7$, $2.9,3.1$, and 3.3 MPa) were applied for 10 minutes each. The expressed water was soaked up quantitatively with cellulose strips in eppendorf cups and weighed. After each pressure level the pressure was reduced to just below the last leaf water potential, and after 10 minutes the new balancing pressure was determined. The sample fresh $\left(F W_{3.3}\right)$ and dry mass $(D W)$ were determined immediately after the procedure and after drying the sample for 48 hours at $105^{\circ} \mathrm{C}$, respectively. Transpirational water loss during the establishment of a pressure-volume curve $\left(V_{\text {trans }}\right)$ was calculated as

$$
V_{\text {trans }}=\left(F W_{\text {sat }}-F W_{3.3}\right)-V_{\mathrm{e}}
$$

where $V_{\mathrm{e}}$ is the cumulative expressed water, which was assigned in equal amounts to the 12 pressure steps.

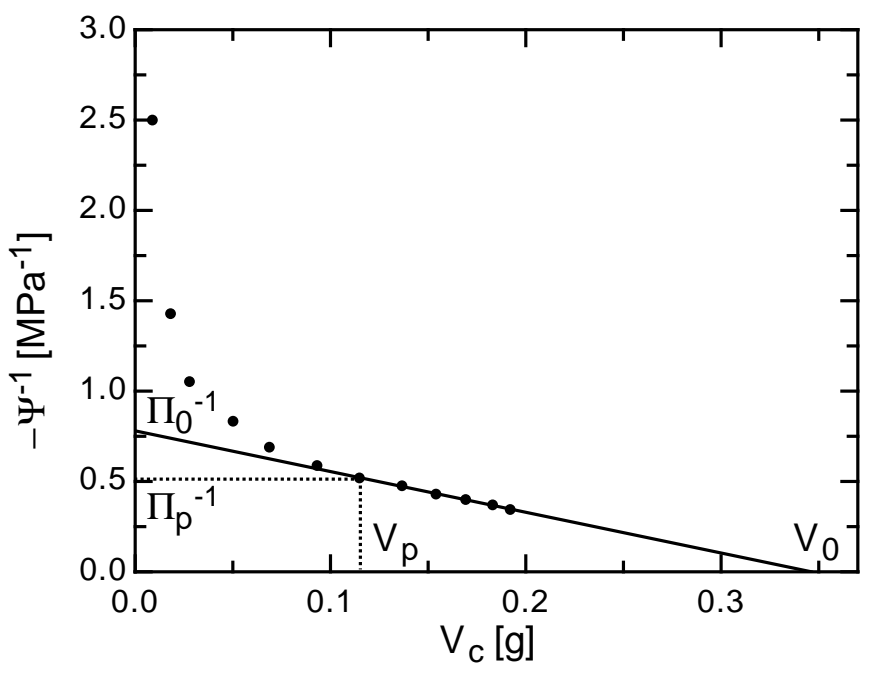

Figure 3.1.: Example of a pressure-volume curve as measured on a well-watered Bp-Aust.1 twig on May 31st, 2000: $V_{\mathrm{t}}=0.45 \mathrm{~g}, V_{0}=0.35 \mathrm{~g}, V_{\mathrm{p}}=0.11 \mathrm{~g}, \Pi_{0}=1.28 \mathrm{MPa}, \Pi_{\mathrm{p}}=1.92 \mathrm{MPa}, \mathrm{RWC}_{s}=V_{0} / V_{\mathrm{t}}=0.78$

The negative reciprocal value of $\Psi$ was then plotted against the cumulative mass of the extruded water $V_{\mathrm{e}}$ (Fig. 3.1). The non-linear part of such a pressure-volume curve is influenced by the turgor $P(P=\Psi-\Pi)$, while the beginning of the linear part characterizes the turgor 
loss point or incipient plasmolysis. In the linear part of the curve, where $P$ is zero, $\Psi$ equals the osmotic potential П. Extrapolation of this straight-line portion of the curve to its intersections with the ordinate and the abscissa yields the total content of expressable water $V_{0}$, which equals the symplastic water content at saturation, and the osmotic potential at saturation $\Pi_{0}$, respectively. To determine the straight line portion of the curve, linear regressions were calculated using the computer program proFit (Cherwell Scientific ltd, Oxford, GB). The number of points included in a regression was gradually increased from the right hand side of the curve, until maximal correlation was reached.

From the point of transition of the straight line part of the curve to the non-linear part, the osmotic potential $\left(\Pi_{p}\right)$ and the mass of expressed water at incipient plasmolysis $\left(V_{p}\right)$ can be extrapolated. The turgor $P$ can be calculated for any point on the curve with $P=\Psi-\Pi$. The total water content of the sampled twig $\left(V_{\mathrm{t}}\right)$ is calculated as the difference between the fresh weight at saturation and the dry weight $\left(V_{\mathrm{t}}=F W_{\text {sat }}-D W\right)$. Thus, the relative content of symplastic water is:

$$
R W C_{s}=\frac{V_{o}}{V_{t}}
$$

The relative water content at the turgor loss point $R W C_{p}$ is calculated as

$$
R W C_{p}=1-\frac{V_{p}}{V_{t}}
$$

Since the change in water potential $(\Delta \Psi)$ for a specific amount of extruded water $V_{\mathrm{e}}\left(\Delta V_{\mathrm{e}}\right)$ can be determined from the curve, the volumetric elastic modulus $\varepsilon$ can be calculated:

$$
\varepsilon=\frac{\Delta \Psi}{\left(\frac{\Delta V_{e}}{V_{0}}\right)} .
$$

The modulus of tissue elasticity near full turgor $\left(\varepsilon_{\max }\right)$ was determined by averaging this relationship over the first 4 data points of the pressure-volume curve (KOIDE et al. 1989).

\subsection{Leaf gas exchange parameters}

\subsubsection{Investigation of $\mathrm{CO}_{2}$ and $\mathrm{H}_{2} \mathrm{O}$ gas exchange under constant conditions Description of the system}

Measurements of leaf gas exchange were made with a LI-6400 portable photosynthesis system (LiCor Inc., Lincoln, NE, USA). This open system works by measuring the differences in concentrations of $\mathrm{CO}_{2}$ and $\mathrm{H}_{2} \mathrm{O}$ between an airstream flowing through the leaf chamber and a reference air stream. Concentrations are measured by infrared gas analysers. The LI-6400 consists of a console, which contains the computer hardware, a display, and a keypad, and the sensor head, where the leaf chamber and the gas analysers are located. $\mathrm{A} \mathrm{CO}_{2}$ scrubber, a dessicant, and a $\mathrm{CO}_{2}$ mixer using pure $\mathrm{CO}_{2}$ from a small tank make it possible to conduct air of defined humidity and $\mathrm{CO}_{2}$ concentration to the leaf. The temperature in the chamber can be controlled by dual Peltier devices, so defined vapour pressure deficits (VPD) can be adjusted. 
Light and temperature sensors are located in the leaf chamber, as well as a LED red and blue light source which enables controlled irradiation of the leaf. With these devices, measurements of photosynthesis and transpiration in a completely controlled and reproducible environment are possible.

\section{Basic equations}

The equations used to calculate net photosynthesis, transpiration etc. from the concentration differences of water vapour and $\mathrm{CO}_{2}$ between the leaf chamber and the reference airstream are essentially those derived by VON CAEMMERER and FARQUHAR (1981) as given in the LiCor manuals.

Transpiration: The mass balance of water vapour in an open system is given by

$$
s E=u_{o} w_{o}-u_{i} w_{i}
$$

where $s$ is the leaf area $\left(6 \cdot 10^{-3} \mathrm{~m}^{2}\right), E$ is the transpiration rate $\left(\mathrm{mol} \mathrm{m} \mathrm{m}^{-2} \mathrm{~s}^{-1}\right), u_{i}$ and $u_{o}$ are incoming and outgoing flowrates $\left(\mathrm{mol} \mathrm{s}^{-1}\right)$ to and from the chamber and $w_{i}$ and $w_{o}$ are the incoming and outgoing water mole fractions $\left(\mathrm{mol} \mathrm{H}_{2} \mathrm{O}\right.$ mol air $\left.{ }^{-1}\right)$. With

$$
u_{o}=u_{i}+s E
$$

Eq. (3.5) can be written as

$$
s E=\left(u_{i}+s E\right) w_{o}-u_{i} w_{i}
$$

which rearranges to

$$
E=\frac{u_{i}\left(w_{o}-w_{i}\right)}{s\left(1-w_{o}\right)}
$$

The parameters given in equations 3.5 to 3.8 are related to the parameters measured by the LI-6400 in the following way:

$$
\begin{aligned}
u_{i} & =F / 10^{6} \\
w_{i} & =W_{r} / 10^{3} \\
w_{o} & =W_{s} / 10^{3} \\
s & =S / 10^{4}
\end{aligned}
$$

where $F$ is the flow rate $\left(\mu \mathrm{mol} \mathrm{s}{ }^{-1}\right), W_{s}$ and $W_{r}$ are sample and reference water mole fractions $\left(\mathrm{mmol} \mathrm{H}{ }_{2} \mathrm{O} \mathrm{mol} \mathrm{air}{ }^{-1}\right)$ and $S$ is the leaf area $\left(\mathrm{cm}^{2}\right)$. Thus, the equation used by the LI-6400 system to calculate transpiration is

$$
E=\frac{F\left(W_{s}-W_{r}\right)}{100 S\left(1000-W_{s}\right)} .
$$


Total conductance for water vapour: The total conductance of the leaf for water vapour

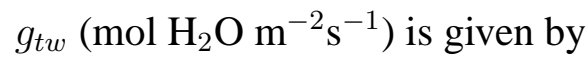

$$
g_{t w}=\frac{E\left(1000-\frac{W_{l}+W_{s}}{2}\right)}{W_{l}-W_{s}}
$$

where $W_{l}$ is the molar concentration of water vapour within the leaf $\left(\mathrm{mmol} \mathrm{H}_{2} \mathrm{O}\right.$ mol air $\left.{ }^{-1}\right)$. The $W_{l}$ is computed from the leaf temperature $T_{l}\left({ }^{\circ} \mathrm{C}\right)$ and the total atmospheric pressure $P$ $(\mathrm{kPa})$ with

$$
W_{l}=\frac{e\left(T_{l}\right)}{P} 1000
$$

with $e(T)=$ saturation vapour pressure $(\mathrm{kPa})$ at temperature $T\left({ }^{\circ} \mathrm{C}\right)$, which is calculated as

$$
e(T)=0.61365 e^{\frac{17.502 T}{240.97+T}}
$$

(BUCK 1981).

Stomatal conductance for water vapour: The stomatal conductance for water vapour

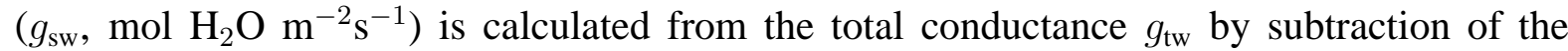
boundary layer conductance from one side of the leaf $\left(g_{\mathrm{bw}}, \mathrm{mol} \mathrm{H}_{2} \mathrm{O} \mathrm{m}^{-2} \mathrm{~s}^{-1}\right)$ :

$$
g_{\mathrm{sw}}=\frac{1}{\frac{1}{g_{\mathrm{tw}}}-\frac{k_{f}}{g_{\mathrm{bw}}}}
$$

where $k_{f}$ is a factor based on the estimate $K$ of the fraction of stomatal conductance of one side of the leaf to the other:

$$
k_{f}=\frac{K^{2}+1}{(K+1)^{2}} .
$$

The correction for the influence of the boundary layer conductance thus depends on whether the leaves are amphi- or hypostomatic, as it is the case in birch.

Net photosynthesis: The mass balance of $\mathrm{CO}_{2}$ in an open system is given by

$$
s a=u_{i} c_{i}-u_{o} c_{o}
$$

where $a$ is the assimilation rate $\left(\mathrm{mol} \mathrm{CO} \mathrm{CO}^{-2} \mathrm{~s}^{-1}\right), c_{i}$ is the incoming mole fraction of $\mathrm{CO}_{2}$ $\left(\mathrm{mol} \mathrm{CO} \mathrm{mol} \mathrm{air}^{-1}\right)$ and $c_{o}$ is the outgoing mole fraction of $\mathrm{CO}_{2}\left(\mathrm{~mol} \mathrm{CO}_{2} \mathrm{~mol} \mathrm{air}^{-1}\right)$. With equation (3.6) this can be written

$$
s a=u_{i} c_{i}-\left(u_{i}+s E\right) c_{o}
$$

which can be rearranged to

$$
a=\frac{u_{i}\left(c_{i}-c_{o}\right)}{s}-E c_{o}
$$


The corresponding terms measured by the LI-6400 are

$$
\begin{aligned}
& c_{i}=c_{r} / 10^{6} \\
& c_{o}=c_{s} / 10^{6} \\
& a=A / 10^{6}
\end{aligned}
$$

where $c_{r}$ and $c_{s}$ are sample and reference $\mathrm{CO}_{2}$ concentrations $\left(\mu \mathrm{mol} \mathrm{CO}_{2} \mathrm{~mol} \mathrm{air}^{-1}\right)$, and $A$ is the net assimilation rate of $\mathrm{CO}_{2}$ by the leaf $\left(\mu \mathrm{mol} \mathrm{m}{ }^{-2} \mathrm{~s}^{-1}\right)$. Thus $A$ is calculated from

$$
A=\frac{F\left(c_{r}-c_{s}\right)}{100 S}-c_{s} E
$$

Intercellular $\mathbf{C O}_{2}$ : The intercellular $\mathrm{CO}_{2}$ concentration $c_{\mathrm{i}}\left(\mu \mathrm{mol} \mathrm{CO} \mathrm{Col} \mathrm{air}^{-1}\right)$ is calculated as

$$
c_{\mathrm{i}}=\frac{\left(g_{\mathrm{tc}}-\frac{E}{2}\right) c_{s}-A}{g_{\mathrm{tc}}+\frac{E}{2}} .
$$

$g_{\mathrm{tc}}$ is the total conductance for $\mathrm{CO}_{2}$ and is given by

$$
g_{\mathrm{tc}}=\frac{1}{\frac{1.6}{g_{\mathrm{sw}}}+\frac{1.37 k_{f}}{g_{\mathrm{bw}}}},
$$

where 1.6 is the ratio of the diffusivities of $\mathrm{CO}_{2}$ and water vapour in air, and 1.37 is the corresponding ratio in the boundary layer.

\section{Measurement protocol}

All gas exchange measurements were conducted on third and fourth leaves counted from the terminal bud of a twig, thus ensuring a comparable age of the leaves. Measurements (both response curves and single measurements) were repeated on 5 leaves per treatment (from different trees). The alternating investigation of 5 trees per treatment of one clone on a single day (10:00 to 17:00 solar time) compensated for the diurnal course of photosynthesis parameters. Consequently, standard deviations calculated for these parameters include their diurnal variability.

When a leaf was clamped into the $6 \mathrm{~cm}^{2}$ leaf chamber, steady state assimilation was reached after 5 to 10 minutes, which was controlled on the display of the LI-6400 system. Only after steady state was reached, values were recorded (logged). When automatic measurements were made, minimum wait time was set to 4 minutes, maximum wait time to 11 minutes. Values were logged by the LI-6400 system, when the coefficient of variation of the variables $\Delta \mathrm{CO}_{2}$, $\Delta \mathrm{H}_{2} \mathrm{O}$, and flow was below $2 \%$ for 30 seconds. For further details see the Li-Cor manuals. A zero-calibration of both sample and reference gas analyzers (IRGA) of the LI-6400 was carried out on the morning of every day it was used. Every two to three days, the analyzers were additionally calibrated with a calibration gas of defined $\mathrm{CO}_{2}$ concentration and air of defined humidity generated by a LI-610 dewpoint generator (Li-Cor Inc., Lincoln, NE, USA). Since measurements of the LI-6400 system are based on differences measured between the 
reference airstream and the sample airstream, it has to be confirmed regularly that reference and sample IRGAs are equalized when measuring the same air. This process, called matching, was done every morning before measurements started, during response curves whenever the $\mathrm{CO}_{2}$ concentration or photosynthetic photon flux density (PPFD) were changed, or after every three to four single measurements.

All measurements were conducted at constant leaf temperatures $\left(T_{\text {leaf }}=21-23{ }^{\circ} \mathrm{C}\right)$ and constant vapour pressure deficits $(\mathrm{VPD}=1 \mathrm{kPa})$.

In June, July, and August 1999 and in August 2000, $\mathrm{CO}_{2}$ response curves (60, 100, 200, 360 , and $1000 \mathrm{ppm} \mathrm{CO}_{2}$ ) for all treatments and clones were established at $1500 \mu \mathrm{mol}$ photons $\mathrm{m}^{-2} \mathrm{~s}^{-1} \mathrm{PPFD}$. They were analysed for photosynthetic capacity at saturating $\left[\mathrm{CO}_{2}\right]\left(A_{\max }\right)$, net assimilation rate at ambient $(=360 \mathrm{ppm})\left[\mathrm{CO}_{2}\right]$, and light saturation $\left(A_{\mathrm{amb}}\right)$, carboxylation efficiency $(\mathrm{CE})$ and compensating and saturating concentrations of $\mathrm{CO}_{2}\left(\left[\mathrm{CO}_{2 \text { comp }}\right]\right.$ and $\left.\left[\mathrm{CO}_{2 \text { sat }}\right]\right)$. The detailed equations used for these calculations are shown in the next section. In June, July, and August 1999, light response curves (1500, 200, 100, 50, and $0 \mu \mathrm{mol}$ photons $\mathrm{m}^{-2} \mathrm{~s}^{-1}$ ) were established at $\left[\mathrm{CO}_{2}\right]=360 \mathrm{ppm}$. From these curves $A_{\mathrm{amb}}$ was calculated, as well as the apparent quantum efficiency $\left(Q_{\mathrm{e}}\right)$ and compensating and saturating photon flux densities (PPFD $\mathrm{P}_{\text {comp }}$ and PPFD $\left._{\text {sat }}\right)$. On two occasions in 1999 and on 5 to 6 occasions between May and August 2000, single measurements of $A_{\mathrm{amb}}$ were additionally conducted at $360 \mathrm{ppm}\left[\mathrm{CO}_{2}\right]$ and $1500 \mu \mathrm{mol}$ photons $\mathrm{m}^{-2} \mathrm{~s}^{-1}$.

\section{Calculation of further parameters}

The LeVEnberg-MARQuARDT algorithm was used to fit Eq. (3.28) to measured response curves. Presuming a gaussian distribution of the measured values, this algorithm assesses the optimal parameters of the curve and calculates intervals of confidence. Regressions were calculated with the computer program proFit (Cherwell Scientific Ltd., Oxford, Great Britain).

$\mathrm{CO}_{2}$ and light response curves were analysed by regressions using the model of JASSBY and PLATT (1976), which is based on a tangens hyperbolicus:

$$
f(x)=b+(a-b) \tanh \left(\frac{k x}{a-b}\right) .
$$

Photosynthetic capacity at saturating $\left[\mathrm{CO}_{2}\right]$ and light intensity, $A_{\max }$, is assumed to be equivalent to the level of the plateau reached in $\mathrm{CO}_{2}$ response curves, consequently it corresponds to parameter $a$ in equation 3.28 . Fit parameters $b$ and $k$ denote the intersection with the ordinate and the slope of the function at this point. In light response curves, $b$ equals the negative value of leaf dark respiration. The net assimilation rate at light saturation and $360 \mathrm{ppm} \mathrm{CO}_{2}, A_{\mathrm{amb}}$, was measured directly in all response curves and did not have to be calculated from the fitted curves.

Compensating $\mathrm{CO}_{2}$ concentrations and light intensities ( $\left[\mathrm{CO}_{2 \text { comp }}\right]$ and $\mathrm{PPFD}_{\text {comp }}$ ) equal the position of the intersection with the abszissas of the respective response curves and are denoted by $x_{\text {comp }}$ below. Calculation of the slope of the curves in this point yields the carboxylation efficiency $\mathrm{CE}$ (from $\mathrm{CO}_{2}$ response curves) or the apparent quantum yield $\Phi_{\mathrm{e}}$ (from light response 
curves):

$$
f^{\prime}\left(x_{\text {comp }}\right)=\frac{k}{\cosh ^{2} \frac{k x_{P}}{a-b}} .
$$

Finally, saturating $\mathrm{CO}_{2}$ concentrations and PPFD were calculated from $\mathrm{CO}_{2}$ and light response curves, respectively. Response curves are assumed to reach saturation when $90 \%$ of the maximal assimilation rate is reached,

$$
\left[\mathrm{CO}_{2 \mathrm{sat}}\right] \text { or } \mathrm{PPFD}_{\mathrm{sat}}=\frac{a-b}{k} \operatorname{artanh} \frac{0.9 a-b}{a-b} .
$$

\subsubsection{Measurement of stomatal conductance and transpiration at ambient VPD}

In addition to measurements of $\mathrm{H}_{2} \mathrm{O}$ gas exchange in the controlled environment of the LI-6400 leaf chamber, investigations with a LI-1600 steady state porometer (Li-Cor Inc., Lincoln, NE, USA) where carried out to examine gas exchange at natural vapour pressure deficits. Transpiration of a leaf placed in the LI-1600 leaf chamber is determined by measuring the flow rate of dry air necessary to maintain a constant relative humidity inside the cuvette against the leaf's transpiration. This target humidity is usually set to the humidity at the site of measurement just before it starts. Stomatal conductance is calculated directly from the measured values of relative humidity, leaf and air temperature, and flow rate. Both leaf transpiration rate $E$ and stomatal conductance $g_{\mathrm{H}_{2} \mathrm{O}}$ are calculated by the LI-1600 in $\mathrm{mmol} \mathrm{m}^{-2} \mathrm{~s}^{-1}$. The vapour pressure deficit VPD [kPa] was calculated from relative humidity $r H[\%]$ and leaf temperature $T_{\text {leaf }}$ $\left[{ }^{\circ} \mathrm{C}\right]$ with

$$
\mathrm{VPD}=\frac{p \cdot{ }_{w}-p_{w}}{1000}
$$

where $p \cdot{ }_{w}[\mathrm{~Pa}]$ is the saturating water vapour pressure, which is calculated using the MAGNUS equation

$$
p \cdot{ }_{w}=610.7 \times 10^{\frac{7.5 T_{\text {leaf }}}{237.3+T_{\text {leaf }}}}
$$

and $p_{w}[\mathrm{~Pa}]$ is the ambient water vapour pressure

$$
p_{w}=\frac{p \cdot w}{100 r H} .
$$

Investigations with the steady state porometer were carried out on 5 to 6 occasions in the summer of 2000 (mid May to late August). Measurements always started at 8:00 to 9:00 a.m. and were repeated approximately every hour until 5:00 to 6:00 p.m.. On the first two dates all treatments of a clone were examined, but later on just the D99/D00- and W99/W00-treatments were investigated. All measurements were made on third and fourth leaves (counted from the terminal bud of a twig) of 6 different trees of each treatment. Different treatments of one clone were measured in alternating order on sunny days. All clones were examined on the same days.

\subsection{Chlorophyll content of the leaves}

Chlorophyll contents of the third and fourth leaves (counted from the terminal bud of a twig) were regularly measured with a SPAD-502 chlorophyll meter (Minolta Co., Ltd., Osaka, Japan). 
Measurements were carried out on 6 occasions from mid June to the end of August in 1999 and on 5 dates from mid June to early September in 2000. In 1999, chlorophyll contents of 10 leaves of different trees of each treatment and clone were analysed, in 2000, 6 trees each were examined.

The SPAD-502 measures the transmission of light from two LEDs (peak wave lengths approximately $650 \mathrm{~nm}$ and $940 \mathrm{~nm}$ ) by the leaf. The output unit of this instrument is a relative unit defined by the producer, the so-called SPAD, which indicates the relative amount of chlorophyll. To calculate the absolute amount of chlorophyll in leaves from these values, they have to be calibrated for the respective type of leaf with a chemical analysis of chlorophyll contents. Therefore, relative chlorophyll contents of 20 leaves of different treatments and clones (and of varied ages and states of senescence) were measured 5 times each at different patches of the blade with the SPAD-502 in July 1999. The leaves were then harvested and 4 circular pieces were punched out of each one with a calibrated punch ( 2 on each side of the middle rib), and extracted individually in $1 \mathrm{ml}$ DMF (N.N-dimethylformamide) in the refrigerator for 24 hours. Just before the analysis, the extracts were diluted with another $1 \mathrm{ml}$ of DMF. Determination of the chlorophyll content in the extracts was done photometrically with an Uvikon 932 spectral photometer (Kontron Instruments, Milton Keynes, Great Britain) at wavelengths of $647 \mathrm{~nm}$ and $664 \mathrm{~nm}$. Total chlorophyll content $C h_{\mathrm{t}}\left[\mu \mathrm{g} \mathrm{ml}^{-1}\right]$ was calculated with

$$
C h_{\mathrm{t}}=7.04 A_{664}+20.27 A_{647},
$$

where $A_{664}$ and $A_{647}$ are the absorptivities measured at the respective wavelengths. Since the area of the pieces punched out of the leaves was known, chlorophyll contents per leaf area could be calculated. A detailed description of this method can be found in MORAN (1982) and MORAN and PORATH (1980).

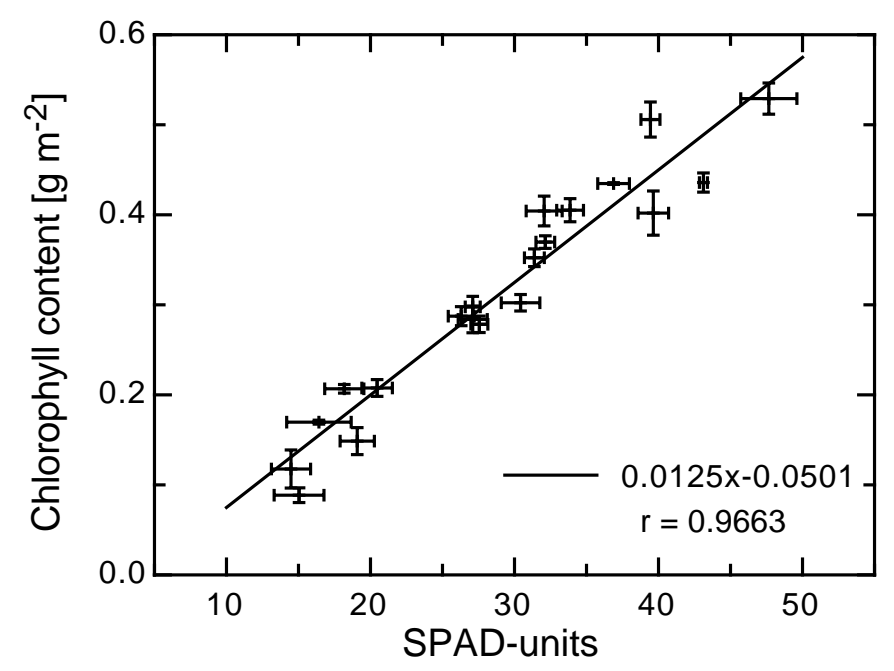

Figure 3.2.: Calibration of the SPAD-502 chlorophyll meter for leaves of Betula pendula. Relative chlorophyll contents were measured 5 times at different patches with the SPAD-502, absolute chlorophyll contents were measured in 4 pieces of each leaf.

The calibration of the SPAD units with the analysis of DMF extracts is shown in Fig. 3.2 
A straight line with a correlation coefficient of 0.97 and the equation

$$
C h_{\mathrm{t}}=0.0125 \mathrm{SPAD}-0.0501
$$

was fitted to the data points and used to calculate the absolute chlorophyll contents [ $\mathrm{g}$ chlorophyll $\mathrm{m}^{-2}$ leaf area] from the SPAD values.

In addition to these investigations, the chlorophyll content of each leaf investigated for photosynthesis with the LI-6400 was measured with the SPAD-502 from late July 1999 on. This facilitates a calculation of photosynthetic rates per chlorophyll mass.

\subsection{Carbon isotope ratio and nitrogen content of bulk leaf tissue}

The ${ }^{13} \mathrm{C}:{ }^{12} \mathrm{C}$ ratio in plant material is chiefly determined by the discrimination of ${ }^{13} \mathrm{CO}_{2}$ by ribulose-1,5-bisphosphate carboxylase/oxygenase (rubisco) in the Calvin cycle of photosynthesis (ZIEGLER 1995). Since this discrimination is influenced by the leaf internal $\mathrm{CO}_{2}$ concentration $\left(c_{\mathrm{i}}\right)$, responses of stomatal conductance and water-use efficiency to drought can be examined by analysis of the $\delta^{13} \mathrm{C}$-values. Thus, less negative values of $\delta^{13} \mathrm{C}$ are related to higher water-use efficiencies (FARQUHAR and RICHARDS 1984).

On 4 to 5 dates from early June to late August 1999 and 2000, 10 leaves of different trees of each treatment ( $3 \mathrm{rd}$ and 4 th counted from the terminal bud) were collected, oven dried $\left(70{ }^{\circ} \mathrm{C}\right.$, $48 \mathrm{~h}$ ), and individually ground to fine powder with a swinging disc mill. The samples were analysed at the Isotopenlabor für biologische und medizinische Forschung of the University of Göttingen with a gas isotope mass spectrometer (Finnigan, MAT 251) coupled with an elemental analyser (Carlo Erba, NA 1500). For the determination of samples with natural concentrations of ${ }^{13} \mathrm{C}$ with this method, the uncertainty of the delta value is less than $0.2 \%$ o (REINEKING et al.1993).

The $\delta^{13} \mathrm{C}$-value indicates the difference between ${ }^{13} \mathrm{C}:{ }^{12} \mathrm{C}$ isotope ratios of the sample and a standard (PeeDee Belemite $=$ PDB). It is calculated as

$$
\delta^{13} C=\frac{\frac{13 C}{12 C} \text { sample }}{\frac{13 C}{{ }^{12} C} \text { PDB }} \cdot 1000[\% o]
$$

(ZIEGLER 1995). The carbon isotope discrimination by rubisco $\Delta$ is then

$$
\Delta=\frac{\delta^{13} C_{\text {air }}-\delta^{13} C_{\text {plant }}}{1000+\delta^{13} C_{\text {plant }}}
$$

The $\delta^{13} \mathrm{C}$-value of the $\mathrm{CO}_{2}$ in the air surrounding the trees is assumed to be $-7 \%$. From the discrimination $\Delta$, the ratio of intercellular $\mathrm{CO}_{2}$ concentration $c_{\mathrm{i}}$ and the $\left[\mathrm{CO}_{2}\right]$ in the air surrounding the leaf $\left(c_{\mathrm{a}}\right)$ can be calculated (HUBICK et al. 1989):

$$
\frac{c_{\mathrm{i}}}{c_{\mathrm{a}}}=\frac{\Delta+d-a}{b-a},
$$

where $a$ is the discrimination of ${ }^{13} \mathrm{CO}_{2}$ during diffusion in the gas phase (0.0044), $b$ is the discrimination by rubisco in the carboxylation reaction $(0.027)$ and $d$ is the discrimination 
occurring with the solution of $\mathrm{CO}_{2}(0.001)$. To calculate absolute $c_{\mathrm{i}}$ concentrations from these values, $c_{\mathrm{a}}=360 \mathrm{ppm}$ was assumed.

The content of nitrogen and the ratio of carbon dioxide and nitrogen $\left[\mathrm{g} \mathrm{g}^{-1}\right]$ of the samples were measured simultanously with the analysis of the $\delta^{13} \mathrm{C}$ values, since an elemental analyzer was coupled with the gas isotope mass spectrometer. The samples delivered to the Isotopenlabor were exactly weighed into tin cups, thus the exact mass of each sample was known and the nitrogen content could be calculated as percentage of unit dry weight.

\subsection{Growth, biomass and allocation parameters}

\subsubsection{Determination of growth and senescence}

During the growth seasons of the two study years, the height of the trees from root collar to top was regularly recorded. In 1999, heights of 10 plants each of the well-watered and the droughted treatments of each clone (a total of 80 trees) were measured 6 times from mid May to the end of August. Since 4 of these birches were harvested at the end of August, two additional measurements in September were made on only 6 trees. From early April to late August 2000, the heigths of 6 trees of each treatment (a total of 72 trees), which were then harvested, were recorded.

Each time tree heights were measured in 1999, their leaves were also counted to monitor phenology and to establish a common measure for the onset of senescence. Since the young birch trees were budding during the whole growth season, senescence and loss of the oldest leaves started long before the end of the season. The regular record of leaf numbers made it possible to determine the time when the total number of leaves per tree did not increase any more or started to decrease. During the summer of 2000, the leaves of those 6 birches of each treatment designed to be harvested were counted 4 times from early June to late August.

\subsubsection{Investigation of biomass and allocation parameters}

In late August and early September 1999 and 2000, 4 and 6 trees, respectively, of each treatment and clone were harvested (32 trees in 1999, 72 in 2000).

\section{Shoot biomass parameters}

To determine the above ground biomass, first all leaves of a tree were harvested according to their position on the twigs, thus being sorted by age (the 1st, 2nd, 3rd, 4th, and 5th leaves counted from the terminal bud of each twig or the top of the tree were harvested separately, older leaves were pooled). All leaves of trees harvested in 1999 were scanned with a flat bed graphics scanner, and the digitalized images were analyzed with an image processing system (WinFolia, Régent Instruments Inc., Québec, Canada) to determine their area. In 2000, 10 randomly chosen leaves of each of the age classes 1 st to 5 th leaf and 20 of the older leaves were scanned, dried and weighed. Average leaf area and mass of these leaves was then used to calculate the leaf area of the unscanned leaves of each tree, of which the dry weight was determined after 48 hours at $70{ }^{\circ} \mathrm{C}$. Leaf area and dry weight were established for every tree, 
as well as for every leaf age, and specific leaf areas (SLA $\left[\mathrm{cm}^{2} \mathrm{~g} \mathrm{DW}^{-1}\right]$ ) were calculated. Since some trees were already senescent and well behind their peak leaf numbers at the date of their harvest, leaf numbers counted in early August and mean leaf size and specific leaf weight data obtained from the harvests were used to recalculate maximum leaf areas and masses for all plants. The buds were harvested from the trees, dried and weighed, with about 20 buds per tree being chosen at random and weighed individually to obtain the average bud dry mass. The remaining shoot was cut off at the root collar, subdivided into diameter classes $(<2 \mathrm{~mm}$, $2-5 \mathrm{~mm},>5 \mathrm{~mm}$ ), dried, and weighed. In this way, total shoot biomass as well as masses of the wood, leaf, and bud fractions, and the leaf area and SLA could be determinded.

\section{Root biomass parameters}

The roots of trees were harvested by carefully sifting the contents of each 451 pot through a sieve (meshsize $3 \mathrm{~mm}$ ) either by hand (1999) or with a jet of water from a hose (2000). The roots were then carefully washed in sieves to clean them of rests of the substrate. Two or three representative cords of root of each tree were separated for analysis of living biomass:necromass ratio. The rest of the root was sorted by diameter (fine roots $<2 \mathrm{~mm}$, coarse roots $2-5 \mathrm{~mm}$, large roots $>5 \mathrm{~mm}$ ). In 2000, a representative, intact cord of fine root of 15 to $20 \mathrm{~cm}$ with all branching roots was used to analyse the surface area. The remaining roots were dried $\left(70{ }^{\circ} \mathrm{C}\right.$, ca. 120 hours) and weighed to obtain dry weights of all diameter classes.

To differentiate dead roots from living ones, the chosen cords were analysed with the help of a binocular. Dead fine roots can be distinguished from living ones by several features: The bark is usually less elastic, becomes brittle, and does not shine. Since the cells of the stele are not turgescent any more, it is more tender and less elastic than that of a living root; the outline of single xylem elements can be seen on the surface of the central cylinder and sometimes it is not pure white any more but of a brownish colour. Pressing, tearing and scratching of a root with a pair of tweezers usually shows whether it is dead or alive (see also HERTEL 1999). Living biomass and necromass of the root were then dried and weighed separately to calculate the ratio of living biomass to necromass for each tree.

To determine the surface area of separated fine roots, they were scanned with a graphics scanner with a special lighting device, which illuminated the roots from below and above. To scan roots without overlapping of the finest roots branching off it, they were spread out and swam in about $1 \mathrm{~cm}$ deep water. Digitalized images were processed using the computer software WinRhizo (Régent Instruments Inc., Québec, Canada). This software analyzes the total surface area of a root and its distribution to different diameter classes. After analysis, each root cord was dried and weighed separately and the specific root area (SRA $\left[\mathrm{cm}^{2} \mathrm{~g} \mathrm{DW}^{-1}\right]$ ) was calculated. Fineroot surface area of each tree and fine root:leaf area ratio were calculated from these data, as were the respective root dry weights.

\subsection{Calculation of plasticity of the measured parameters}

To calculate the plasticity of a genotype with regard to a certain physiological, biochemical, or morphological parameter, the method described by FISCHER et al. (2000) was used. Absolute 
plasticity per genotype was quantified as the difference between the means of the well-watered plants and the droughted plants. Relative plasticity was calculated as percentage of the absolute plasticity in relation to the genotype means over both treatments. The reaction of a genotype with regard to a certain parameter was considered the more plastic, the greater the relative plasticity was. Plasticities of the four clones are shown in Appendix A.

\subsection{Statistical analysis of the data}

Arithmetic average and standard deviation were calculated for all investigated parameters from the number of individual measured values. For further statistical investigations, the computer program SAS (Statistical Analysis System, SAS-Institute Inc., Cary, NC, USA) was used.

First, all data were tested for gaussian distribution using SHAPIRO \& WILK's test $(P \leq$ 0.05). If the data were not gaussian distributed, non-parametric tests were used for their further analysis. The KRUSKALL-WALLIS test was used to detect significant influences of certain factors on a parameter. To test for significant differences between two samples, the U-test of MAnN \& Whitney was used $(P \leq 0.05)$. If the SHAPIRO \& WilK test did not reject a gaussian distribution of the data, significant differences between samples were analysed using the test of SCHEFFÉ. As in the U-test, means were considered significantly different with $P \leq$ 0.05. Results of these analyses are shown in the respective figures.

Multivariate analyses (ANOVA) were carried out with data that showed gaussian distribution to assess the influences of both genotype and treatment, as well as their interrelation, on the respective parameter. Results of these analyses are shown in Appendix B. If a parameter had been measured repeatedly, e.g. gas-exchange parameters or $\delta^{13} \mathrm{C}$ values, a repeated measurements design was used. To do this, a repeated statement was incorporated into the SAS glm-procedure. Univariate F-tests were calculated for the time factor (date of measurement) as well as for all interrelations with the factors clone and treatment. Results of multivariate analyses with $P>F$ values adjusted according to GREENHOUSE-GEISSER are shown in Appendix B.

Regressions were calculated using the LEVENBERG-MARQUARDT algorithm described earlier in the text with the computer program proFit (Cherwell Scientific Ltd., Oxford, GB). 


\section{Results}

\subsection{Isoenzyme systems}

All four birch clones were genetically distinguishable by the analysis of six enzyme systems. Their genotypes at these enzyme loci are shown in Tab. 4.1

Table 4.1.: Genotypes of the four birch clones at six enzyme loci. The variants of isoenzymes are named with regard to these clones only, the one migrating fastest being labelled 1. (PGI $=$ Phosphoglucose-Isomerase, LAP = Leucin-Aminopeptidase, GOT = Glutamatoxalacetat-Transaminase, IDH = Isocitrat-Dehydrogenase, $\mathrm{MNR}=$ Menadionreductase, 6-PGDH = 6-Phosphogluconat-Dehydrogenase.)

\begin{tabular}{lllllll}
\hline clone & PGI & LAP & GOT & IDH & MNR & 6-PGDH \\
\hline Bp-Aust.1 & 22 & 12 & 22 & 11 & 11 & 11 \\
Bp-Aust.2 & 12 & 12 & 22 & 11 & 11 & 11 \\
Bp-Swed. & 12 & 11 & 22 & 11 & 12 & 11 \\
Bp-Germ. & 12 & 11 & 12 & 12 & 11 & 11 \\
\hline
\end{tabular}

The clones did not differ with regard to the enzyme 6-PGDH, and only PGI differed between the two Austrian clones. Bp-Swed. differed from Bp-Aust.1 in three, and from BpAust. 2 in two enzymes. Differences between the German clone Bp-Germ. and the Austrian clones were detected in four and three of the six enzyme loci (Bp-Aust.1 and Bp-Aust.2, respectively), from the Swedish clone the German one differed in three enzyme loci. The genetic distances between the clones as calculated from these multilocus genotypes are shown as a matrix of distances in Tab.4.2.

Table 4.2.: Matrix of the percental genetic distances between the four birch clones.

\begin{tabular}{lllll}
\hline & Bp-Aust.1 & Bp-Aust.2 & Bp-Swed. & Bp-Germ. \\
\hline Bp-Aust.1 & 0.000 & 0.083 & 0.250 & 0.333 \\
Bp-Aust.2 & 0.083 & 0.000 & 0.167 & 0.250 \\
Bp-Swed. & 0.250 & 0.167 & 0.000 & 0.250 \\
Bp-Germ. & 0.333 & 0.250 & 0.250 & 0.000 \\
\hline
\end{tabular}

While the genetic distance between the two Austrian clones was only $0.08 \%$, the distance of the Swedish clone Bp-Swed. to both Austrian ones was twice (Bp-Aust.2) to three times (Bp-Aust.1) as high. The German clone Bp-Germ. was genetically most distinct from all other clones. 


\subsection{Leaf water status parameters}

\subsubsection{Leaf water potential}
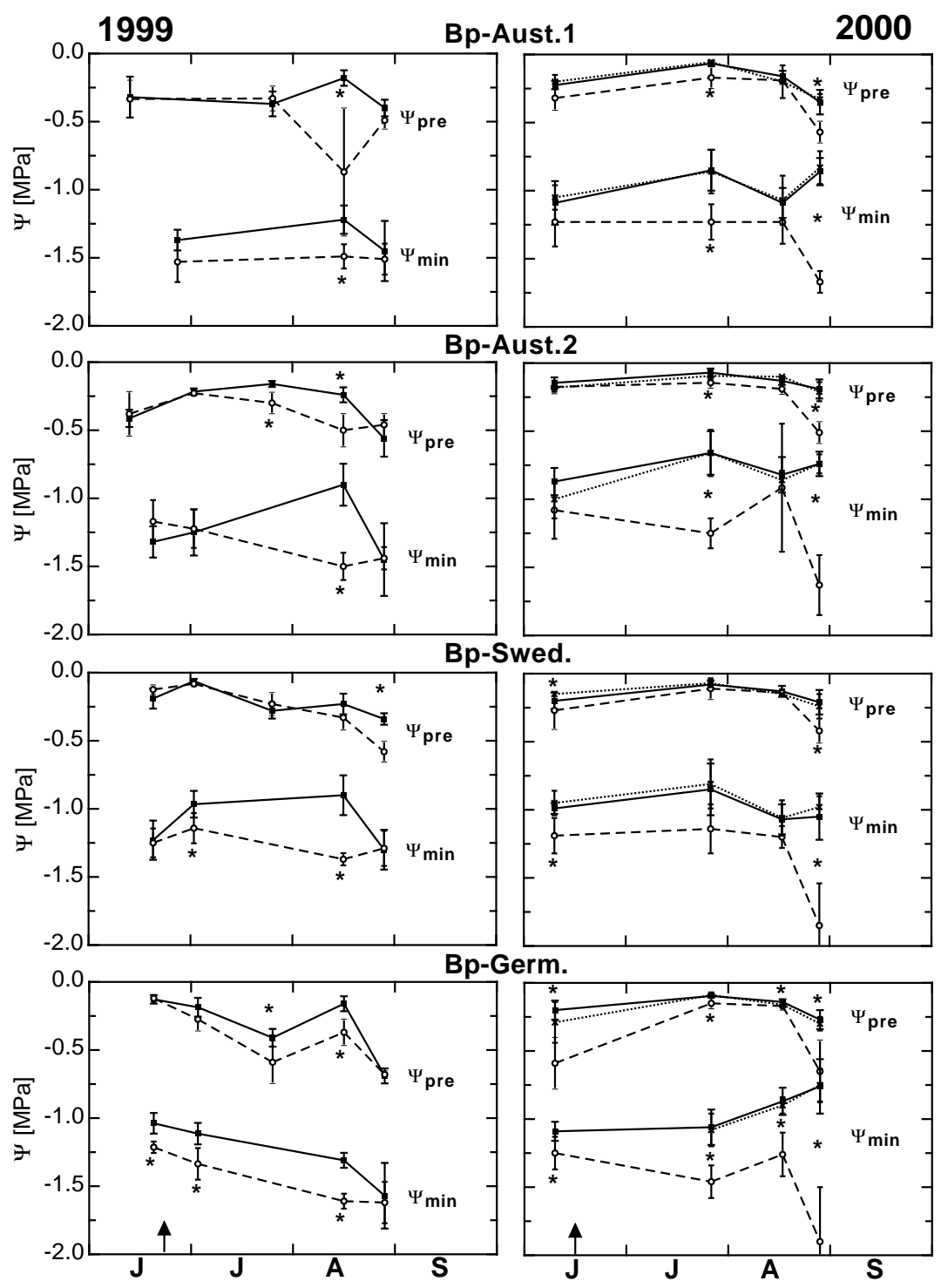

Figure 4.1.: Leaf water potentials before dawn $\left(\Psi_{\text {pre }}\right)$ and in the early afternoon $\left(\Psi_{\min }\right)$ of the four birch clones during the summers of 1999 and 2000. Open circles and dashed lines represent the droughted plants (D99 and D99/D00), filled squares and solid lines the well watered controls (W99 and W99/W00), and crosses and dotted lines the drought-and-recovery treatment in 2000 (D99/W00). Means and standard deviations of 5 leaves from different plants are given. Asterisks indicate significant differences $(P \leq 0.05)$ between droughted (D99 and D99/D00) and well watered plants (W99/W00). After the day indicated by the black arrow the volumetric soil water content of the droughted pots was below $3 \%$.

In both years, the water potentials measured before dawn $\left(\Psi_{\text {pre }}\right)$ showed seasonal variation with lower values towards the end of the summer in all treatments (Fig. 4.1). In 1999, $\Psi_{\text {pre }}$ 
values of the well watered plants were between -0.1 and $-0.7 \mathrm{MPa}$, the averages of the individual clones being -0.2 to $-0.3 \mathrm{MPa}$. In the summer of 2000 , the $\Psi_{\text {pre }}$ values only reached $-0.4 \mathrm{MPa}$ and the averages of the clones were markedly less negative ( -0.12 to $-0.18 \mathrm{MPa})$. Values of those trees that were subjected to a dry period were more negative than those of well watered plants in both years, but did not exceed -0.9 MPa. Mean annual $\Psi_{\text {pre }}$ values of the droughted plants were less negative in 2000 than in 1999 as well. In 1999, differences between well watered and drought stressed plants became obvious quite early after the onset of the drought treatment within the clones Bp-Aust.2 and Bp-Germ. (first statistically significant difference $(P \leq 0.05)$ in July), while $\Psi_{\text {pre }}$ values of the droughted Bp-Aust.1 and Bp-Swed. clones reached markedly more negative values only in mid- to late August. In 2000, water potentials of all clones except from Bp-Aust. 2 responded earlier to the drought treatment than in 1999. Significant differences between well watered treatments (W99/W00 and D99/W00) on the one hand and droughted plants (D99/D00) on the other were reached as early as in the second week of June by the German and the Swedish clone. The drought-and-recovery treatment D99/W00 did not differ from the W99/W00 treatment in any of the clones.

Differences between droughted and well watered plants were more pronounced with regard to the minimum leaf water potentials measured in the early afternoon $\left(\Psi_{\min }\right)$. In the second year of investigation, the D99/D00-treatment of the German clone showed markedly lower $\Psi_{\text {min }}$ values than those of the other clones, while in 1999 both Bp-Germ. and Bp-Aust.1 reached more negative $\Psi_{\min }$ values than Bp-Aust.2 and Bp-Swed.. Minimum leaf water potentials of the Swedish and the German genotype responded earlier to the drought stress than those of the Austrian clones in both 1999 and 2000. Like the predawn values, minimum values of $\Psi$ of the D99/W00-trees did not differ from those of the W99/W00-treatment.

Absolute plasticity (FISCHER et al. 2000) of predawn leaf water potentials, which is defined as difference between the values reached by the W99/W00-treatment and the D99/D00treatment, varied from 0.07 to $0.29 \mathrm{MPa}$ in 1999 and from 0.08 to $0.21 \mathrm{MPa}$ in 2000 (Tab.A.1. In both years, the Swedish clone responded least plastic, which is also true for the relative plasticity with regard to this parameter. Relative plasticity averaged to between 19 and $42 \%$ in 1999 and between 34 and $61 \%$ in 2000. Absolute plasticities of the $\Psi_{\min }$ values by far exceeded those of the predawn potentials. Again, the relative plasticity of this parameter was much higher in the summer of 2000 (29 to $42 \%$ ) than in 1999 (12 to $16 \%$ ).

\subsubsection{Parameters obtained from pressure-volume curves}

Like the leaf water potentials, the osmotic potentials at saturation $\left(\Pi_{0}\right)$ and incipient plasmolysis $\left(\Pi_{\mathrm{p}}\right)$ dropped markedly over the course of the summers of both years of investigation (Fig.4.2). In 1999, average annual $\Pi_{0}$ of the well watered Swedish clone (-1.06 MPa) were significantly less negative than those of the other genotypes (-1.21 to $-1.28 \mathrm{MPa})$. The droughted plants showed lower values of $\Pi_{0}$ than the W99/W00-treatments, particularly towards the end of summer, after about two months of drought stress. Only in Bp-Aust.2 this difference never became statistically significant.

Osmotic potentials at the turgor loss point in 1999 were on average $0.81 \mathrm{MPa}$ lower than those at saturation. Annual averages of the well watered Swedish and German trees were slightly more positive than those of the Austrian plants. The $\Pi_{p}$ values of the D99/D00- 

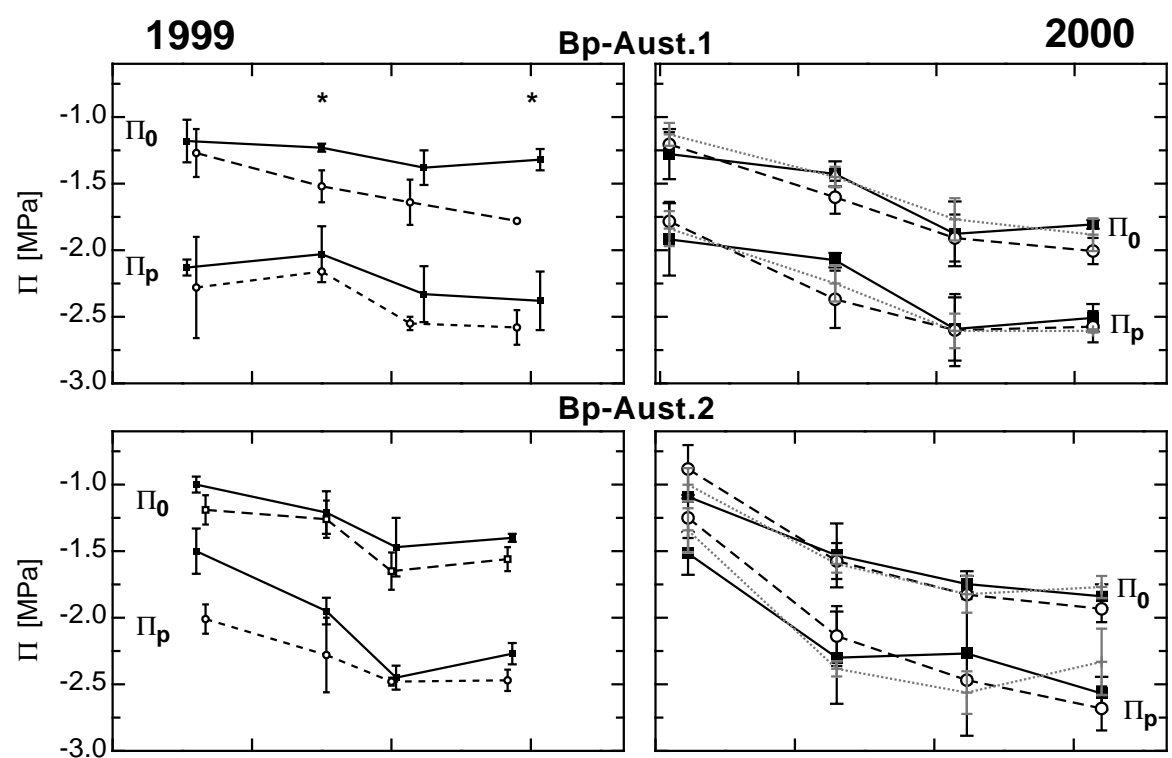

Bp-Swed.

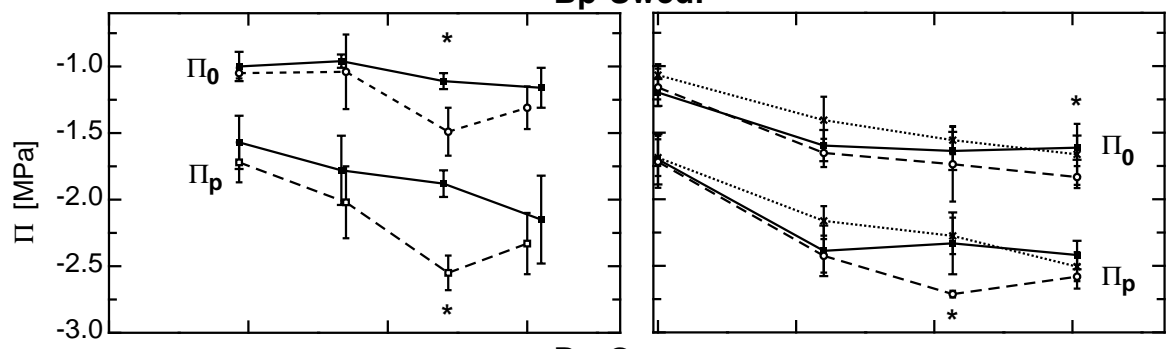

Bp-Germ.

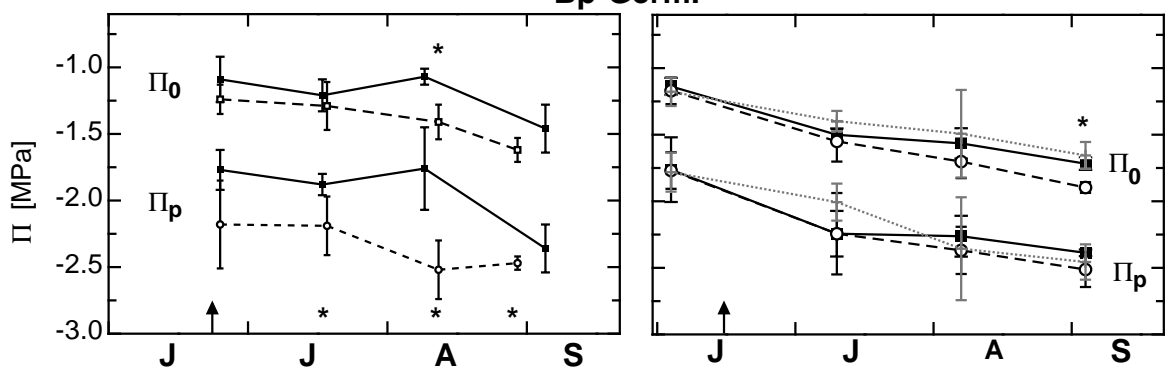

Figure 4.2.: Osmotic potentials at saturation and at the turgor loss point $\left(\Pi_{0}\right.$ and $\left.\Pi_{p}\right)$ of the four birch clones during the summers of 1999 and 2000. Open circles and dashed lines represent the droughted plants (D99 and D99/D00), filled squares and solid lines the well watered controls (W99 and W99/W00), and crosses and dotted lines the drought-and-recovery treatment in 2000 (D99/W00). Means and standard deviations of 5 leaves from different plants are given. Asterisks indicate significant differences $(P \leq 0.05)$ between droughted (D99 and D99/D00) and well watered plants (W99/W00). After the day indicated by the black arrow the volumetric soil water content of the droughted pots was below $3 \%$.

treatments were markedly more negative than those of the W99/W00-treatments in all genotypes. These differences became particularly significant in mid-August, after a long period of drought but before leaf senescence began.

During the investigated period of 2000, averages of both $\Pi_{0}$ and $\Pi_{p}$ of the well watered 

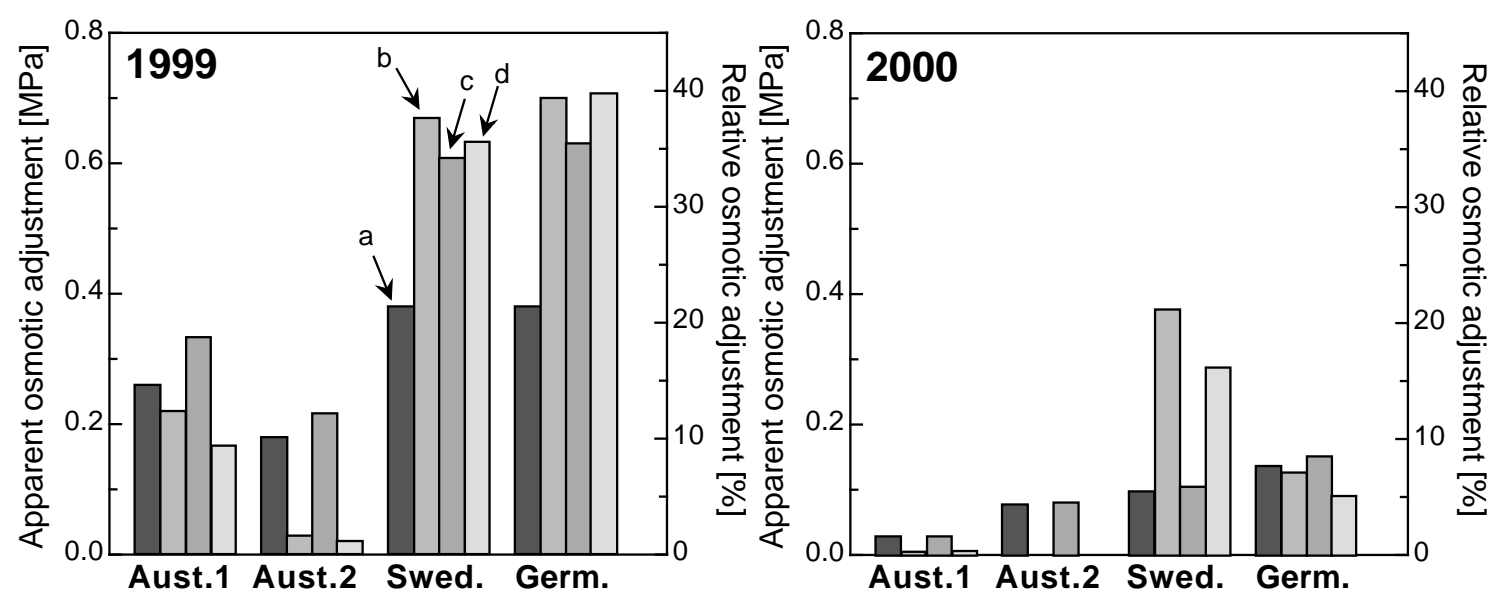

Figure 4.3.: Apparent and relative osmotic adjustment of the four birch clones in early August 1999 and 2000. The dark bars $(a+c)$ show the osmotic adjustment at saturation, the lighter ones $(b+d)$ that at the turgor loss point. The left bars of each clone $(a+b)$ show the apparent osmotic adjustment [MPa], which is the absolute difference between the osmotic potentials of the well watered and the droughted plants. The two right bars $(c+d)$ show the relative osmotic adjustment [\%], where these differences are given as percentages of the osmotic potentials of the well watered plants.

plants were lower than in 1999. Again, the mean $\Pi_{0}$ of the W99/W00 treatments of Bp-Swed. was more positive than those of the other genotypes. Differences between $\Pi_{p}$ and $\Pi_{0}$ of the well watered plants averaged to $0.67 \mathrm{MPa}$. As in 1999, osmotic potentials at incipient plasmolysis were more negative in the droughted treatment in 2000 as well, though apart from the values measured on Bp-Swed. in early August 2000, these differences never became statistically significant. Osmotic potentials of the D99/W00-treatments in 2000 did not significantly differ from those of the the W99/W00-treatments.

Differences between osmotic potentials of the droughted and the well watered plants of a given genotype can be termed apparent osmotic adjustment, which can be expressed either as the absolute value, or as a percentage related to the osmotic potentials of the corresponding W99/W00-treatment. Osmotic adjustment of the four genotypes as measured in mid-August of both 1999 and 2000 is shown in Fig. 4.3. Both the absolute and the relative values of osmotic potentials were up to twice as high in the Swedish and the German genotypes (0.38 MPa corresponding to 34 to $36 \%$ for $\Pi_{0}$ and 0.67 to $0.70 \mathrm{MPa}$ corresponding to 36 to $40 \%$ for $\Pi_{\mathrm{p}}$ ) than in the two Austrian clones in 1999 ( 0.18 to $0.26 \mathrm{MPa}$ corresponding to 12 to $19 \%$ for $\Pi_{0}$ and 0.03 to $0.22 \mathrm{MPa}$ corresponding to 1 to $9 \%$ for $\Pi_{\mathrm{p}}$ ). Osmotic adjustment measured in 2000 was much smaller for all clones, but nevertheless Bp-Swed. and Bp-Germ. osmotically adjusted to a greater extent to the drought stress than the Austrian genotypes in this summer as well.

Moduli of tissue elasticity near full turgor $\left(\varepsilon_{\max }\right)$ of the four birch genotypes as obtained from pressure-volume curves in 1999 are shown in Tab.4.3. Droughted plants, especially in the genotypes Bp-Aust.1 and Bp-Swed., reached distinctly higher $\varepsilon_{\max }$ values than the W99/W00treatments. In 2000, the moduli of elasticity of all clones were higher than in 1999 and showed a marked tendency to higher values towards the end of the summer (Tab. 4.3). Like in 1999, 
Table 4.3.: Moduli of tissue elasticity near full turgor $\left(\varepsilon_{\max }\right.$ [MPa]) of leaves of the four birch clones troughout the growing seasons 1999 and 2000. Means of 4 (3 in June) twigs from different plants are given. Asterisks indicate significant differences $(P \leq 0.05)$ between droughted (D99/D00) and well watered (W99/W00) plants.

\begin{tabular}{llcccc}
\hline clone & treatment & June & July & early August & late August \\
\hline 1999 & & & & & \\
\hline Bp-Aust.1 & W99/W00 & 4.85 & 4.35 & 5.08 & 5.02 \\
& D99/D00 & 4.45 & $8.57 *$ & $6.93 *$ & $7.29 *$ \\
\hline Bp-Aust.2 & W99/W00 & 3.95 & 4.09 & 5.83 & 4.85 \\
& D99/D00 & $5.82 *$ & 6.20 & 7.50 & 6.66 \\
\hline Bp-Swed. & W99/W00 & 3.80 & 2.46 & 2.94 & 2.95 \\
& D99/D00 & 4.21 & 3.15 & $6.07 *$ & $5.19 *$ \\
\hline Bp-Germ. & W99/W00 & 3.60 & 4.62 & 4.29 & 5.53 \\
& D99/D00 & 4.70 & 5.15 & 6.26 & 6.80 \\
\hline 2000 & & & & & \\
\hline Bp-Aust.1 & W99/W00 & 8.83 & 7.94 & 10.49 & 11.56 \\
& D99/W00 & 9.69 & 6.96 & 9.61 & 10.98 \\
& D99/D00 & 8.89 & 8.48 & 12.22 & 12.52 \\
\hline Bp-Aust.2 & W99/W00 & 4.58 & 8.41 & 10.71 & 10.58 \\
& D99/W00 & 4.05 & 9.40 & 10.80 & 11.37 \\
& D99/D00 & 3.00 & 9.86 & 12.73 & 10.99 \\
\hline Bp-Swed. & W99/W00 & 5.11 & 7.28 & 8.05 & 7.36 \\
& D99/W00 & 3.96 & 6.26 & 7.21 & 7.76 \\
& D99/D00 & 4.25 & 8.23 & 10.33 & 10.42 \\
\hline Bp-Germ. & W99/W00 & 4.48 & 8.07 & 8.54 & 8.68 \\
& D99/W00 & 4.82 & 7.67 & 8.59 & 8.91 \\
& D99/D00 & 4.87 & 8.57 & 11.60 & 11.99 \\
\hline
\end{tabular}

$\varepsilon_{\max }$ values of both well watered and droughted Swedish trees were the lowest ones, while BpAust.1 obtained the highest values in these treatments. Values of $\varepsilon_{\max }$ were again consistently higher in droughted plants than in well watered ones in all genotypes, although these differences were not statistically significant. The $\varepsilon_{\max }$ values of the drought-and-recovery treatments showed no marked differences from the W99/W00-plants.

Plasticities of osmotic potentials and moduli of elasticity are shown in the appendix in Tab. A.1. In 1999, absolute and relative plasticity with regard to $\Pi_{0}$ were highest in Bp-Aust.1, while with regard to $\Pi_{p}$ the Swedish and especially the German clone responded more plastic than the Austrian genotypes. Plasticity was generally higher regarding $\varepsilon_{\max }$, with Bp-Swed. reaching the highest values. In 2000, plasticity of all parameters derived from pressure-volume curves was much lower than in 1999, but again Bp-Swed. responded most plastic with regard to $\varepsilon_{\max }$.

The moduli of elasticity showed gaussian distributions in both years of investigation, so an analysis of variance could be carried out to evaluate the influences of the individual factors. Results of this analysis are shown in the appendix in Tab. B.1. In both years the influence of both genotype and treatment on the modulus of elasticity were highly significant. 


\subsection{Daily means of stomatal conductance for water vapour}

\subsubsection{Stomatal conductance measured under constant conditions with low VPD}

Figure 4.4 shows daily means of stomatal conductance for water vapour $\left(g_{\mathrm{sw}}\right)$, as measured under constant conditions in the LI-6400 leaf chamber. All measurements were carried out at saturating light intensities, at $22{ }^{\circ} \mathrm{C}$ leaf temperature, and with a VPD of $10 \mathrm{hPa}$.

In the first year of investigation, $g_{\mathrm{sw}}$ values of the well watered trees of all genotypes showed a seasonal variation with lower values in spring, an increase towards mid- to late summer and then a rapid decrease towards the end of August. The annual averages of $g_{\mathrm{sw}}$ ranged from $288 \mathrm{mmol} \mathrm{m}^{-2} \mathrm{~s}^{-1}$ in Bp-Aust. 2 to $506 \mathrm{mmol} \mathrm{m}^{-2} \mathrm{~s}^{-1}$ in Bp-Swed.. W99/W00-treatments of the Swedish and the German genotype reached distinctly higher stomatal conductances than those of the Austrian clones, though these differences were not statistically significant. Since the daily means of stomatal conductance included the pronounced daily course of this parameter (measurements were carried out between 10:00 and 17:00 solar time), standard deviations are quite high. Nevertheless, stomatal conductances reached in 1999 were high in all genotypes. Maximum daily averages reached by Bp-Germ. and Bp-Swed. were $690 \mathrm{mmol}$ $\mathrm{m}^{-2} \mathrm{~s}^{-1}$ and $736 \mathrm{mmol} \mathrm{m}^{-2} \mathrm{~s}^{-1}$, respectively, but Bp-Aust. $1\left(536 \mathrm{mmol} \mathrm{m}^{-2} \mathrm{~s}^{-1}\right)$ and Bp-Aust.2 (468 $\mathrm{mmol} \mathrm{m}^{-2} \mathrm{~s}^{-1}$ ) reached high daily $g_{\mathrm{sw}}$ values as well.

Stomatal conductances of the droughted plants decreased in all clones from mid-July 1999 onward, after about 4 weeks at soil water contents below $3 \%$, and reached values lower than $50 \mathrm{mmol} \mathrm{m} \mathrm{m}^{-2} \mathrm{~s}^{-1}$ by the end of August. Differences between well watered and droughted plants became significant first in Bp-Aust. 1 and Bp-Germ. in early July, then in Bp-Swed. and Bp-Aust. 2 in late July to early August. Like in the W99/W00-treatment, Bp-Swed. exhibited the highest annual means of conductance $\left(348 \mathrm{mmol} \mathrm{m}^{-2} \mathrm{~s}^{-1}\right)$ in the D99/D00-treatment as well, while the annual averages of the Austrian genotypes were the lowest (203 to $207 \mathrm{mmol}$ $\mathrm{m}^{-2} \mathrm{~s}^{-1}$ ).

Seasonal variation of stomatal conductances was quite different in 2000 , when the highest values were reached in late May by all clones, and $g_{\mathrm{sw}}$ decreased to mid-June. From June to August stomatal conductances did not change markedly, then they rapidly declined with advancing leaf senescence towards the end of August, as in 1999. Mean annual conductances of all genotypes were much lower than in 1999, ranging from $240 \mathrm{mmol} \mathrm{m}^{-2} \mathrm{~s}^{-1}$ in Bp-Aust.2 to $347 \mathrm{mmol} \mathrm{m}^{-2} \mathrm{~s}^{-1}$ in the German clone. Maximum daily means were reached by Bp-Germ. (532 mmol m $\mathrm{m}^{-2} \mathrm{~s}^{-1}$ ), while the other genotypes only reached maximum daily conductances of 380 to $390 \mathrm{mmol} \mathrm{m}^{-2} \mathrm{~s}^{-1}$. The $g_{\mathrm{sw}}$ values reached by the German clone were the highest in mid-summer (significant in July), while those of Bp-Aust.2 were, like in 1999, the lowest throughout most of the measurements.

The $g_{\mathrm{sw}}$ values of the D99/D00-treated plants decreased markedly with the beginning drought and stayed on a more or less constant level of about $100 \mathrm{mmol} \mathrm{m}^{-2} \mathrm{~s}^{-1}$ from early July onward. The differences between well watered and droughted trees became statistically significant as early as mid- to late June in Bp-Aust.1, Bp-Swed., and the German genotype; in Bp-Aust.2, significant differences were reached only in August. The D99/W00-treatments did not differ markedly from the well watered ones. No significant differences could be detected between 

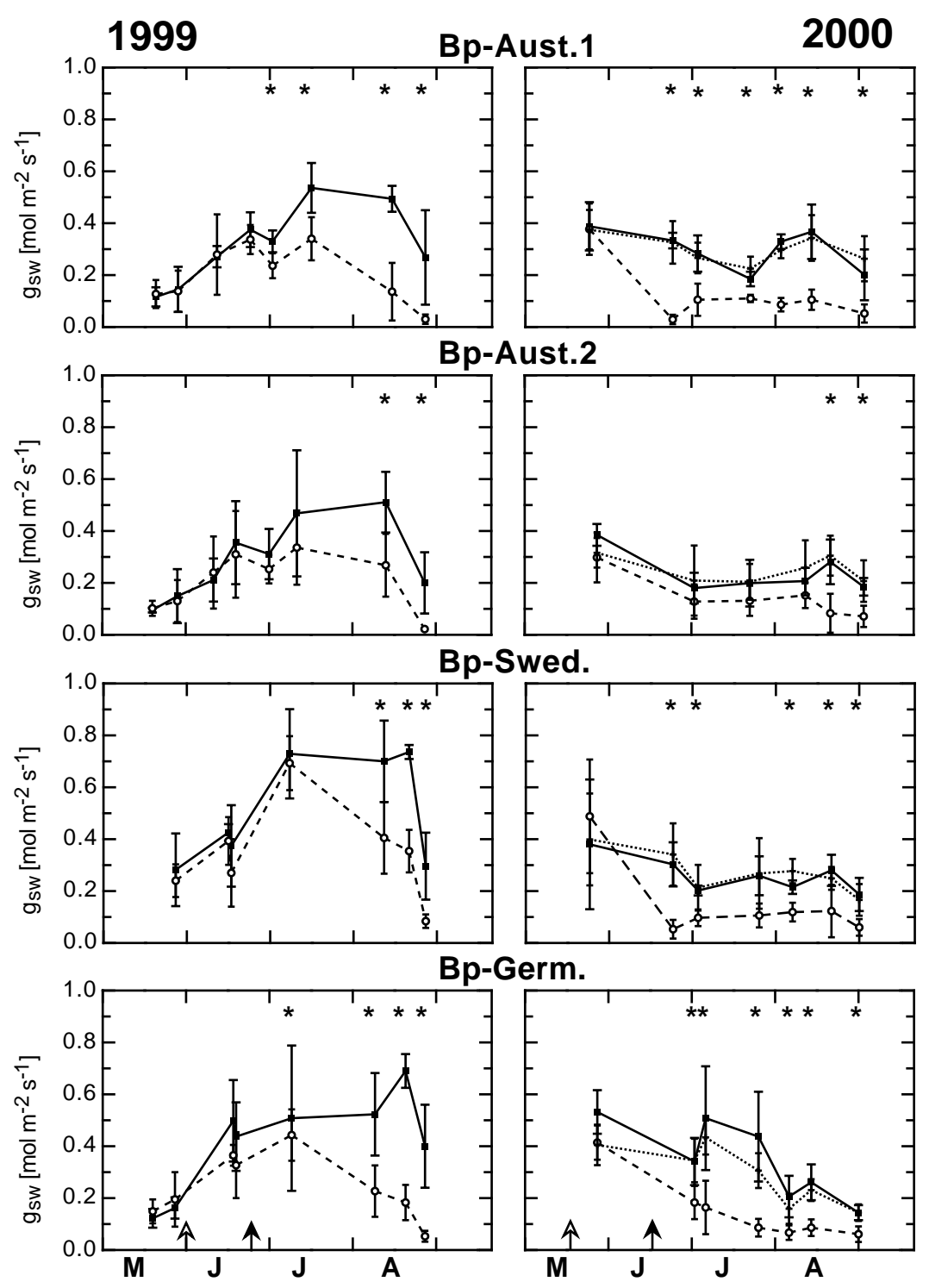

Figure 4.4.: Daily means \pm standard deviations of stomatal conductance $\left(g_{\mathrm{sw}}\right)$ of the four birch clones throughout the growing seasons 1999 and $2000\left(c_{\mathrm{a}}=360 \mathrm{ppm}, \mathrm{PPFD}=1500 \mu \mathrm{mol}\right.$ photons $\mathrm{m}^{-2} \mathrm{~s}^{-1}$, $T_{\text {leaf }}=22{ }^{\circ} \mathrm{C}$ and VPD $=1 \mathrm{kPa}$, all measurements taken between 10:00 and 17:00 solar time). Open circles and dashed lines represent the droughted plants (D99 and D99/D00), filled squares and solid lines the well watered controls (W99 and W99/W00), and crosses and dotted lines the drought-andrecovery treatment in 2000 (D99/W00). Means and standard deviations of 5 leaves from different plants are given. Asterisks indicate significant differences $(P \leq 0.05)$ between droughted (D99 and D99/D00) and well watered plants (W99/W00). The white arrow marks the onset of the drought; after the day indicated by the black arrow the volumetric soil water content of the droughted pots was below $3 \%$.

genotypes in the D99/W00- and the D99/D00-treatment.

Relative plasticity of stomatal conductance ranged from 57 to $93 \%$ in 1999 and from 61 to $98 \%$ in 2000 (Tab. A.3). In both years, relative as well as absolute plasticity of the 
genotypes Bp-Germ. and Bp-Aust.1 were higher than those of Bp-Swed. and Bp-Aust.2. BpAust. 2 responded least plastic in both years.

Analysis of variance proved the significant seasonal variation of stomatal conductance, which was strongly influenced by both the genotype of the examined tree and the treatment it was subjected to (Tab. B.4).

\subsubsection{Stomatal conductance measured under natural conditions}
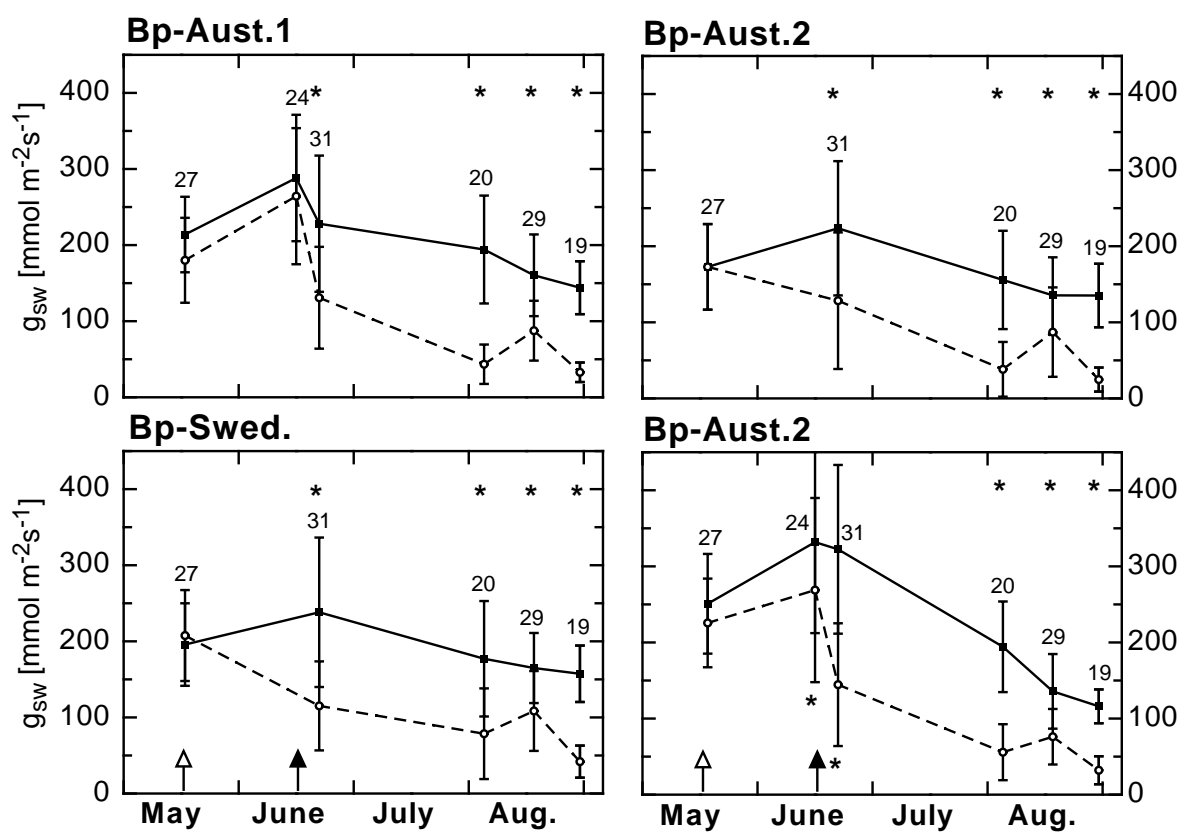

Figure 4.5.: Daily means \pm standard deviations of stomatal conductance $\left(g_{\mathrm{sw}}\right)$ of the four birch clones from May to August 2000. Open circles and dashed lines represent the droughted plants (D99/D00), filled squares and solid lines the well watered controls (W99/W00). Means and standard deviations of 6 leaves from different plants are given. Numbers show the daily means of VPD [hPa]. Asterisks indicate significant differences $(P \leq 0.05)$ between droughted and well watered plants. The white arrow indicates the begin of the drought treatment, after the day indicated by the black arrow the volumetric soil water content of the droughted pots was below $3 \%$.

Stomatal conductances measured under natural conditions were generally lower than those reached under the influence of the comparatively low VPD in the LI-6400 leaf chamber (Fig. 4.5). All measurements with the steady-state porometer were carried out on sunny days to guarantee light saturation of photosynthesis as in the measurements with the photosynthesis system, but daily averages of VPD reached up to $31 \mathrm{hPa}$.

The annual course of the $g_{\mathrm{sw}}$ showed peak values for all genotypes in mid June, after which the conductances declined continuously despite lower VPD; this effect was most pronounced in Bp-Germ., which also reached the highest daily conductances in the well watered trees. In general, $g_{\mathrm{sw}}$ values of Bp-Aust. 2 were lowest. Annual averages ranged from $165 \mathrm{mmol} \mathrm{m} \mathrm{m}^{-2} \mathrm{~s}^{-1}$ (Bp-Aust.2) to $225 \mathrm{mmol} \mathrm{m}^{-2} \mathrm{~s}^{-1}$ in the German genotype, thus being about $30 \%$ lower than those measured under constant VPD. 
The trees of all genotypes responded significantly to the drought from mid June on, when the soil water contents dropped below $3 \%$ for the first time. Annual averages ranged from $90 \mathrm{mmol} \mathrm{m}{ }^{-2} \mathrm{~s}^{-1}$ in Bp-Aust. 2 to $134 \mathrm{mmol} \mathrm{m}^{-2} \mathrm{~s}^{-1}$ in the German clone, but daily means as low as 25 to $42 \mathrm{mmol} \mathrm{m}{ }^{-2} \mathrm{~s}^{-1}$ were reached by the end of August. Two subsequent measurements in the course of one week with a rise of average daily VPD from 24 to $31 \mathrm{hPa}$ carried out on Bp-Aust.1 and Bp-Germ. in June revealed the pronounced response of the plants to this change in VPD in the early drought phase. Since in June 2000, 26 days had a cloud cover of more than $80 \%$ (Fig. 2.3), measurements of the daily course of stomatal conductance were not possible in this month. In August though, both well watered and droughted plants did not show any reaction to changes in VPD, presumably because leaf senescence was quite advanced by then.

Plasticity of stomatal conductances ranged from 80 to $104 \%$ (Tab. A.2. Since daily averages of $g_{\mathrm{sw}}$ values did not show a gaussian distribution, analyses of variance were carried out with regard to the daily maxima of $g_{\mathrm{sw}}$ (Tab. B.2). Like the stomatal conductances measured under constant VPD with the LI-6400, morning maxima of $g_{\mathrm{sw}}$ under ambient VPD were significantly influenced by both genotype and treatment, though not by their interrelation.

\subsection{Leaf gas exchange and photosynthesis}

\subsubsection{Net photosynthesis and photosynthetic water-use efficiency at ambient $\mathrm{CO}_{2}$ concentration and light saturation}

Net photosynthesis at light saturation $\left(A_{\mathrm{amb}}\right)$ followed a seasonal variation more or less mirroring that of $g_{\mathrm{sw}}$ (Fig. 4.6). In 1999, rates of photosynthesis of the Austrian genotypes rose from May on to a maximum in early July, then they decreased to late August, the decline being particularly steep from the middle to the end of August. In Bp-Swed. and Bp-Germ., $A_{\text {amb }}$ increased to an early maximum in mid-June, then showed a slight depression before reaching a second maximum in August. Values then sank rapidly towards the end of August.

Well watered trees of the genotypes Bp-Aust.1 and Bp-Swed. reached markedly higher rates of $A_{\mathrm{amb}}$ than the other clones, which reflects the higher chlorophyll contents of their leaves (Fig. 4.8). In all genotypes, the $A_{\mathrm{amb}}$ of the droughted plants responded later to the water shortage than stomatal conductances, the differences became significant $(P \leq 0.05)$ only in the second half of August 1999.

In the second year of investigation, rates of $A_{\mathrm{amb}}$ of the W99/W00-treatments were lower than in 1999, but exhibited the same order: Bp-Aust.1 and Bp-Swed. reached higher average values than Bp-Aust. 2 and the German genotype. Droughted plants of Bp-Aust.1 and BpSwed. responded early to the water deficit, their $A_{\mathrm{amb}}$ sank rapidly in response to the first drop of soil water contents below $3 \%$ in late June. They recovered from this decline until the end of July, before $A_{\mathrm{amb}}$ started to decrease again towards the end of August. Apart from the initial response of these two genotypes, the decrease of rates of $A_{\mathrm{amb}}$ of the droughted plants in comparison with the well watered ones became statistically significant from late July to midAugust in all clones. Differences between rates of photosynthesis of the drought-and-recovery treatment and the well watered trees could not be detected in any of the clones. 

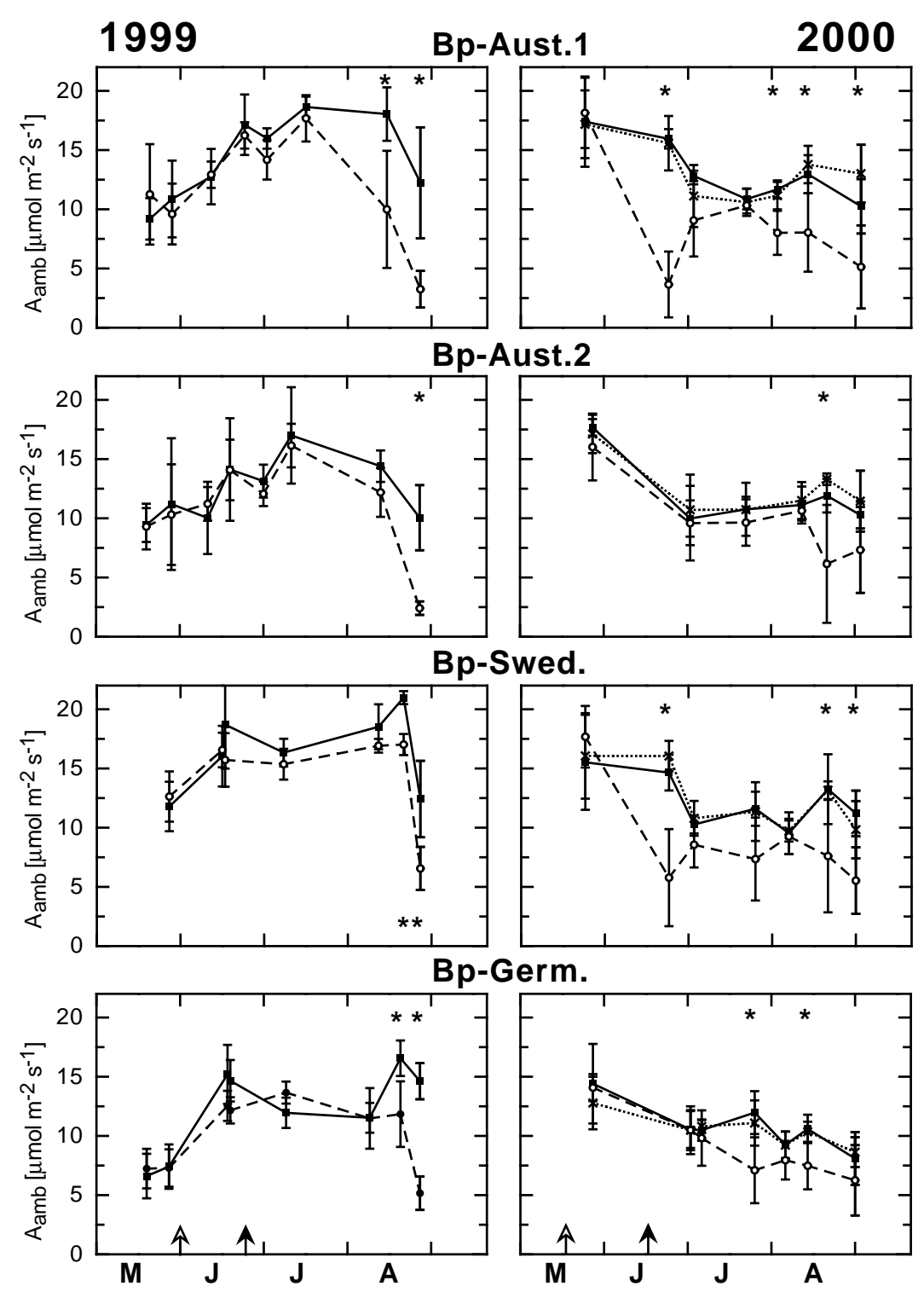

Figure 4.6.: Daily means \pm standard deviations of net photosynthesis $\left(A_{\mathrm{amb}}\right)$ of the four birch clones throughout the growing seasons 1999 and $2000\left(c_{\mathrm{a}}=360 \mathrm{ppm}, \mathrm{PPFD}=1500 \mu \mathrm{mol}\right.$ photons $\mathrm{m}^{-2} \mathrm{~s}^{-1}$, $T_{\text {leaf }}=22{ }^{\circ} \mathrm{C}$ and $\mathrm{VPD}=1 \mathrm{kPa}$, all measurements taken between 10:00 and 17:00 solar time). Open circles and dashed lines represent the droughted plants (D99 and D99/D00), filled squares and solid lines the well watered controls (W99 and W99/W00), and crosses and dotted lines the drought-andrecovery treatment in 2000 (D99/W00). Means and standard deviations of 5 leaves from different plants are given. Asterisks indicate significant differences $(P \leq 0.05)$ between droughted (D99 and D99/D00) and well watered plants (W99/W00). The white arrow marks the onset of the drought; after the day indicated by the black arrow the volumetric soil water content of the droughted pots was below $3 \%$.

Plasticity of net photosynthesis (Tab. A.3 was much lower than plasticities exhibited with regard to stomatal conductance. In both years, $A_{\mathrm{amb}}$ of Bp-Aust.1 responded more plastic to the drought than those of the other clones. 

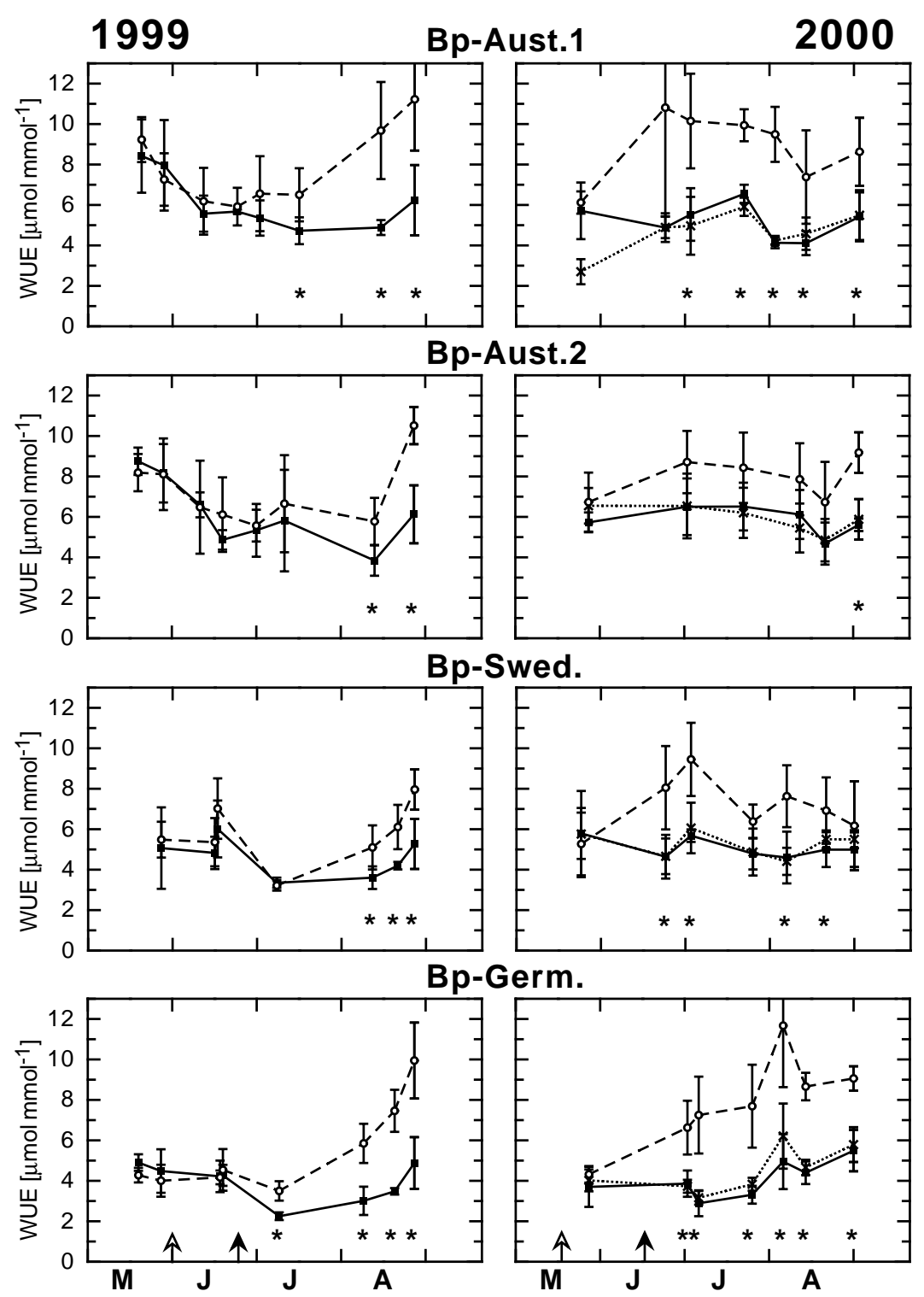

Figure 4.7.: Daily means \pm standard deviations of the water use efficiency (WUE) of the four birch clones throughout the growing seasons 1999 and $2000\left(c_{\mathrm{a}}=360 \mathrm{ppm}\right.$, PPFD $=1500 \mu$ mol photons $\mathrm{m}^{-2} \mathrm{~s}^{-1}, T_{\text {leaf }}=22^{\circ} \mathrm{C}$ and VPD $=1 \mathrm{kPa}$, all measurements taken between 10:00 and 17:00 solar time). Open circles and dashed lines represent the droughted plants (D99 and D99/D00), filled squares and solid lines the well watered controls (W99 and W99/W00), and crosses and dotted lines the droughtand-recovery treatment in 2000 (D99/W00). Means and standard deviations of 5 leaves from different plants are given. Asterisks indicate significant differences $(P \leq 0.05)$ between droughted (D99 and D99/D00) and well watered plants (W99/W00). The white arrow marks the onset of the drought; after the day indicated by the black arrow the volumetric soil water content of the droughted pots was below $3 \%$.

The analysis of variance showed the pronounced seasonal variation of all gas exchange parameters (Tab. B.4). While rates of net photosynthesis were significantly influenced by both 
Table 4.4.: Daily means and standard deviation of net photosynthesis at ambient $\left[\mathrm{CO}_{2}\right]\left(A_{\mathrm{amb}}[\mu \mathrm{mol}\right.$ $\left.\left.\mathrm{m}^{-2} \mathrm{~s}^{-1}\right]\right)$, stomatal conductance $\left(g_{\mathrm{sw}}\left[\mathrm{mmol} \mathrm{m}^{-2} \mathrm{~s}^{-1}\right]\right)$, intercellular $\mathrm{CO}_{2}$ concentration $\left(c_{\mathrm{i}}[\mathrm{ppm}]\right)$, and photosynthetic water use efficiency (WUE $\left[\mu \mathrm{mol} \mathrm{mmol}^{-1}\right]$ ) of the well watered (W99/W00 - labelled $\mathrm{W}$ ) and the droughted (D99/D00 - labelled D) birch trees after about 11 weeks of drought $\left(c_{\mathrm{a}}=360 \mathrm{ppm}\right.$, PPFD $=1500 \mu \mathrm{mol}$ photons $\mathrm{m}^{-2} \mathrm{~s}^{-1}, T_{\text {leaf }}=22{ }^{\circ} \mathrm{C}$ and $\left.\mathrm{VPD}=1 \mathrm{kPa}\right)$. Averages \pm standard deviations of 5 leaves from different plants are given. Asterisks indicate significant differences $(P \leq 0.05)$ between droughted and well watered plants. The columns headed $\%$ show the differences between the droughted and the control plants.

\begin{tabular}{|c|c|c|c|c|c|c|c|c|c|c|c|c|}
\hline & \multicolumn{3}{|c|}{ Bp-Aust.1 } & \multicolumn{3}{|c|}{ Bp-Aust. 2} & \multicolumn{3}{|c|}{ Bp-Swed. } & \multicolumn{3}{|c|}{ Bp-Germ. } \\
\hline & W & $\mathrm{D}$ & $\%$ & W & $\mathrm{D}$ & $\%$ & W & D & $\%$ & W & $\mathrm{D}$ & $\%$ \\
\hline \multicolumn{13}{|c|}{ 24.08.1999 } \\
\hline \multirow[t]{2}{*}{$A_{\mathrm{amb}}$} & 12.24 & 3.25 & $-76 *$ & 10.05 & 2.41 & $-73 *$ & 12.42 & 6.56 & $-47 *$ & 14.62 & 5.16 & $-64 *$ \\
\hline & \pm 4.68 & \pm 1.55 & & \pm 2.75 & \pm 0.57 & & \pm 3.23 & \pm 1.82 & & \pm 1.53 & \pm 1.41 & \\
\hline \multirow[t]{2}{*}{$g_{s w}$} & 268 & 30 & $-89 *$ & 200 & 22 & $-89 *$ & 296 & 84 & $-72 *$ & 400 & 53 & $-87 *$ \\
\hline & \pm 182 & \pm 18 & & \pm 118 & \pm 4 & & \pm 129 & \pm 26 & & \pm 160 & \pm 21 & \\
\hline \multirow[t]{2}{*}{$c_{\mathrm{i}}$} & 254 & 167 & $-34 *$ & 252 & 180 & $-29 *$ & 270 & 222 & $-18 *$ & 274 & 189 & $-31 *$ \\
\hline & \pm 29 & \pm 43 & & \pm 25 & \pm 12 & & \pm 20 & \pm 13 & & \pm 23 & \pm 30 & \\
\hline \multirow[t]{2}{*}{ WUE } & 6.24 & 11.23 & $+71 *$ & 6.13 & 10.51 & $+80 *$ & 5.27 & 7.96 & $+51 *$ & 4.88 & 9.95 & $+104 *$ \\
\hline & \pm 1.74 & \pm 2.53 & & \pm 0.92 & \pm 1.43 & & \pm 1.24 & \pm 1.00 & & \pm 1.28 & \pm 1.88 & \\
\hline \multicolumn{13}{|c|}{$11 .-18.08 .2000$} \\
\hline \multirow[t]{2}{*}{$A_{\mathrm{amb}}$} & 12.96 & 8.04 & $-38 *$ & 11.91 & 6.14 & $-48 *$ & 13.25 & 7.60 & $-43 *$ & 10.59 & 7.48 & $-29 *$ \\
\hline & \pm 1.61 & \pm 3.31 & & \pm 1.42 & \pm 4.98 & & \pm 2.95 & \pm 4.75 & & \pm 1.2 & \pm 1.99 & \\
\hline \multirow[t]{2}{*}{$g_{s w}$} & 367 & 105 & $-71 *$ & 281 & 83 & $-70 *$ & 280 & 123 & $-56 *$ & 261 & 86 & $-67 *$ \\
\hline & \pm 105 & \pm 39 & & \pm 86 & \pm 75 & & \pm 60 & \pm 101 & & \pm 69 & \pm 32 & \\
\hline \multirow[t]{2}{*}{$c_{\mathrm{i}}$} & 283 & 224 & $-21 *$ & 270 & 230 & -15 & 266 & 232 & $-13 *$ & 277 & 204 & $-26 *$ \\
\hline & \pm 11 & \pm 40 & & \pm 21 & \pm 31 & & \pm 15 & \pm 28 & & \pm 11 & \pm 14 & \\
\hline \multirow[t]{2}{*}{ WUE } & 4.11 & 7.38 & $+80 *$ & 4.68 & 6.73 & +44 & 4.99 & 6.92 & $+39 *$ & 4.40 & 8.66 & $+97 *$ \\
\hline & \pm 0.59 & \pm 2.31 & & \pm 1.04 & \pm 1.99 & & \pm 0.86 & \pm 1.64 & & \pm 0.56 & \pm 0.68 & \\
\hline
\end{tabular}

plant genotype and treatment, in the second year of investigation only the water-supply had a pronounced influence on this parameter.

Daily averages of photosynthetic water-use efficiency (WUE) are shown in Fig. 4.7. In 1999, they sank from an initial maximum in mid-May to lower values in July, before rising again with advancing senescence of the leaves. Well watered plants of the Austrian genotypes reached higher WUE than those of the Swedish and German clones throughout the whole season, though these differences were not statistically significant. Like all parameters measured with the LI-6400 photosynthesis system, standard deviation of mean daily WUE includes the diurnal variation of this parameter, and is thus quite high. In all clones, the WUE of droughted plants began to rise from mid- to late July on to maximum values in late August. As with regard to stomatal conductance and net photosynthesis, differences became first apparent in the German genotye and in Bp-Aust.1. The Austrian clones reached the highest WUE in the D99/D00-treatment as well. In late August, when the water shortage had continued longest and leaf senescence was advanced, the droughted trees reached WUE ranging from $7.96 \mathrm{mmol}$ $\mathrm{mol}^{-1}$ (Bp-Swed.) to $11.22 \mathrm{mmol} \mathrm{mol}^{-1}$ (Bp-Aust.1). 
In 2000, WUE of the well watered Austrian clones were lower than in 1999, while the WUE of the Swedish and German plants did not change to that extent. Like in the first year of investigation, the average WUE of the W99/W00 treated German trees were lower than those of the other genotypes. WUE of the droughted plants started with values not significantly different from those of the W99/W00 treated ones in late May, but they responded earlier to the water shortage than in 1999, and started to increase from early July on. From this time on, the differences between well watered and droughted plants were significant in all clones except Bp-Aust.2. As in 1999, Bp-Aust.1 exhibited the highest average WUE in the D99/D00 treated trees $\left(8,65 \mathrm{mmol} \mathrm{mol}^{-1}\right)$, while the values reached by the other genotypes ranged from 7.39 to $7.90 \mathrm{mmol} \mathrm{mol}^{-1}$. Droughted trees of the Swedish clone and Bp-Aust.1 reached their maximal WUE after the initial drop of soil water contents to below $3 \%$ in late June to early July.

Similar to the stomatal conductance, the German genotype and Bp-Aust.1 responded most plastic concerning photosynthetic water use efficiency as well (Tab. A.3). In the second year of investigation, when both absolute and relative plasticity of WUE were higher than in 1999 in all clones, they exhibited plasticities of 69 and $63 \%$, respectively, while Bp-Aust.2 and Bp-Swed. only reached half of these values. Internal $\mathrm{CO}_{2}$ concentration and WUE were significantly influenced by the genotype of the investigated plant, as well as by the treatment it was subjected to (Tab. B.4).

Tab. 4.4 summarizes the effects of water shortage on various gas exchange parameters after about 11 weeks of drought in each of the summers of 1999 and 2000.

In both years, percental reduction of stomatal conductance was significant in all clones, being smallest in Bp-Swed. and largest in the two Austrian genotypes, which was reflected by reductions of the internal $\mathrm{CO}_{2}$ concentration $\left(c_{\mathrm{i}}\right)$.

Since $c_{\mathrm{i}}$ of droughted plants of the Swedish genotype were least affected by stomatal closure, $A_{\text {amb }}$ was reduced to a lesser extend than in the other clones as well. In comparison with the Austrian plants, rates of $A_{\mathrm{amb}}$ were less affected in the droughted German trees, too, but this clone exhibited a doubling of its WUE after 11 weeks of drought, which was not reached by the other clones.

\subsubsection{Photosynthetic capacity, carboxylation efficiency, and compensating and saturating $\mathrm{CO}_{2}$ concentrations}

To distinguish the effects of stomatal limitation on net photosynthesis from limitations caused by reactions of the photosynthetic apparatus itself to water shortage, $\mathrm{CO}_{2}$-effect curves were measured in early August 1999 and 2000, after 6 to 8 weeks at soil water contents below $3 \%$. Tab. 4.5 shows the photosynthetic capacity at light- and $\mathrm{CO}_{2}$-saturation $\left(A_{\max }\right)$, the carboxylation efficiency (CE), and the $\mathrm{CO}_{2}$ saturation concentration $\left(\mathrm{CO}_{2 \text { sat }}\right)$ as calculated from these curves. With regard to $A_{\max }$ (leaf area-based data), no significant differences were detected between droughted and well watered trees in any of the genotypes. Rates of $A_{\max }$ reached by Bp-Aust.1 and Bp-Swed. in 1999 were significantly higher than those of Bp-Aust.2 and BpGerm., which reflects the different foliar chlorophyll contents of the four genotypes (Tab. 4.8). Plasticity of $A_{\max }$ was small in comparison to that of $A_{\mathrm{amb}}$, which is susceptible to stomatal limitation (Tab. A.4 and Tab. A.3. Analysis of variance of the data obtained in 1999 revealed a highly significant influence of the genotype on photosynthetic capacity per leaf area, while 
Table 4.5.: Daily means of photosynthetic capacity $\left(A_{\max }\left[\mu \mathrm{mol} \mathrm{m}{ }^{-2} \mathrm{~s}^{-1}\right]\right.$ and $\left.\left[\mu \mathrm{mol} \mathrm{g} \mathrm{chl.}{ }^{-1} \mathrm{~s}^{-1}\right]\right)$, carboxylation efficiency $\left(\mathrm{CE}\left[\mu \mathrm{mol} \mathrm{m}{ }^{-2} \mathrm{~s}^{-1} \mathrm{ppm}^{-1}\right]\right)$, and saturating $\mathrm{CO}_{2}$ concentration $\left(\mathrm{CO}_{2 \text { sat }}[\mathrm{ppm}]\right)$ of the droughted (D99/D00, labelled D) and the well watered (W99/W00, labelled W) trees in early August 1999 and 2000 (PPFD $=1500 \mu \mathrm{mol}$ photons $\mathrm{m}^{-2} \mathrm{~s}^{-1}, T_{\text {leaf }}=22{ }^{\circ} \mathrm{C}$ und VPD $=1 \mathrm{kPa}$ ). Means \pm standard deviations of 5 (1999) or 4 (2000) leaves of different trees are shown. Asterisks indicate significant differences $(P \leq 0.05)$ between droughted and well watered plants.

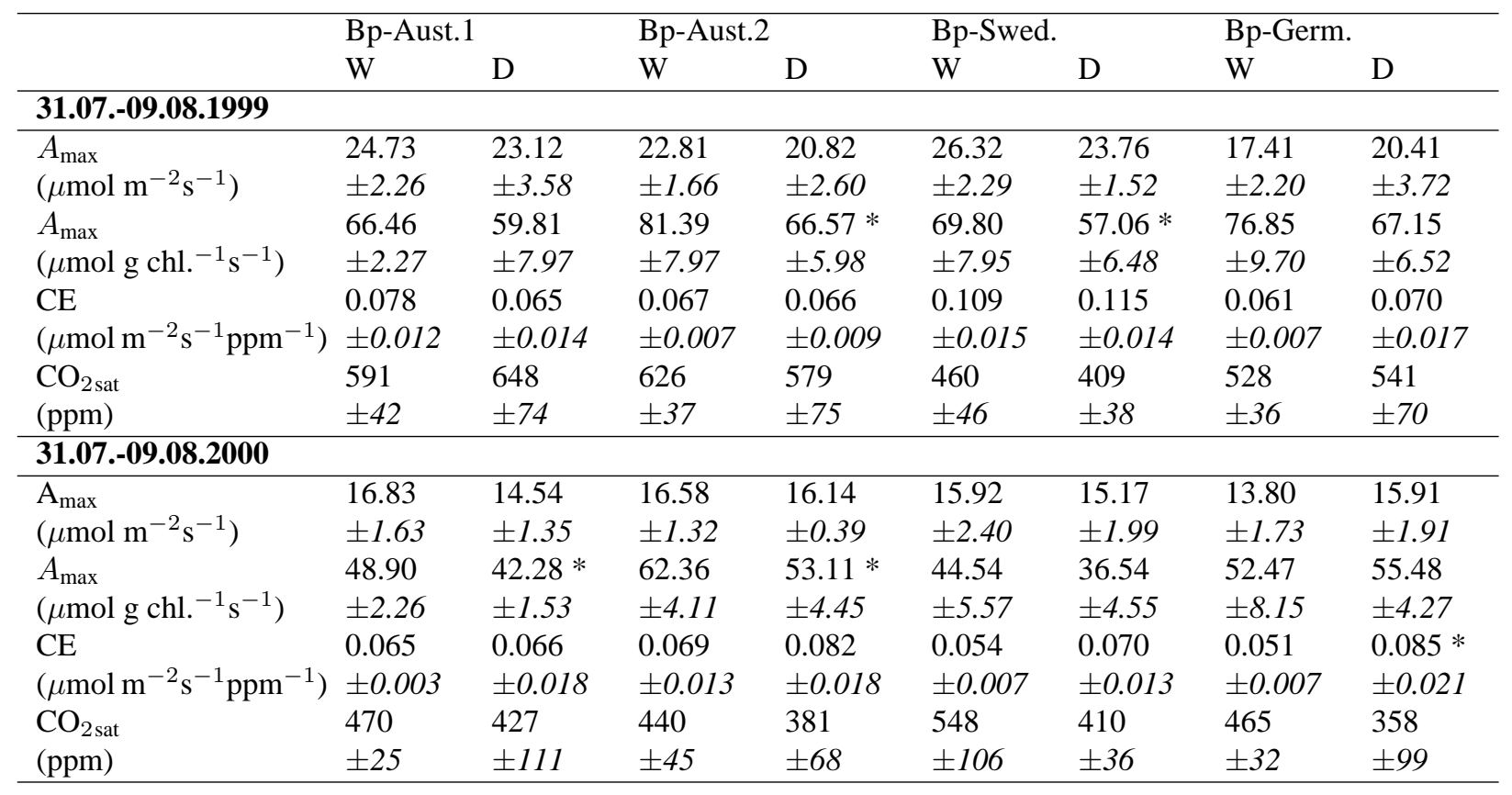

the water supply did not influence this parameter (Tab. B.3). When calculated based on chlorophyll contents of the leaves, the genotypes with the lowest chlorophyll content per leaf area, Bp-Aust.2 and Bp-Germ., exhibited the highest $A_{\max }$. With regard to chlorophyll-based $A_{\max }$, the droughted trees of all clones showed lower values than the well watered ones, though these differences were statistically significant only in Bp-Swed. and Bp-Aust.2. To interpret these findings, the higher foliar chlorophyll contents of the droughted plants of all genotypes have to be considered (Fig. 4.8). Analysis of variance showed a significant influence of the water treatment on this parameter, which even dominated that of the clone.

In August 2000, the rates of photosynthetic capacity calculated on both a leaf area and chlorophyll content basis were markedly lower than in 1999. Although leaf area based $A_{\max }$ values were again lowest in the German clone and, like in 1999, Bp-Aust.2 and Bp-Germ. reached highest chlorophyll content-based values of $A_{\max }$, no significant differences between the genotypes were detected in this year. When calculated based on foliar chlorophyll content, $A_{\max }$ of the droughted trees were lower than those reached by the well watered ones, the differences being significant in the Austrian clones. Unlike in 1999, neither genotype, nor water treatment could explain the variation of leaf area-based $A_{\max }$ (Tab. B.3). When calculated on a chlorophyll content basis, $A_{\max }$ was influenced by both clone and the treatment in a higly 
significant way.

Carboxylation efficiencies of the well watered Swedish trees were significantly higher than those of the other genotypes in 1999, while Bp-Germ. exhibited the lowest values. CE of the droughted plants did not differ significantly from those of the well watered ones, though the Austrian clones showed a tendency to lower values, while CE of the D99/D00-treatment in Bp-Swed. and Bp-Germ. were higher than those of the W99/W00-treatment. This tendency was confirmed by measurements in 2000. In this year, all genotypes except Bp-Aust. 2 showed lower CE than in 1999, but while the CE of droughted plants did not change in comparison to the well watered ones in Bp-Aust.1, they were higher than those of the well watered trees in the other clones. This difference was statistically significant in the German genotype. While the plasticity of carboxylation efficiency only ranged from 0 to $19 \%$ in 1999 (Tab. A.4), it reached up to $50 \%$ in the German clone in 2000. The genotype was the only factor significantly influencing CE in 1999 (Tab. B.3), but had no influence in 2000, when, in contrast, the influence of the treatment on $\mathrm{CE}$ was highly significant.

\subsection{Chlorophyll and nitrogen content of the leaves}

\subsubsection{Chlorophyll content per unit leaf area}

Foliar chlorophyll contents per leaf area are shown in Fig. 4.8. The contents measured in 1999 increased towards the end of summer in all genotypes. Leaves of the well watered Bp-Aust.2 and Bp-Germ. (annual averages 259 and $237 \mathrm{mg} \mathrm{m}^{-2}$, respectively) contained significantly lower amounts of chlorophyll than those of Bp-Aust.1 $\left(359 \mathrm{mg} \mathrm{m}^{-2}\right)$ and especially Bp-Swed. (383 $\mathrm{mg} \mathrm{m}^{-2}$ ) throughout the whole summer. In 2000, chlorophyll contents of the W99/W00treatments were lower than in 1999, but again the Swedish clone and Bp-Aust.1 exhibited significantly higher means than Bp-Aust. 2 and Bp-Germ.. These results confirm observations by eye, that the leaves of these clones were of a darker green colour, rendering it possible to distinguish the genotypes by the colour of their leaves. From late July 1999 on, foliar chlorophyll contents of the droughted plants were significantly higher than in those of the well watered ones in all genotypes except Bp-Aust.1. Nevertheless, contents in the leaves of Bp-Swed. and Bp-Aust.1 proved to be higher than those of the other genotypes in this treatment as well. In the summer of 2000, the leaves of droughted trees of all clones contained constantly higher amounts of chlorophyll per area than those of the other treatments from midJune to early July on. Chlorophyll contents in the leaves of the D99/W00-treatments did not significantly differ from those of the well watered trees. Like in the W99/W00-treatments, trees of the Swedish clone and Bp-Aust.1 had distinctly higher amounts of chlorophyll than Bp-Aust. 2 and Bp-Germ. in the other treatments as well.

The pronounced seasonal variation, and the influence of both genotype and water treatment on foliar chlorophyll contents was highly significant in both investigated years (Tab. B.6).

While the absolute plasticity of chlorophyll contents was 10 to $50 \mathrm{mg} \mathrm{m}^{-2} \mathrm{mg}$ in 1999 , it was much higher (50 to $100 \mathrm{mg} \mathrm{m}^{-2} \mathrm{mg} \mathrm{m}^{-2}$ ) in 2000 (Tab. A.5). The main reason for this increase are lower values of the well watered plants, whereas the contents of the droughted plants did not change to such an extent. In 1999, leaves of Bp-Germ. responded by far the most 

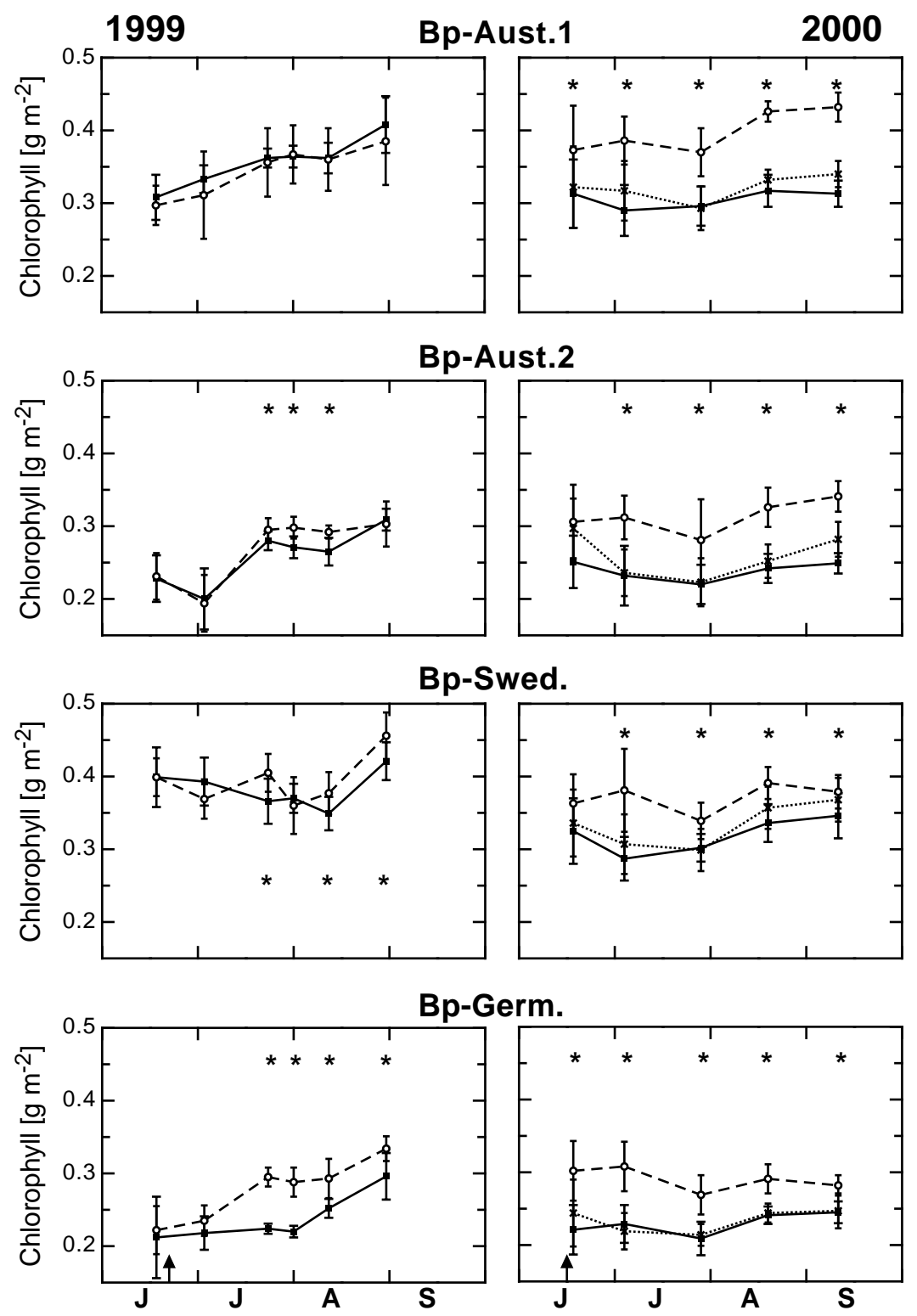

Figure 4.8.: Chlorophyll content of the birch leaves during the summers 1999 and 2000. Open circles and dashed lines represent the droughted plants (D99 and D99/D00), filled squares and solid lines the well watered controls (W99 and W99/W00), and crosses and dotted lines the drought-and-recovery treatment in 2000 (D99/W00). Means and standard deviations of 10 third and fourth leaves (counted from the terminal bud of a twig) from different plants are given. Asterisks indicate significant differences $(P \leq 0.05)$ between droughted (D99 and D99/D00) and well watered plants (W99/W00). After the day indicated by the black arrow the volumetric soil water content of the droughted pots was below $3 \%$.

plastic with regard to their chlorophyll contents, while in 2000 , the Austrian clones exhibited highest plasticities. 


\subsubsection{Foliar nitrogen content and $\mathrm{C}: \mathrm{N}$ ratio}
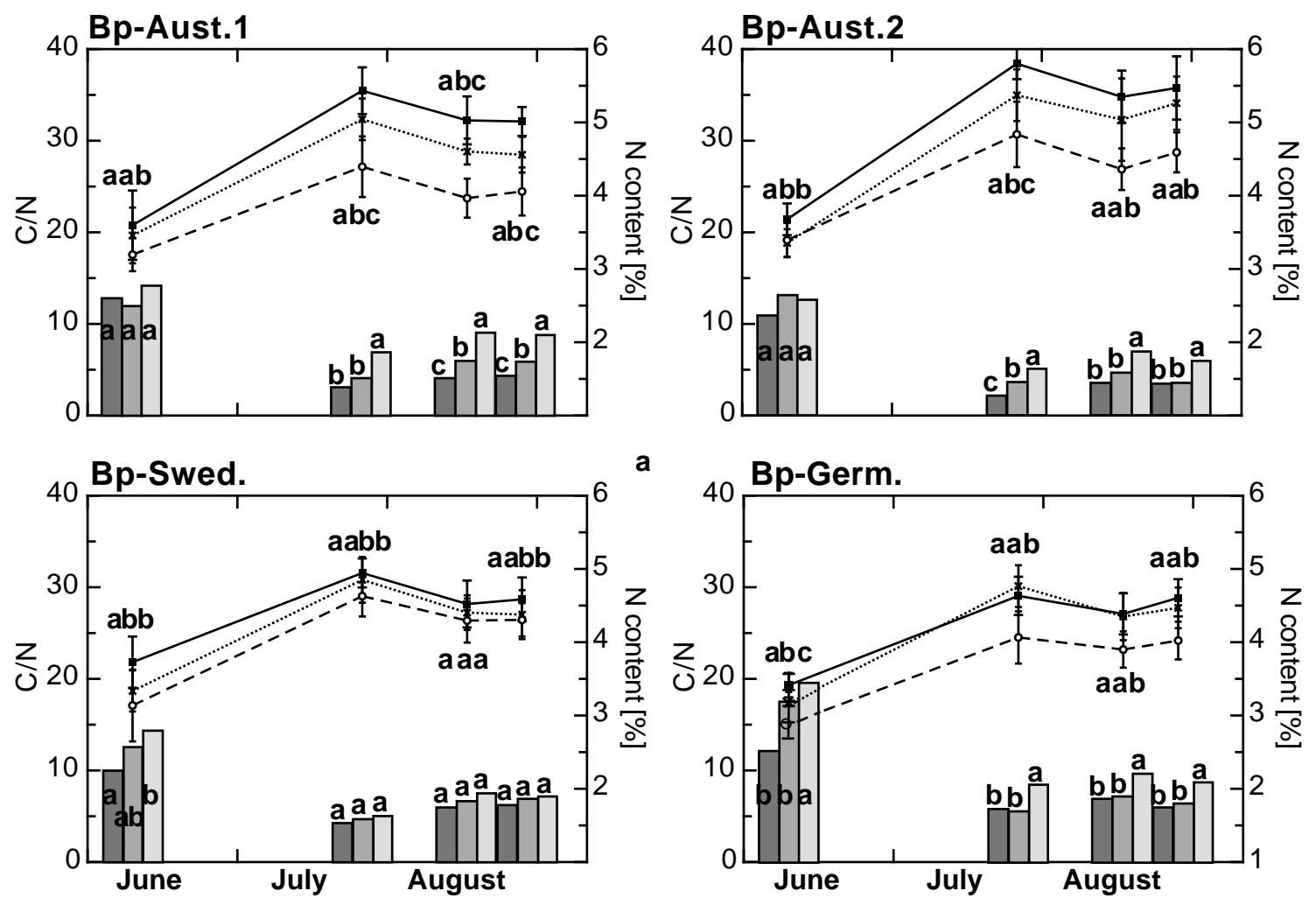

Figure 4.9.: $\mathrm{C}: \mathrm{N}$ ratio $\left[\mathrm{g} \mathrm{g}^{-1}\right]$ and nitrogen content per dry mass of the birch leaves during the summer of 2000. Open circles and dashed lines show the C:N ratios of the droughted plants (D99/D00), filled squares and solid lines those of the well watered controls (W99/W00) and crosses and dotted lines those of the drought-and-recovery treatment (D99/W00). The dark bars represent the nitrogen content per gram dry mass in the leaves of the well watered plants, the light bars that of the droughted trees and the medium ones in the centre that of the drought-and-recovery treatment. Means and standard deviations of 10 third and fourth leaves (counted from the terminal bud of a twig) from different plants are given. Asterisks indicate significant differences $(P \leq 0.05)$ between droughted and well watered plants. After the day indicated by the black arrow the volumetric soil water content of the droughted pots was below $3 \%$.

While the nitrogen contents and $\mathrm{C}: \mathrm{N}$ ratios of leaves did not show any distinct pattern in 1999 (BREIHOLZ, in preparation), the increase of percental nitrogen content per dry weight of the droughted plants in comparison with the well watered ones was significant in all genotypes except the Swedish one in 2000 (Fig. 4.9). In all clones and treatments, N-contents of third and fourth leaves were comparatively high in early June and dropped towards the end of July. From July on, the German and Swedish genotypes showed continually higher (significant at $P \leq 0.05)$ foliar nitrogen contents than the Austrian clones. The increase of percental nitrogen contents of the droughted plants was significant in Bp-Germ. from early June on, while in the Austrian clones it became first significant in July. Throughout the whole growing season, droughted trees of the German genotype had significantly higher nitrogen contents than those 

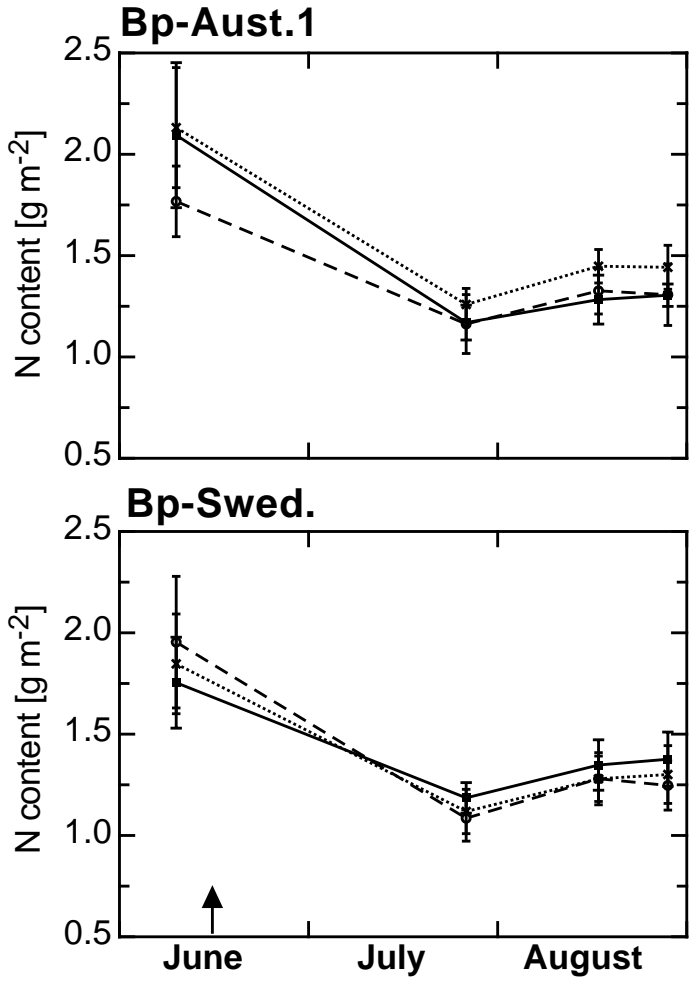
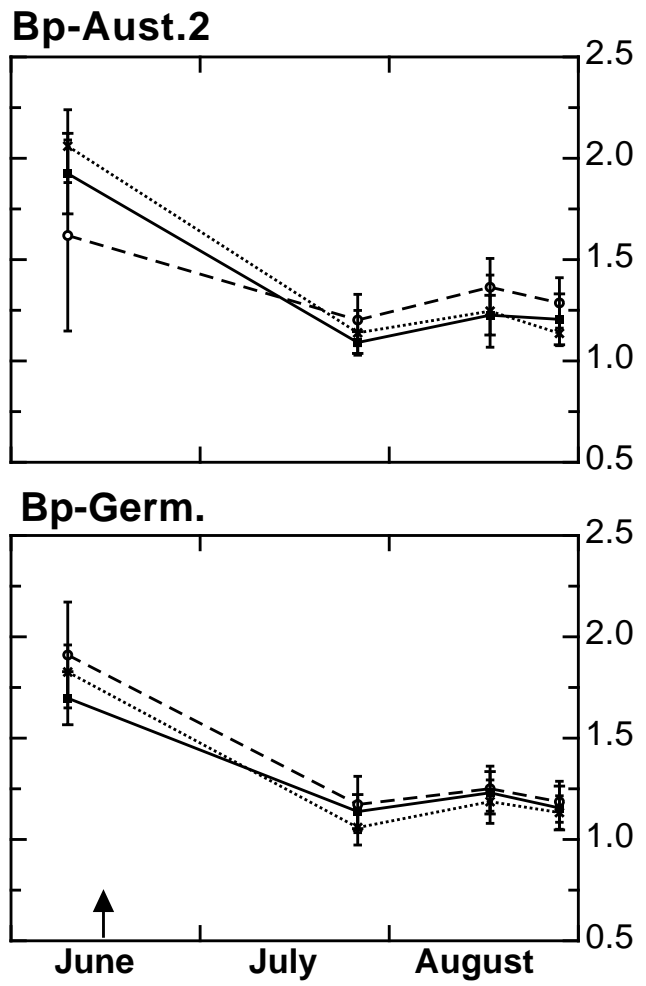

Figure 4.10.: Nitrogen content per leaf area of the birch leaves during the summer of 2000. Open circles and dashed lines show the $\mathrm{N}$ contents of the droughted plants (D99/D00), filled squares and solid lines those of the well watered controls (W99/W00) and crosses and dotted lines those of the drought-andrecovery treatment (D99/W00). Means and standard deviations of 10 third and fourth leaves (counted from the terminal bud of a twig) from different plants are given. Asterisks indicate significant differences $(P \leq 0.05)$ between droughted and well watered plants. After the day indicated by the black arrow the volumetric soil water content of the droughted pots was below $3 \%$.

of Bp-Aust.2. Nitrogen contents of the drought-and-recovery treatments were generally in between the W99/W00-and the D99/D00-treatments throughout the whole season. As in the other treatments, the Austrian clone Bp-Aust. 2 exhibited the lowest values in this treatment as well, the differences being significant when compared to the Swedish and the German genotype.

$\mathrm{C}: \mathrm{N}$ ratios also shown in Fig. 4.9 mirror the percental nitrogen contents. In all clones they showed a distinct rise from early June to mid-summer. From the first measurement on, the droughted plants of all genotypes had significantly lower C:N ratios than the well watered ones. C:N ratios of the W99/W00-treated trees of the Austrian clones were significantly higher than those of the Swedish and the German clone. In all treatments, the German clone had the lowest foliar $\mathrm{C}: \mathrm{N}$ ratios, while those of Bp-Aust.2 were highest.

While the rise of percental foliar nitrogen contents of the droughted plants was striking, no such response to drought stress could be detected in the nitrogen contents per unit leaf area (Fig. 4.10). In this context the increase of specific leaf areas of the droughted trees of all genotypes is interesting (see Tab. 4.6.

Nitrogen contents per square meter leaf area showed less variation between the genotypes 
than the percental values. The contents of the drought-and-recovery treatment of Bp-Aust.1 were consistently higher than those of the other genotypes, but no significant differences between the clones were observed in the other treatments.

Differences between the nitrogen contents expressed on a dry weight basis and on a leaf area basis are reflected by the plasticities of these parameters (Tab. A.5. While the relative plasticity of the percental nitrogen content ranged from $8 \%$ in Bp-Swed. to $31 \%$ in BpAust.1, it reached only $1 \%$ (Bp-Aust.1) to $8 \%$ (Bp-Swed.) when based on leaf area, thus being influenced by the plasticity of the specific leaf area (Tab. A.6).

\subsection{Carbon isotope composition of bulk leaf tissue}
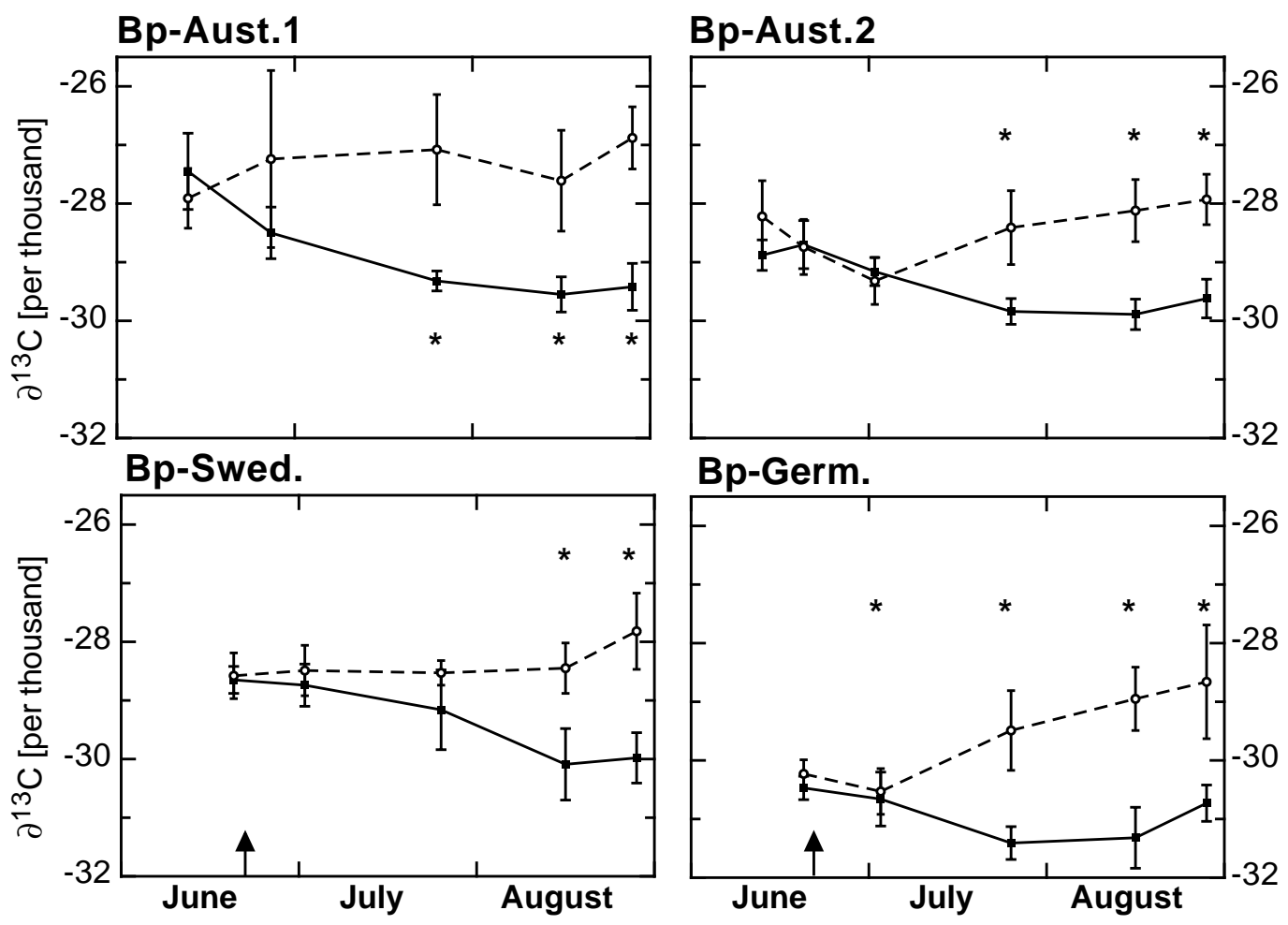

Figure 4.11.: $\delta^{13} \mathrm{C}$ values of bulk leaf tissue of the four birch clones during the summer of 1999. Open circles and dashed lines show the values of the droughted plants (D99), filled squares and solid lines those of the well watered controls (W99). Means and standard deviations of 10 third and fourth leaves (counted from the terminal bud of a twig) from different plants are given. Asterisks indicate significant differences $(P \leq 0.05)$ between droughted and well watered plants. After the day indicated by the black arrow the volumetric soil water content of the droughted pots was below $3 \%$.

Figures 4.11 and 4.12 show $\delta^{13} \mathrm{C}$ values of bulk leaf tissue of third and fourth leaves, as measured on 5 or 6 dates during the summer of 1999 and on 4 dates in 2000. In 1999, the curves started with higher (less negative) values in mid-June, which then decreased in the course of mid-summer before rising again towards the end of August (Fig. 4.11). The $\delta^{13} \mathrm{C}$ 

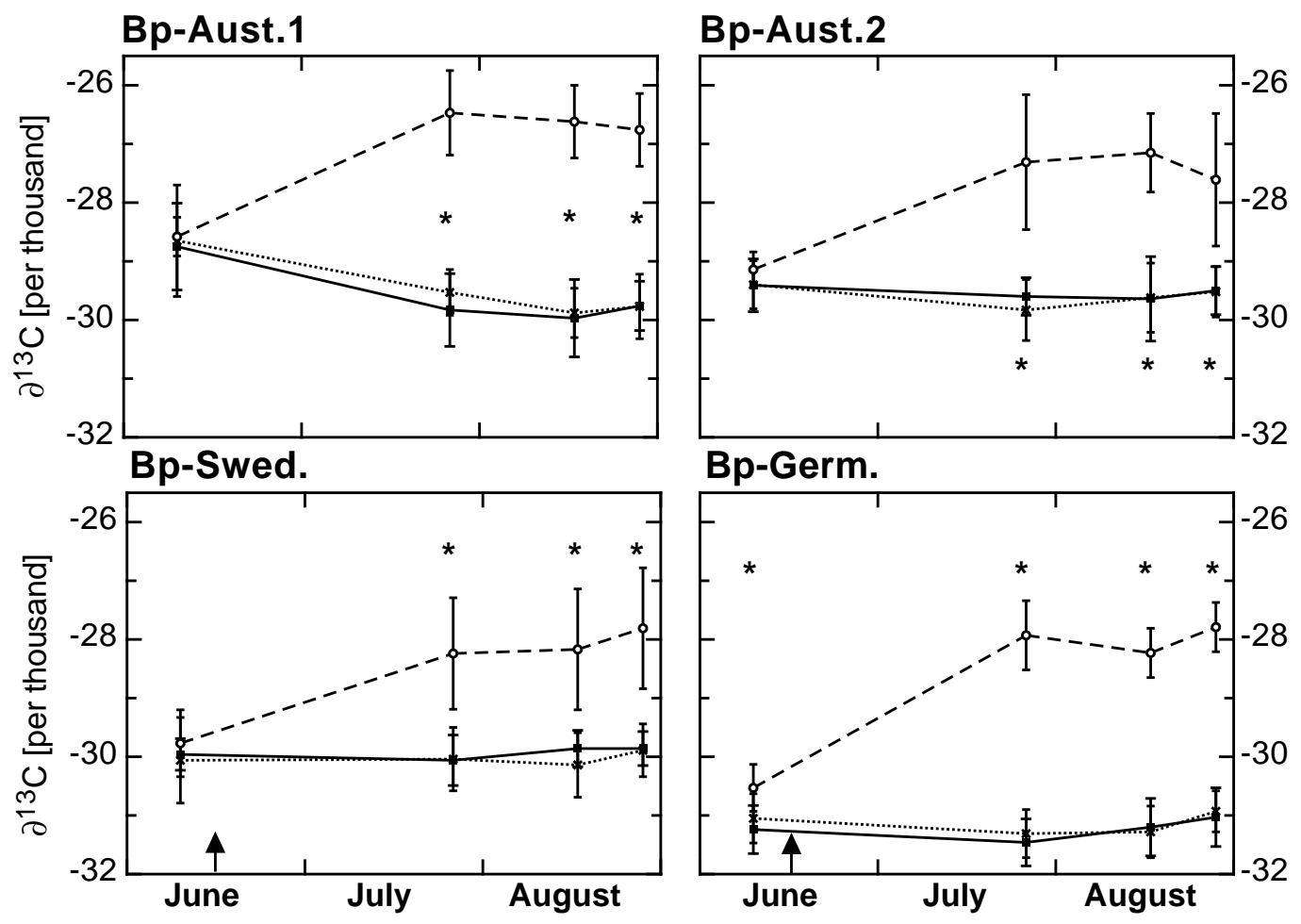

Figure 4.12.: $\delta^{13} \mathrm{C}$ values of bulk leaf tissue of the four birch clones during the summer of 2000. Open circles and dashed lines show the values of the droughted plants (D99/D00), filled squares and solid lines those of the well watered controls (W99/W00) and crosses and dotted lines those of the drought-andrecovery treatment (D99/W00). Means and standard deviations of 10 third and fourth leaves (counted from the terminal bud of a twig) from different plants are given. Asterisks indicate significant differences $(P \leq 0.05)$ between droughted and well watered plants. After the day indicated by the black arrow the volumetric soil water content of the droughted pots was below $3 \%$.

values of the well watered trees averaged in 1999 to $-28.85 \%$ in Bp-Aust.1, $-29.35 \%$ in BpAust.2, $-29.32 \%$ in Bp-Swed. and $-30.92 \%$ in Bp-Germ.. Values of $\delta^{13} \mathrm{C}$ of the German clone were significantly $(P \leq 0.05)$ lower than those of all other genotypes throughout the whole season, while the values of Bp-Aust.1 were continuously least negative, the differences in comparison with Bp-Aust. 2 and the Swedish clone being significant at two and three dates of sampling, respectively. The $\delta^{13} \mathrm{C}$ values of the droughted trees were getting progressively less negative than those of the well watered ones from the early drought phase in late June to early July on. Average values of the droughted trees ranged from $-27.38 \%$ in Bp-Aust.1 to $-29.57 \%$ in Bp-Germ., exhibiting the same order of the genotypes as in the well watered trees: values of Bp-Aust.1 were significantly less negative than those of Bp-Swed. and Bp-Germ. at all measured dates and less negative than those of Bp-Aust. 2 on four dates, while Bp-Aust.2 and Bp-Swed. reached less negative values than the German trees on three and two occasions, respectively. At the end of August 1999 differences between the W99/W00-treated and the droughted trees of one clone averaged to $2.12 \%$.

In the summer of 2000, the $\delta^{13} \mathrm{C}$ values of the well watered plants showed a less pronounced annual variation than in 1999, being more or less constant from early June to late August 

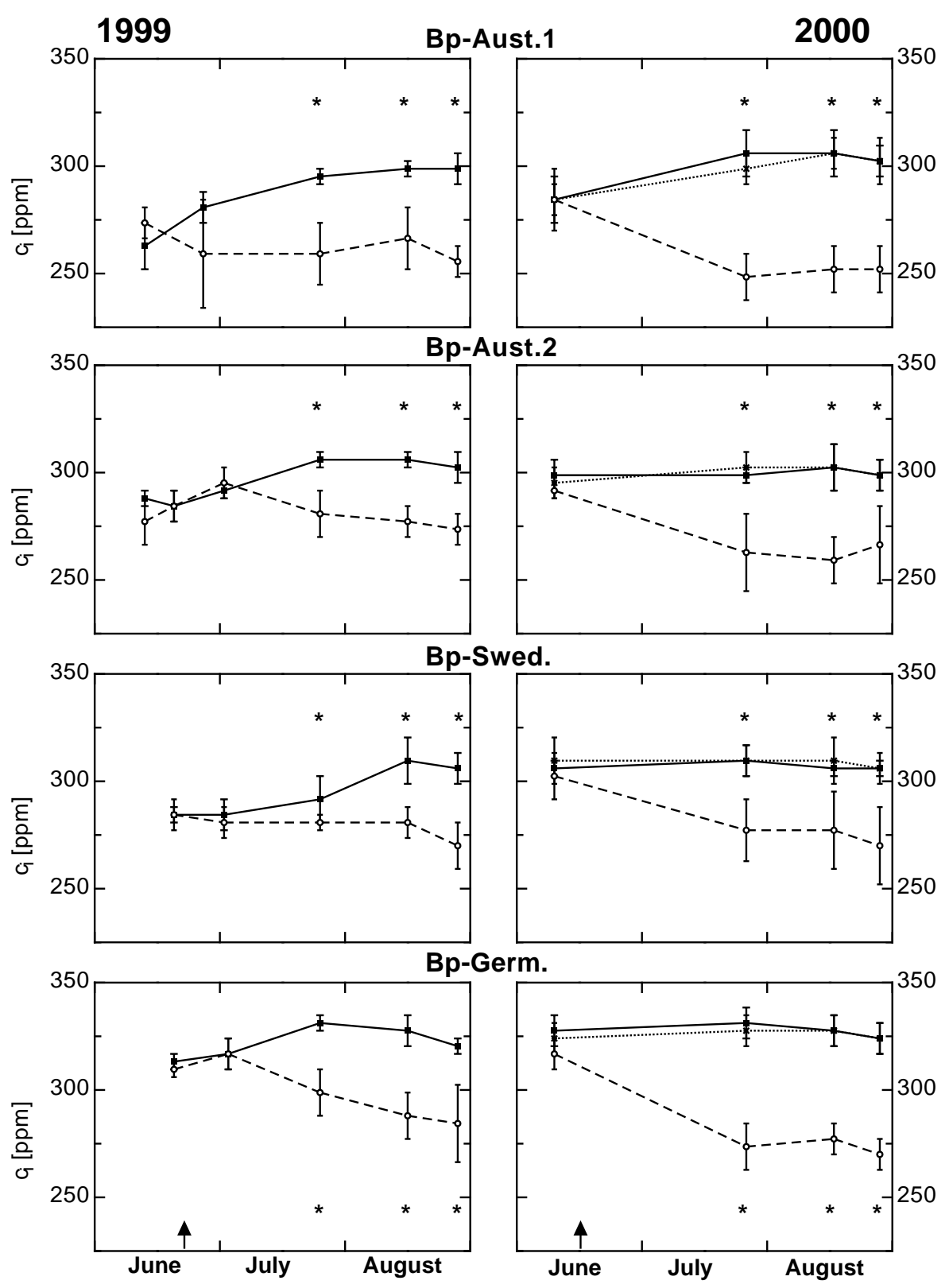

Figure 4.13.: Leaf-internal $\mathrm{CO}_{2}$ concentration $\left(c_{\mathrm{i}}\right)$ as calculated from foliar $\delta^{13} \mathrm{C}$ values of the four birch clones during the growing seasons of 1999 and 2000. Open circles and dashed lines represent the droughted plants (D99 and D99/D00), filled squares and solid lines the well watered controls (W99 and W99/W00), and crosses and dotted lines the drought-and-recovery treatment in 2000 (D99/W00). Means and standard deviations of 10 third and fourth leaves (counted from the terminal bud of a twig) from different plants are given. Asterisks indicate significant differences $(P \leq 0.05)$ between droughted (D99 and D99/D00) and well watered plants (W99/W00). After the day indicated by the black arrow the volumetric soil water content of the droughted pots was below $3 \%$.

(Fig. 4.12). They were more negative than in 1999 in all genotypes, with the values of the German trees being significantly more negative than those of the other clones at all sampled 
dates. Values of $\delta^{13} \mathrm{C}$ of the droughted trees were slightly less negative than those of the well watered ones from early June on, the difference was significant only in the German clone. They increased rapidly to late July in all clones and remained constantly higher than those of the well watered plants from then on. Annual averages ranged from -27.11\%o in Bp-Aust.1, which exhibited significantly less negative values than both Bp-Swed. and Bp-Germ., to $-28.62 \%$ o in the German genotype. Values reached by the droughted trees of Bp-Aust.2 were usually less negative than those of the Swedish and the German genotype as well. At the end of August 2000, $\delta^{13} \mathrm{C}$ values of the droughted Bp-Aust. 1 and Bp-Germ. were 3.00\%o and 3.24\%o less negative than those of the well watered ones, while the differences between these two treatments were only $1.89 \%$ in Bp-Aust. 2 and $2.05 \%$ in the Swedish genotype. The droughtand-recovery treatments of all clones exhibited the same $\delta^{13} \mathrm{C}$ values as the well watered trees throughout the whole season. Analyses of variance (Tab. B.5) confirmed the seasonal course of the $\delta^{13} \mathrm{C}$ values, as well as the marked influence of the genotype and the treatment.

Plasticity with regard to the $\delta^{13} \mathrm{C}$ values (Tab. A.5) devided the clones into two pairs: while Bp-Aust. 2 and the Swedish clone showed plasticities of $1.63 \%$ and $1.47 \%$ in 1999 , the second Austrian and the German genotype reached plasticities of $2.24 \%$ and $2.12 \%$. All clones showed more plastic responses in 2000, when differences between them were even more pronounced: while the plasticity of Bp-Aust. 2 and Bp-Swed. was about $2 \%$, plasticities of both Bp-Aust.1 and the German clone reached more than $3 \%$.

Fig. 4.13 shows intercellular $\mathrm{CO}_{2}$ concentrations $\left(c_{\mathrm{i}}\right)$ as calculated from the $\delta^{13} \mathrm{C}$ values (HUBICK et al. 1989) with an assumed $\mathrm{CO}_{2}$ concentration of the surrounding air of $360 \mathrm{ppm}$. They mirror the $\delta^{13} \mathrm{C}$ values exactly, though with opposite signs, but they clarify the ecophysiological meaning of differences between the treatments and genotypes. While the well watered trees of the Austrian clones and Bp-Swed. carried out photosynthesis in 1999 with an average $c_{\mathrm{i}}$ of 287 to $296 \mathrm{ppm}$, trees of the German genotype had $322 \mathrm{ppm}$ to operate with. The $c_{\mathrm{i}}$ of the droughted trees averaged to between 263 ppm (Bp-Aust.1) and 300 ppm (Bp-Germ.). From June to August 2000, $\mathrm{CO}_{2}$ fixation was carried out with an average $300 \mathrm{ppm}$ (Austrian clones) to $328 \mathrm{ppm}$ (Bp-Germ.) in the well watered trees, while $c_{\mathrm{i}}$ ranged from $259 \mathrm{ppm}$ (Bp-Aust.1) to $285 \mathrm{ppm}$ (Bp-Germ.) within the droughted plants. By multiplying the difference between $c_{\mathrm{i}}$ of the D99/D00-treated and the W99/W00-treated plants of one genotype with the carboxylation efficiency $\mathrm{CE}$ of the well watered plants of this genotype (both measurements from early August, Tab. 4.5), effects of a lowered $\mathrm{CO}_{2}$ on the rate of photosynthesis are elucidated. If the reduction had occured in the linear part of the $\mathrm{CO}_{2}$ response curve, net-assimilation of the droughted plants would have been reduced by $1.57 \mu \mathrm{mol} \mathrm{m} \mathrm{m}^{-2} \mathrm{~s}^{-1}$ (Bp-Swed.) to $3.51 \mu \mathrm{mol}$ $\mathrm{m}^{-2} \mathrm{~s}^{-1}$ (Bp-Aust.1) in August 2000. Since all $c_{\mathrm{i}}$ values calculated from $\delta^{13} \mathrm{C}$ values were well below saturating $\mathrm{CO}_{2}$ concentrations, $\left(\mathrm{CO}_{2 \text { sat }}\right.$, see Tab. 4.5$)$, reduction of net assimilation should be lower than this estimate, but nevertheless substantial.

\subsection{Morphology of the leaves and fine roots}

\subsubsection{Morphology of the leaves}

Averaged areas of single third and fourth leaves (counted from the terminal bud of a twig) of the well watered trees ranged in 1999 from $11.3 \mathrm{~cm}^{2}$ in Bp-Aust. 1 to $14.8 \mathrm{~cm}^{2}$ in Bp-Aust.2 

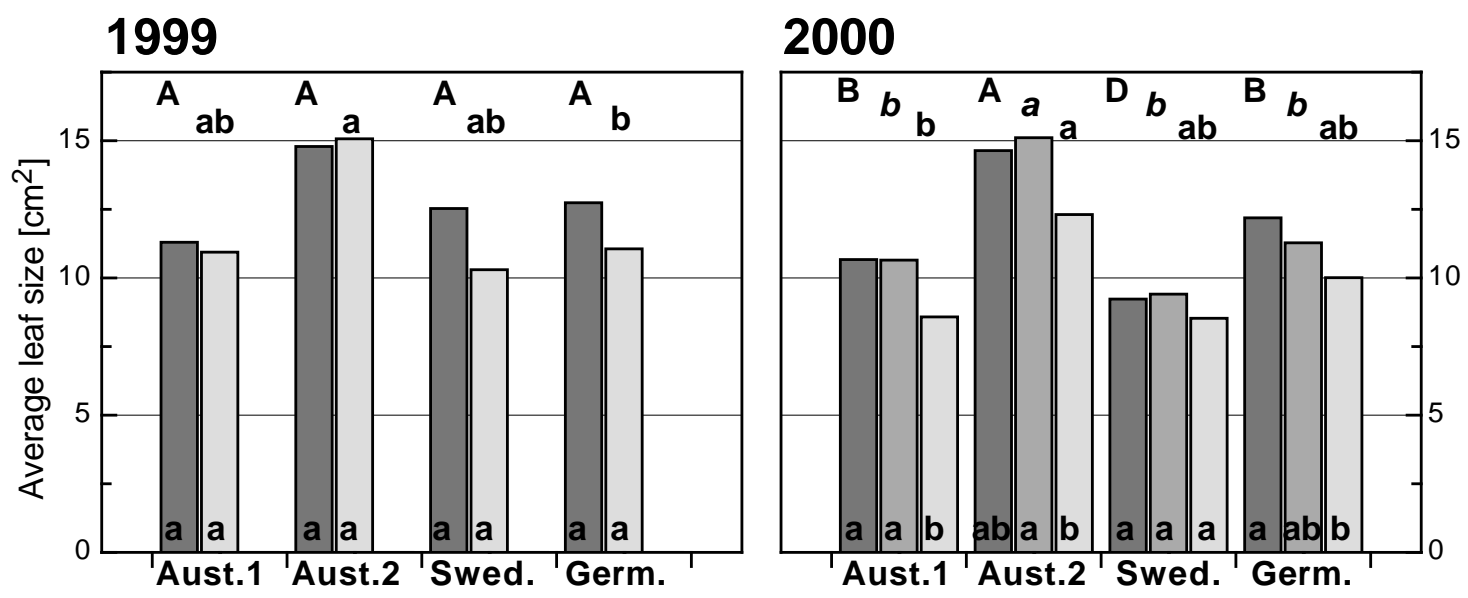

Figure 4.14.: Average leaf areas $\left[\mathrm{cm}^{2}\right]$ of the third and fourth leaves (counted from the terminal bud of a twig) of the trees harvested in 1999 and 2000. Means and standard deviations were obtained from harvests of 4 trees per treatment in 1999, and 6 trees per treatment in 2000. The lightest bars represent the droughted treatments (D99 and D99/D00), the darker ones the drought-and-recovery treatment in 2000 (D99/W00), and the darkest bars show the results of the well watered plants (W99 and W99/W00) Different capital letters indicate statistically significant differences $(P \leq 0.05)$ between well watered clones, small letters those between the droughted clones, and italics those between the different clones of the D99/W00-treatment. Asterisks indicate significant differences between droughted and the well watered treatment of one clone.

Table 4.6.: Specific leaf area [ SLA cm $\mathrm{g}^{-1} \mathrm{DW}$ ] of the third and fourth leaves of the four birch clones in late August 1999 and 2000. Means and standard deviations are calculated from the data obtained from 4 harvested trees in 1999 and from 6 harvested trees in 2000. Different small letters in brackets behind the values indicate statistically significant differences $(P \leq 0.05)$ between the different treatments of a given clone. Different capital letters in the last column of each of the two investigated years indicate significant differences between the W99/W00-treatments of the four clones, while different italics and small letters indicate such differences between the D99/W00- and the D99/D00-treatments, respectively.

\begin{tabular}{|c|c|c|c|c|c|c|c|}
\hline & \multicolumn{3}{|l|}{1999} & \multicolumn{4}{|l|}{2000} \\
\hline & W99/W00 & D99/D00 & & W99/W00 & D99/W00 & D99/D00 & \\
\hline Bp-Aust.1 & $136 \pm 11$ (a) & $144 \pm 9$ (a) & $\mathrm{BC} \mathrm{b}$ & $118 \pm 7(\mathrm{~b})$ & $121 \pm 8$ (b) & $161 \pm 11$ (a) & $\mathrm{B} c \mathrm{ab}$ \\
\hline Bp-Aust. 2 & $121 \pm 4(\mathrm{~b})$ & $141=$ & $\mathrm{Cb}$ & $119 \pm 7(b)$ & $128 \pm 8(a b)$ & $137 \pm 14$ (a) & $\mathrm{B} c \mathrm{c}$ \\
\hline Bp-Swed. & $151 \pm 6(\mathrm{a})$ & $161 \pm 24$ (a) & $\mathrm{AB} a b$ & $130 \pm 8(b)$ & $144 \pm 8(a b)$ & $152 \pm 12$ (a) & $\mathrm{B} b \mathrm{bc}$ \\
\hline Bp-Germ. & $165 \pm 5(\mathrm{~b})$ & $183 \pm 6(\mathrm{a})$ & A a & $152 \pm 7(\mathrm{~b})$ & $160 \pm 8(b)$ & $176 \pm 10$ (a) & $\mathrm{A} a \mathrm{a}$ \\
\hline
\end{tabular}

(Fig. 4.14). Leaves of Bp-Aust.2 were the biggest, while the average leaf size of the Swedish and the German clone was quite similar and Bp-Aust.1 had the smallest leaves. The leaves of droughted plants were smaller than those of well watered ones except in Bp-Aust.2, though these differences were not significant in any of the clones. Comparing the average leaf sizes of droughted plants of the different genotypes, they were biggest in Bp-Aust.2 and smallest in the Swedish clone, though only the difference between Bp-Aust. 2 and the German clone was 
statistically significant $(P \leq 0.05)$.

In 2000, well watered plants of Bp-Aust.2 had significantly larger leaves than those of the other genotypes. While the leaf size of well watered trees of the German and the Austrian clones did not differ much from 1999, Bp-Swed. had particularly smaller leaves now. Reduction of the average leaf size in response to water shortage was more obvious after the second drought period. Leaves of the droughted plants were 16 to $20 \%$ smaller than those of the well watered ones in the Austrian clones and Bp-Germ., and $8 \%$ smaller in Bp-Swed.. Average sizes of the leaves of the drought-and-recovery treatments were not significantly different from those of the W99/W00-treated trees.

Specific leaf areas (SLA) of the well watered trees in 2000 were smaller than in 1999, with the SLA of the Austrian trees being smaller than those of the Swedish and the German ones in both years of investigation (Tab. 4.6). In 1999, SLA of the droughted trees of all clones were higher than those of the well watered ones, though these differences were significant only in Bp-Aust. 2 and Bp-Germ.. In 2000, the droughted trees of all genotypes exhibited distinctly higher SLA than the W99/W00-treated ones. The drought-and-recovery treated trees showed intermediate SLA values in all genotypes. In this second year of investigation, leaves of the German trees exhibited significantly higher SLA than those of the other clones in all treatments.

Plasticity of the specific leaf area ranged from 5 to $15 \%$ in 1999 (Tab. A.6), but was much higher (14 to $30 \%$ ) in 2000. Analysis of variance proved the highly significant influences of both genotype and treatment on the SLA in both years (Tab. B.7). However, in 1999, the influence of the clone was nearly twice as high than that of the water supply, whereas both factors nearly equalled each other in 2000.

\subsubsection{Morphology of the fine roots}

Table 4.7.: Specific fine root surface area (SRA $\left[\mathrm{cm}^{2} \mathrm{~g}^{-1} \mathrm{DW}\right]$ ), and number of root-tips per $\mathrm{mg}$ DW of the fine roots of the four birch clones as obtained from harvests in 2000. Averages \pm standard deviations of 6 harvested plants are given. Asterisks indicate significant differences $(P \leq 0.05)$ between droughted and well watered plants of a given genotype.

\begin{tabular}{lrrrrrr}
\hline & \multicolumn{3}{c}{ Specific fine root area $\left[\mathbf{c m}^{2} \mathbf{g}^{-1}\right.$ ] } & \multicolumn{3}{c}{ numer of root tips [ $\mathbf{m g}^{-1}$ ] } \\
& W99/W00 & D99/W00 & D99/D00 & W99/W00 & D99/W00 & D99/D00 \\
\hline Bp-Aust.1 & 504 & 440 & 485 & 17 & 10 & 16 \\
& \pm 128 & \pm 100 & \pm 73 & \pm 11 & \pm 3 & \pm 5 \\
Bp-Aust.2 & 423 & 433 & 432 & 13 & 14 & 15 \\
& \pm 59 & \pm 78 & \pm 90 & \pm 6 & \pm 6 & \pm 6 \\
Bp-Swed. & 503 & 639 & 447 & 16 & 18 & 11 \\
& \pm 98 & \pm 159 & \pm 114 & \pm 2 & \pm 7 & \pm 8 \\
Bp-Germ. & 429 & 496 & 361 & 12 & 15 & 9 \\
& \pm 69 & \pm 116 & \pm 61 & \pm 4 & \pm 9 & \pm 4 \\
\hline
\end{tabular}

In contrast to the specific leaf areas, specific fine root surface areas (SRA) of the droughted trees showed a tendency to decrease in response to water shortage, especially in the German and the Swedish genotype. In these two clones, the number of tips per mg fine root dry mass 
was reduced by 25 to $31 \%$ as well, while the number of root tips in the drought-and-recovery treatment had increased. Since the variability of these parameters was quite high, statistically significant differences could be detected neither between different genotypes, nor between different treatments of one genotype. Plasticity with regard to the number of root tips ranged from 10 to up to $40 \%$ (Tab. A.7), with values of the German and the Swedish genotype being twoto fourfold higher than those of the Austrian clones. With regard to SRA, the Austrian trees only showed plasticities of 2 and $4 \%$, while the Swedish and the German clone reached 12 and $17 \%$, respectively.

The influence of both genotype and treatment on the specific area of the fine roots was highly significant, though that of the water treatment predominated by far (Tab. B.8).
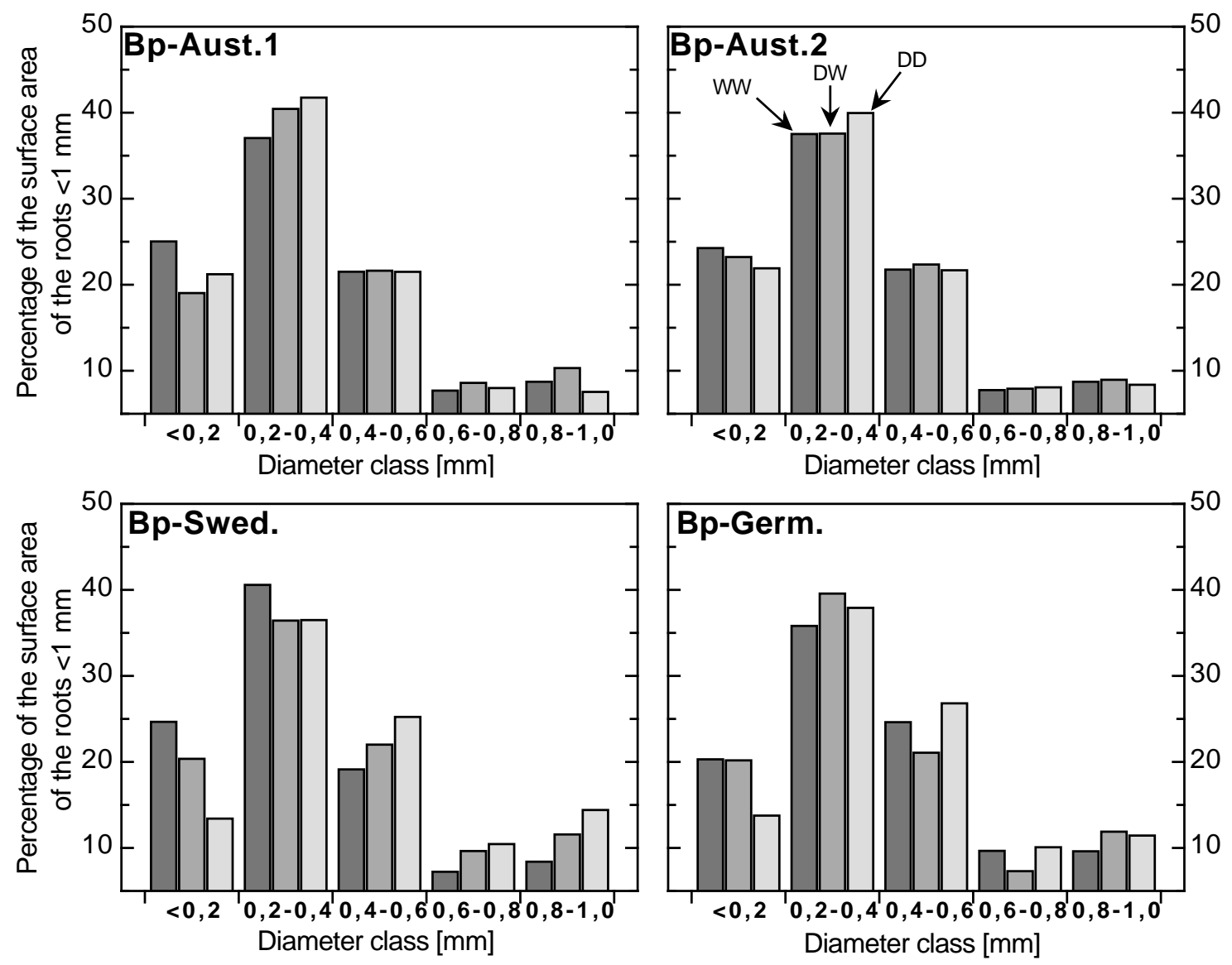

Figure 4.15.: Relative contribution of five diameter classes to total finest root surface area (diameter $\leq$ $1.0 \mathrm{~mm}$ ) 2000. Means and standard deviation were obtained from harvests of 6 trees per treatment. The lightest bars represent the droughted treatment (D99/D00), the darker ones the drought-and-recovery treatment (D99/W00), and the darkest bars show the results of the well watered plants (W99/W00) Different capital letters indicate statistically significant differences $(P \leq 0.05)$ between well watered clones, small letters those between the droughted clones, and italics those between the different clones of the D99/W00-treatment. Asterisks indicate significant differences between droughted and the well watered treatment of one clone.

Fig. 4.15 shows the finest roots $(\leq 1.0 \mathrm{~mm})$ classed by diameter. While in the Austrian and 
the Swedish clone 62 to $65 \%$ of the finest roots had diameters smaller than $0.4 \mathrm{~mm}$, in BpGerm. only $56 \%$ of the roots belonged to the two smallest diameter classes. The percentage of the finest roots $(\leq 0.2 \mathrm{~mm})$ was reduced in all clones in response to water shortage. This reduction was only 4 and $2 \%$ in Bp-Aust. 1 and Bp-Aust.2, respectively, whereas it amounted to $11 \%$ in the Swedish and to $7 \%$ in the German genotype. While in droughted Austrian trees an increase of the roots in the 0.2 to $0.4 \mathrm{~mm}$-class compensated for the reduction of finer roots, roots in this diameter class were reduced in Bp-Swed. and Bp-Germ. as well. In these two clones, only the roots of diameters larger than $0.4 \mathrm{~mm}$ increased, thus explaining the greater reduction of specific fine root surface area of the droughted plants in comparison to the well watered ones.

\subsection{Growth and phenology}

To monitor phenology of the leaves and to establish an objective measure for the beginning of senescence, the leaves of six trees of each treatment and clone were counted repeatedly in both summers (Fig. 4.16). Buds began to burst in both years in early to mid-April, showing no distinct differences between the clones. The number of leaves slowly increased until late June in 1999, while the rise of the leaf numbers became steeper from early July on in all clones except Bp-Aust.2. The young birches of all genotypes continuously produced new leaves throughout the whole summer, while older ones became senescent and were eventually shed. The well watered trees reached their highest leaf numbers in mid-August to September and started to shed leaves (or shed more leaves than were newly grown) from mid-September onward. From early July 1999 on, the droughted trees of Bp-Aust.1 and Bp-Germ. grew less leaves than the well watered plants of these genotypes. The difference became first significant in the German clone in early July. The droughted plants of all clones except Bp-Aust.2 reached their peak leaf numbers earlier than the W99/W00-treated ones, and started to shed more leaves than they produced earlier as well. If the stage where leaf shedding exceeds leaf growth is termed senescence, this phase started about 3 to 6 weeks earlier in the droughted plants than in the well watered ones in all clones but Bp-Aust. 2 .

In 2000, peak leaf numbers of the well watered trees were reached in early June by the Swedish clone and in early August by the other clones. Leaf numbers of the droughted plants were smaller than those of the well watered ones in all clones from early June on, the difference being particularly marked in Bp-Aust.1. In all genotypes the droughted plants grew less leaves than the W99/W00-treated ones throughout the whole season. While senescence in 2000 started about three weeks earlier in the droughted Austrian plants than in the well watered ones, it was postponed by 3 weeks in the Swedish clone and did not differ in the German one. With regard to their leaf numbers, the D99/W00-treated trees of the Austrian and the German genotype were in between the well watered and the droughted trees. Only in the Swedish genotype the drought-and-recovery treated plants had more leaves than the well watered ones from early June on. Maximum leaf numbers were reached in both years by the well watered Bp-Aust.1, while Bp-Aust. 2 produced the fewest leaves. 

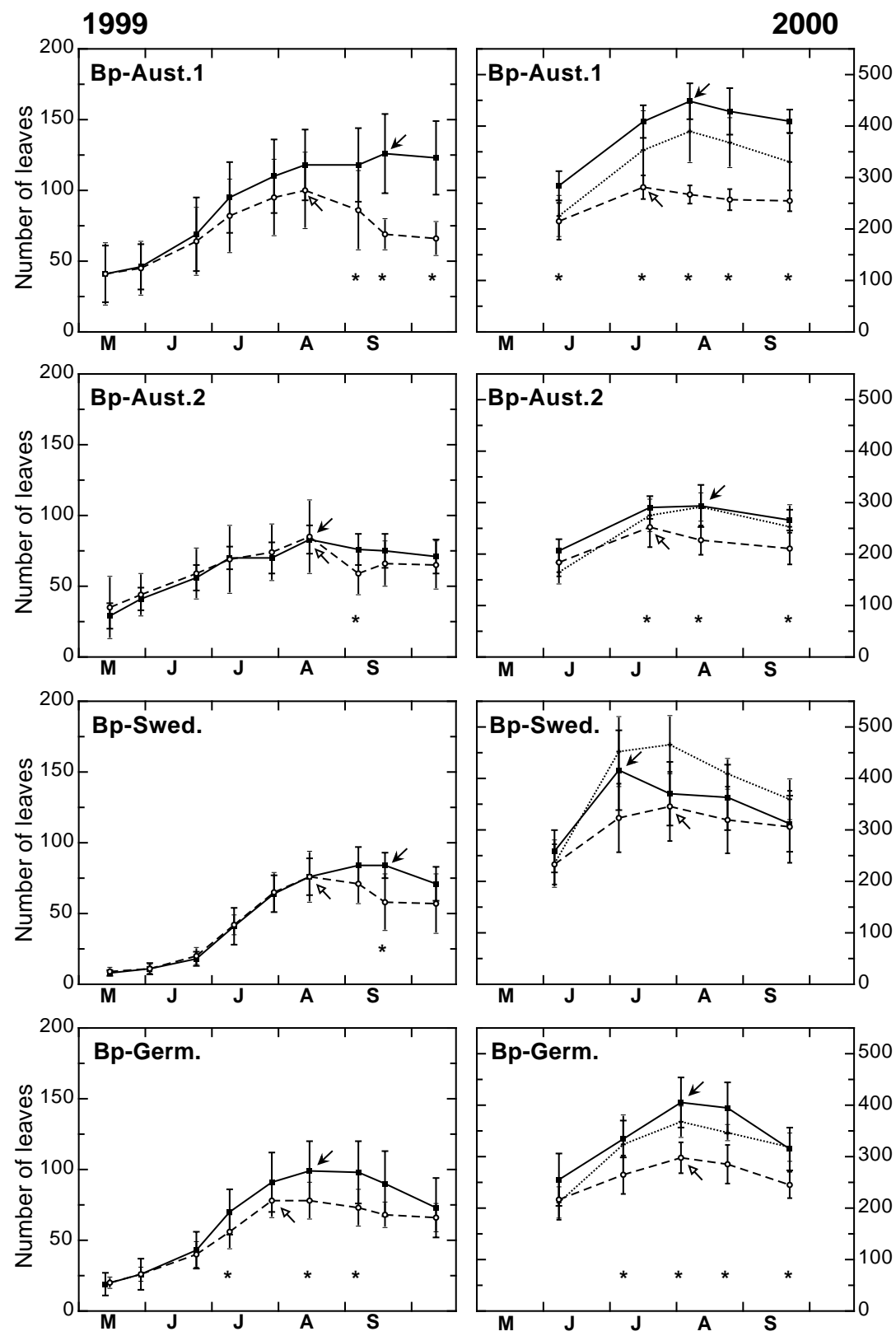

Figure 4.16.: Leaf numbers of the birch trees in the growing seasons 1999 and 2000. Open circles and dashed lines represent the droughted plants (D99/D00), filled squares and solid lines the well watered controls (W99/W00), and crosses and dotted lines the drought-and-recovery treatment in 2000 (D99/W00). Means and standard deviations of 10 trees in 1999 and 6 trees in 2000 given. Asterisks indicate significant differences $(P \leq 0.05)$ between droughted and the W99/W00-treated plants. The black arrows indicate the beginning senescence of the well watered trees, the white arrows that of the droughted ones. 

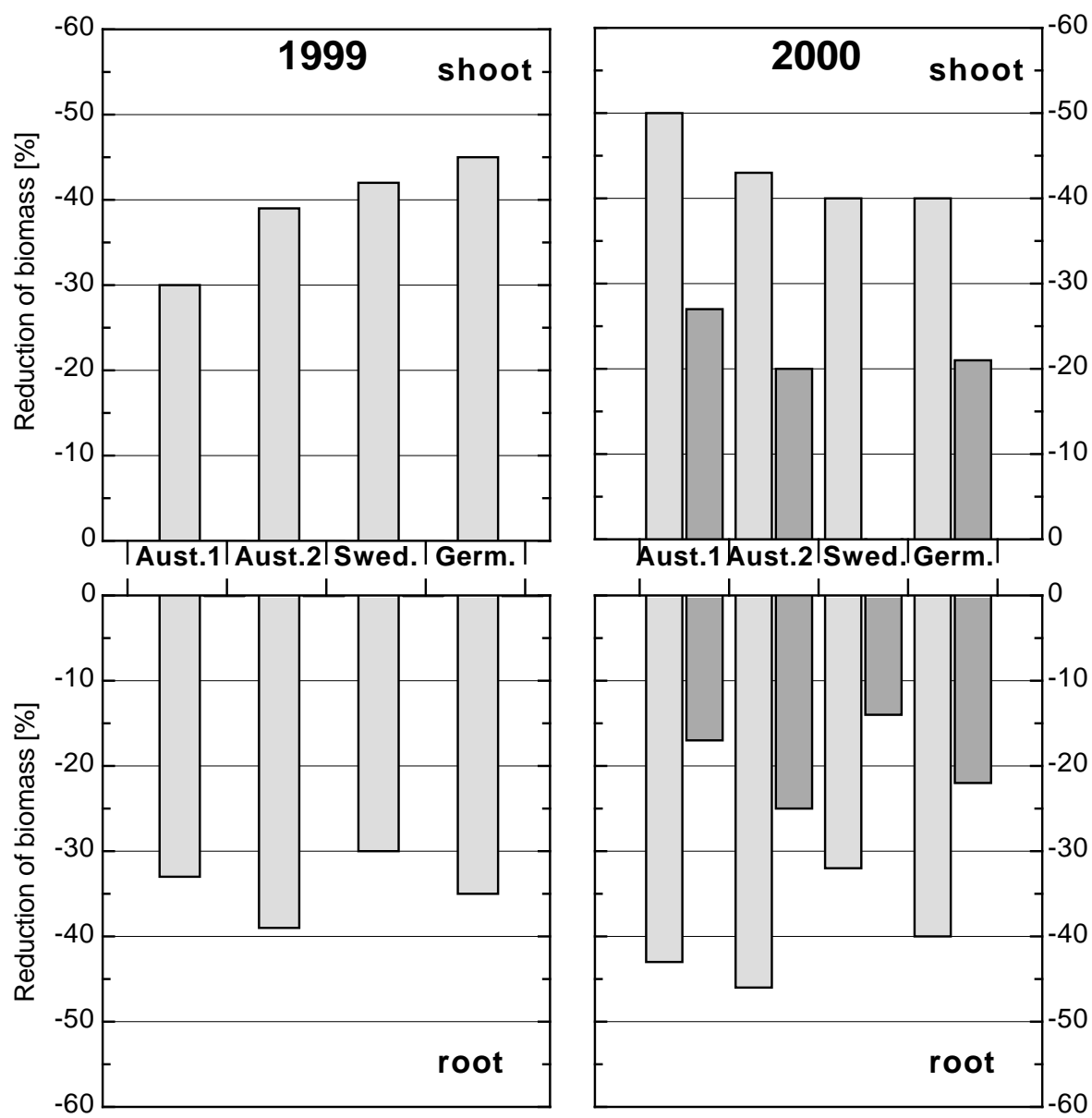

Figure 4.17.: Relative shoot and root biomass reduction of the droughted plants in comparison with the well watered ones 1999 and 2000. The light bars represent the droughted treatments (D99 and D99/D00), the darker ones the drought-and-recovery treatment in 2000 (D99/W00).

\subsection{Biomass and allocation}

Reduction of shoot and root biomass of the droughted plants in comparison with the well watered control plants is shown in Fig. 4.17, Aboveground biomass of the droughted plants of all genotypes was strongly reduced after the first drought period, but while the reduction of root biomass was similar to or even more pronounced than the reduction of the shoot in the Austrian trees, root biomass was by far less reduced than shoot biomass in Bp-Swed. and Bp-Germ..

After the second drought period, the reduction of shoot biomass was most pronounced in Bp-Aust.1, where it averaged to $50 \%$. Reduction of aboveground biomass was smallest in the Swedish and the German genotype; however, in these clones shoot biomass was also reduced by $40 \%$ in response to the water shortage. With regard to belowground biomasses, the Austrian clones exhibited the greatest reduction as well. Unlike in 1999 though, the German and especially the Swedish genotype did not reduce root biomass to a greater extend than shoot biomass after the second drought period. 


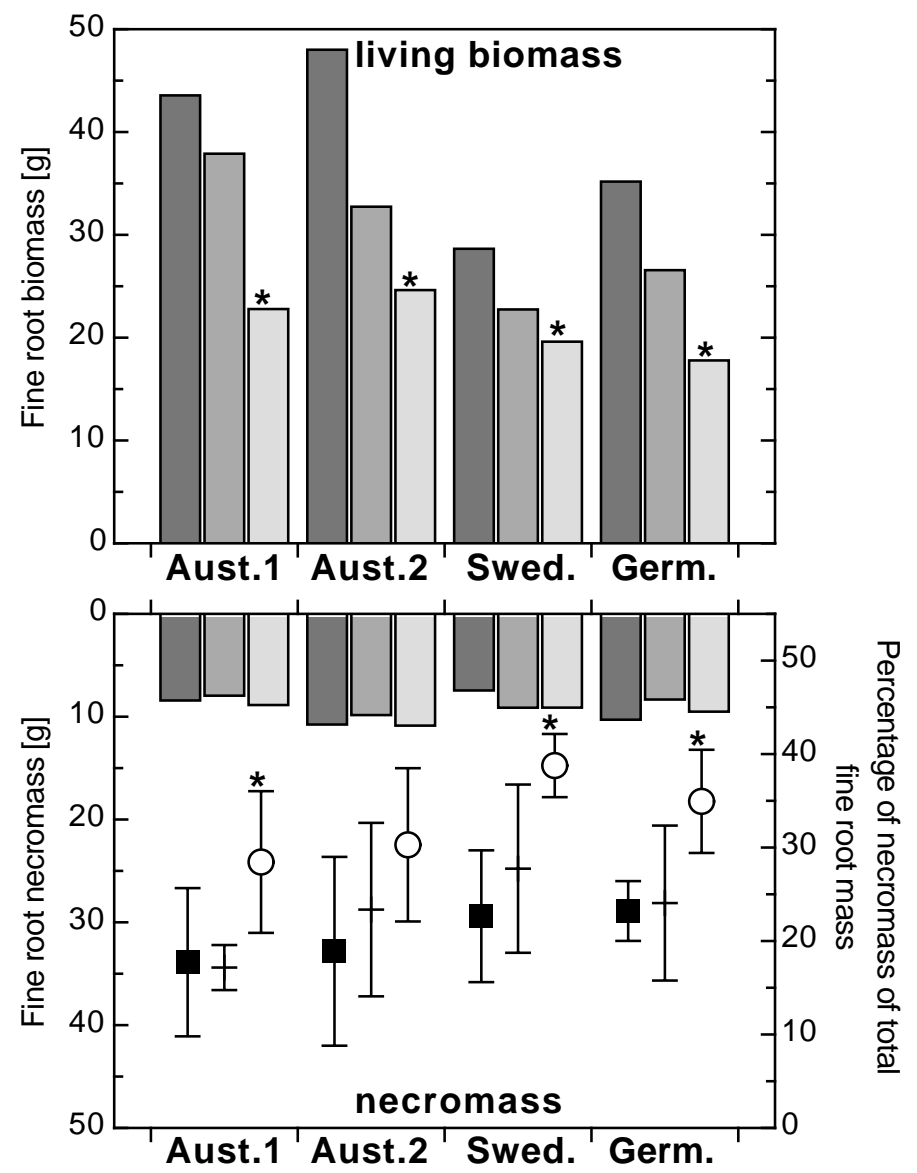

Figure 4.18.: Living biomass and necromass of the roots of the trees harvested in 2000. Means and standard deviations were obtained from harvests of 6 trees per treatment. The bars show the drymass, where the lightest bars represent the droughted treatment (D99/D00), the darker ones the drought-and-recovery treatment (D99/W00), and the darkest bars show the results of the well watered plants (W99/W00). In the lower section, the closed squares represent the percentage of necromass of the whole root dry mass of the well watered plants, the open circles that of the droughted plants, and the crosses the percental necromass of the D99/W00-treatment. Different capital letters indicate statistically significant differences $(P \leq 0.05)$ between well watered clones, small letters those between the droughted clones, and italics those between the different clones of the D99/W00-treatment. Asterisks indicate significant differences between droughted and the well watered treatment of one clone.

With regard to the fine roots, not only the total biomass, but also the ratio of dead and living mass was determined (see Fig. 4.18). Living fine root biomasses of the trees harvested after two drought periods was reduced by $32 \%$ (Bp-Swed.) to $50 \%$ (Bp-Germ.), the reduction being highly significant in all clones. Fine root biomasses of the drought-and-recovery treatments were reduced by $13 \%$ to $32 \%$. While the living root biomass differed between the genotypes, necromasses averaged to about $9 \mathrm{~g}$ in all clones and treatments. This was confirmed by analyses of variance (Tab. B.8), which showed a highly significant influence of the clone and especially the treatment on the living mass of fine roots, but the two factors did not explain the variance 
detected in the necromass.

Percentage of dead fine root dry mass averaged to about $20 \%$ in the well watered plants of all genotypes. It was distinctly higher in the droughted trees, though this was caused not by an increase of the absolute amount of necromass, but by reductions of living fine root biomass in these trees. Thus, the percentage of necromass was significantly influenced by both genotype and treatment, though the influence of water supply was by far the dominant one (Tab. B.8).
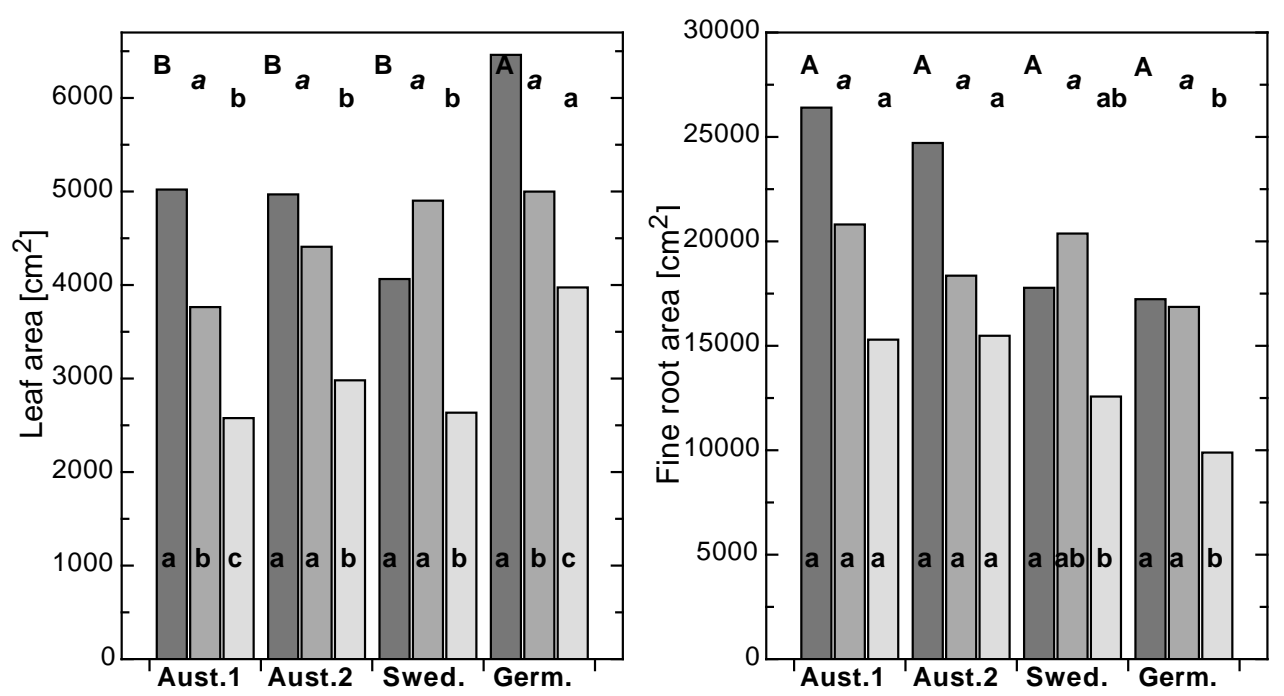

Figure 4.19.: Average total leaf and fine root areas of the trees harvested in 2000. Means and standard deviations were obtained from harvests of 6 trees per treatment. The lightest bars represent the droughted treatments (D99/D00), the darker ones the drought-and-recovery treatment (D99/W00), and the darkest bars show the results of the well watered plants (W99/W00) Different capital letters above the bars indicate statistically significant differences $(P \leq 0.05)$ between well watered clones, small letters those between the droughted clones, and italics those between the different clones of the D99/W00treatment. Different small letters in the bars indicate significant differences between the different treatments of one genotype.

In 1999, the well watered German trees had distinctly larger leaf areas than the Austrian and particularly the Swedish trees (data not shown). Leaf areas of the droughted trees were reduced in all clones, though these reductions were small in the Austrian clones when compared with the Swedish and the German plants. After the second drought period, however, leaf areas of the D99/D00-treated Austrian clones were $40 \%$ to even $49 \%$ smaller than those of the well watered trees (Fig. 4.19, left graph), while the total leaf area was only reduced by $35 \%$ in the Swedish and $38 \%$ in the German genotype. Similar to 1999, leaf areas of the well watered German trees were distinctly larger than those of the other clones in 2000, which was also true for the droughted treatment. The other genotypes did not differ with regard to their total leaf areas in any of the treatments. The drought-and-recovery treatments of all clones except Bp-Swed. had intermediate total leaf areas. Only in the Swedish genotype, leaf areas of the D99/W00-treatment were greater $(+21 \%)$ than those of the well watered plants at the end of the summer. In contrast to the leaf areas, the average surface area of fine roots of the German trees was smaller than those of the other genotypes in all treatments (Fig. 4.19, right 
graph). Fine root surfaces of the droughted plants were markedly smaller than those of the well watered ones in all genotypes, though these differences were significant only in the German and the Swedish clone. After two dry summers, fine root surface areas of the German plants were distinctly smaller than those of the Austrian trees. The drought-and-recovery treatments of the Austrian clones exhibited fine root surfaces still 21 to $26 \%$ smaller than those of the well watered plants, while those of Bp-Germ. were only $2 \%$ smaller and in the Bp-Swed. the D99/W00-treated trees even had the highest root surface areas of all treatments.
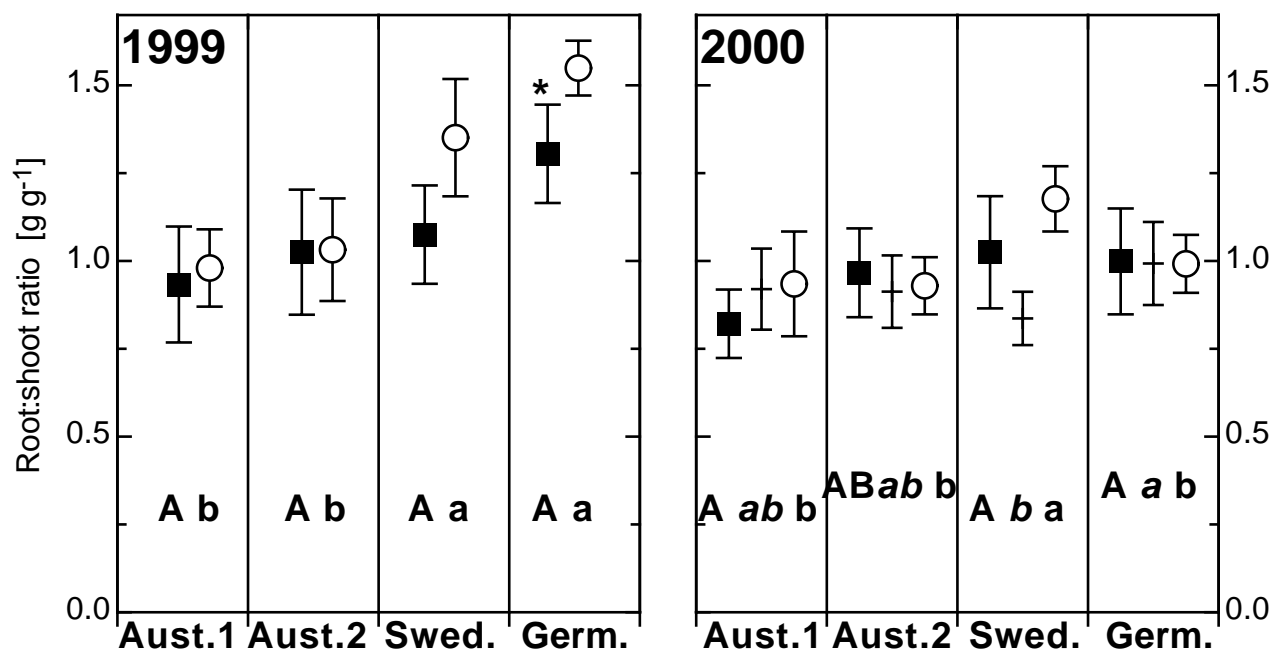

Figure 4.20.: Root:shoot ratios of the harvested birch trees. Means and standard deviations were obtained from harvests of 4 trees per treatment in 1999, and 6 trees per treatment in 2000. The open circles represent the droughted treatments (D99 and D99/D00), the crosses the drought-and-recovery treatment in 2000 (D99/W00), and the closed squares show the results of the well watered plants (W99 and W99/W00). Different capital letters indicate statistically significant differences $(P \leq 0.05)$ between well watered clones, small letters those between the droughted clones, and italics those between the different clones of the D99/W00-treatment. Asterisks indicate significant differences between droughted and the well watered treatment of one clone.

The root:shoot mass ratios of the well watered trees ranged from 0.93 in Bp-Aust. 1 to 1.31 in the German Bp-Germ. in 1999 (Fig. 4.20). Ratios of the droughted Austrian plants were not different from the well watered ones, but in the Swedish and the German clone the D99/D00treated trees exhibited a marked increase of root:shoot ratios, having allocated relatively more dry mass to the roots. This was reflected by the plasticities with regard to this parameter, which was only 1 to $3 \%$ in the Austrian clones, but 17 to $23 \%$ in the German and the Swedish ones (Tab. A.8). With regard to the W99/W00-treated plants, no significant differences between genotypes were detected in 1999. The droughted Swedish and German birches, however, had significantly higher root:shoot ratios than the Austrian ones after 3 months of water shortage.

After the second year of investigation, root:shoot ratios of all genotypes were smaller than in 1999. As in 1999, the Austrian trees showed no reaction to the drought treatment with regard to their root:shoot ratios, but unlike after the first summer of water shortage, the German plants showed no response either. The Swedish genotype, however, exhibited increased root:shoot 

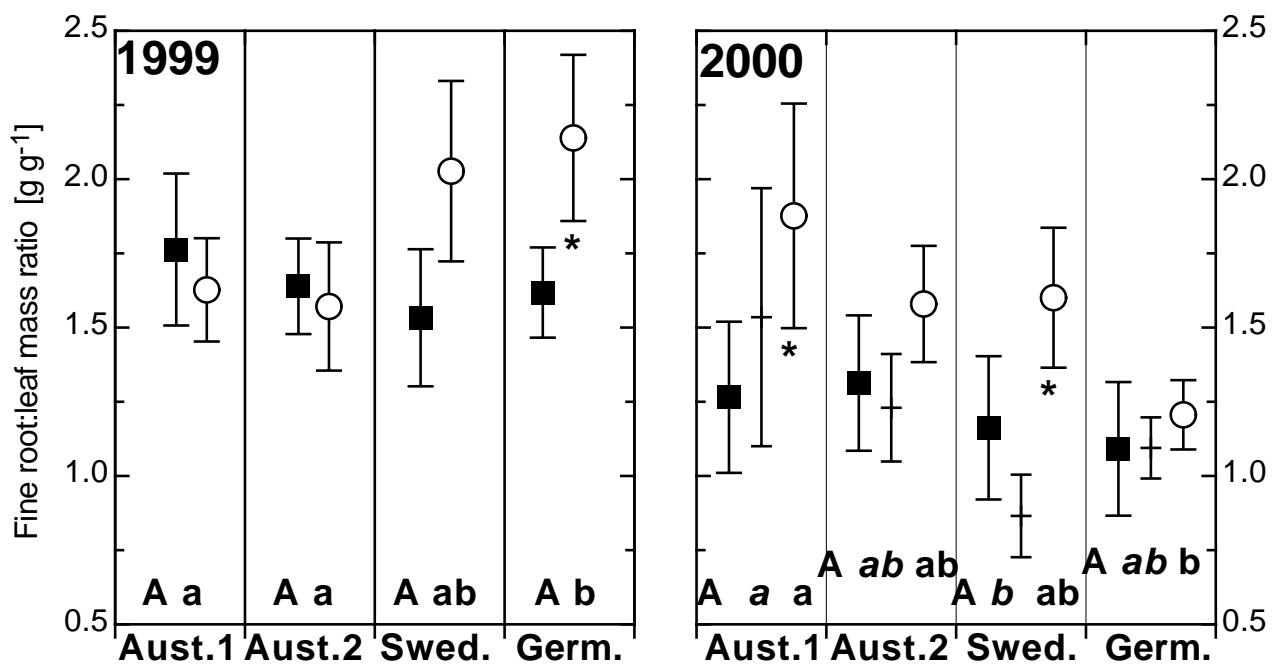

Figure 4.21.: Fine roots:leaves dry mass ratios of the harvested birch trees. Means and standard deviations were obtained from harvests of 4 trees per treatment in 1999, and 6 trees per treatment in 2000. The open circles represent the droughted treatments (D99 and D99/D00), the crosses the drought-andrecovery treatment in 2000 (D99/W00), and the closed squares show the results of the well watered plants (W99 and W99/W00). Different capital letters indicate statistically significant differences $(P \leq$ 0.05 ) between well watered clones, small letters those between the droughted clones, and italics those between the different clones of the D99/W00-treatment. Asterisks indicate significant differences between droughted and the well watered treatment of one clone.

ratios after the second dry period as well, while the drought-and-recovery treated plants of this genotype had smaller root:shoot ratios than those which had been regularly watered for two years. In 1999, the influence of the genotype of the examined plant on its root:shoot ratio was nearly three times as high as the influence of the water supply it was subjected to (Tab. B.9.) After the second summer of investigation, the influences of the clone, the treatment, and their interrelation on root:shoot ratio were significant as well.

The fine root:leaf mass ratio as obtained from harvest in August 1999 and 2000 is shown in Fig. 4.21. Ratios measured in 1999 reflect the tendencies shown with regard to the root:shoot ratios. Fine root:leaf ratios of the well watered trees did not significantly differ between the genotypes and ranged from 1.53 in Bp-Swed. to 1.63 in Bp-Aust.1, thus being about 0.5 higher than the overall root:shoot ratios. While the fine root:leaf ratios of the Austrian trees showed no response to the 3 months of dry period, ratios of the Swedish and the German genotypes increased in response to water shortage and reached values of 2.03 and 2.14, respectively. This is reflected by the plasticities calculated for the clones with regard to this parameter. The droughted German trees had distinctly higher fine root:leaf ratios than the Austrian trees after the first summer of investigation.

In 2000, the Austrian clones showed a marked increase of this ratio in response to the second drought period. While differences between the clones were not statistically significant in the W99/W00-treatments, the droughted Bp-Aust. 1 had significantly higher fine roots:leaves mass ratios than the German plants. The drought-and-recovery treatments did not differ from 


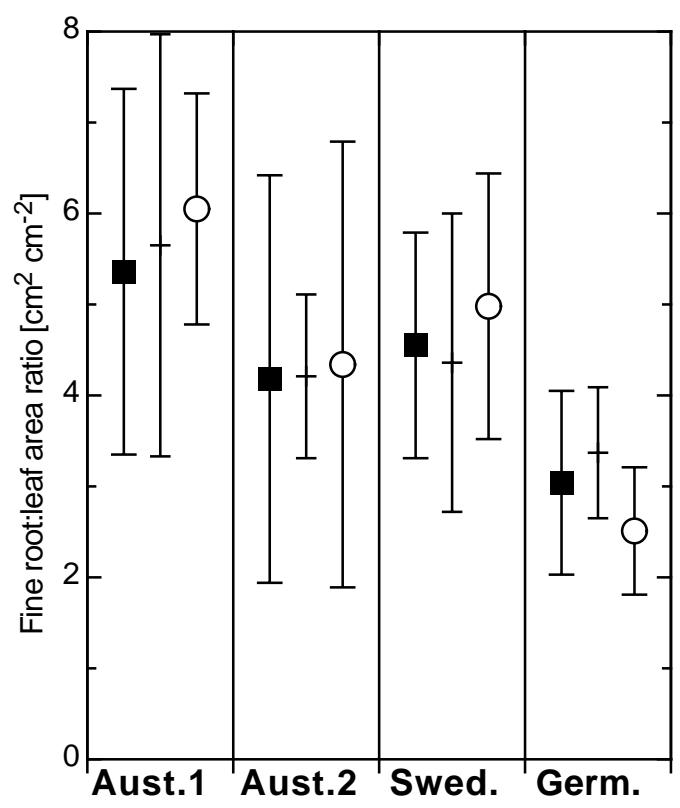

Figure 4.22.: Fine root surface area:leaf area ratios of the harvested birch trees. Means and standard deviations were obtained from harvests of 4 trees per treatment in 1999, and 6 trees per treatment in 2000. The open circles represent the droughted treatments (D99 and D99/D00), the crosses the droughtand-recovery treatment in 2000 (D99/W00), and the closed squares show the results of the well watered plants (W99 and W99/W00). Different capital letters indicate statistically significant differences ( $P \leq$ $0.05)$ between well watered clones, small letters those between the droughted clones, and italics those between the different clones of the D99/W00-treatment. Asterisks indicate significant differences between droughted and the well watered treatment of one clone.

the well watered plants in all genotypes except Bp-Swed.. In this clone, fine root:leaf ratios of the D99/W00-treated plants were smaller than those of the other treatments. The influence of the treatment on fine roots:leaves mass ratios was evident in 1999 (Tab. B.9), but even more so after the second year of investigation, when the genotype had significant influence as well and the percentage of variance explained by these factors and their interrelation was higher.

Total leaf areas and fine root surface areas (Fig. 4.19) were used to calculate fine root:leaf area ratios shown in Fig. 4.22. The variation of this parameter was high in comparison to the mass ratios, and statistical differences were detected neither between the different genotypes in a treatment, nor between the different treatments of a clone. The area ratios of the droughted plants showed no marked reaction to two dry summers in any of the genotypes. As Tab. B.8 shows, the influence the genotype on fine root:leaf area ratio was highly significant, while the treatment could not explain the variation between plants. 


\section{Discussion}

The Betulaceae are a characteristic family of the northern temperate and boreal zone. More then 40 species of the genus Betula are distributed quite uniformly over this areal, with a marked maximum of species in north-eastern Asia. In general, birches are shade intolerant and most important where unfavourable conditions modify competition. Especially in subpolar regions, birches and conifers form the tree limit and dwarf birches dominate the shrub tundra (SCHMUCKER 1942).

HEGI (1981) described the areal of silver birch (Betula pendula), reaching from northern Great Britain through Scandinavia (Lapland) to northern Asia, while being limited in southern Europe to mountain ranges from Spain to temperate Asia. The ecogram of $B$. pendula shows the species to be capable of growth at both the wet and the dry limit of forest growth even on the poorest soils (ELLENBERG 1996). Silver birch is insensitive to frost and low nutrient availability, but while ELLENBERG (1996) rated it susceptible to limited water supply, HEGI (1981) classified the species completely insensitive to drought.

B. pendula shows characteristic traits of a pioneer species (BAZZAZ 1979). It is windpollinated and produces large numbers of wind-spread seeds (50000 to 300000 seeds per tree SITTE et al. 1991), enabling it to reach and populate disturbed areas fast. Low nutrient demand allows silver birch to grow on poor soils, and its relative growth rate is high, especially in young trees (KLEINSCHMIT 1998). B. pendula reaches high rates of net assimilation and transpiration (GREVE et al. 1992; BACKES 1996), which is facilitated by a highly differenciated hydrosystem (BRAUN 1970) and a flexible and quite deep-reaching root system (KÖSTLER et al. 1968). Silver birch is highly susceptible to shade. HAGEMEIER (2001) measured relative rates of photosynthetically active radiation (PAR) in stands of tree species of different successional order, and found a 10-fold decrease of relative PAR below the canopy from early-successional silver birch and scotch pine to late successional beech, hornbeam, and lime tree. While saplings of birch and pine grew at relative PAR values of 14 to $30 \%$, saplings of the late-successional species were found at relative PAR of only 0.8 to $3.7 \%$.

Pioneer species generally have broad reaction norms on different environmental gradients including nutrients and moisture (BAZZAZ 1996) and are able to respond to environmental changes fast. This kind of opportunistic strategy is especially adapted to environments where resource availability is particularly unpredictable, and competition for resources is high. 


\subsection{Order of appearance and plasticity of different leaf and plant level responses to drought - the strategy of Betula pendula}

\subsubsection{Leaf gas exchange, water potential, and water use efficiency}

The first function to respond to water shortage in both years was stomatal conductance - as early as two weeks after the onset of the dry period on June 1, 1999 and May 15, 2000, daily stomatal conductances measured at the droughted German plants were lower than at the wellwatered ones (Tab. 5.1). After 11 weeks of drought treatment the stomatal conductances were reduced by up to $90 \%$ in 1999 and $70 \%$ in 2000 (Tab. 4.4). Tab. 5.5 emphasizes that stomatal closure was not only the first response to water shortage, but the most plastic as well (absolute plasticity is quantified as the difference between means of the well-watered plants and the droughted plants, the relative value is calculated as percentage of absolute plasticity in relation to the genotype means over both treatments, see chapter 2).

In both years, predawn leaf water potentials $\left(\Psi_{\text {pre }}\right)$ were lowered in response to the drought by all clones, but only after stomatal conductance had been reduced, and only to a small extend. The lowest $\Psi_{\text {pre }}$ values of the droughted plants were -0.9 and -0.7 MPa in 1999 and 2000 , respectively. Comparatively high values of $\Psi_{\text {pre }}$ in conjunction with marked reductions of stomatal conductance in response to water shortage have been observed in silver birch by other authors as well. RANNEY et al. (1991) investigated 6 species of birch, including $B$. pen$d u l a$, and none reached predawn leaf water potentials below $-0.8 \mathrm{MPa}$ after 28 days without irrigation. BACKES (1996) examined water status parameters and stomatal conductance in a mature stand of silver birch in the German Northwest, never measuring values below $-0.6 \mathrm{MPa}$ even on sandy soils. GREVE et al. (1992) and LEUSCHNER (1992) studied the same stand and

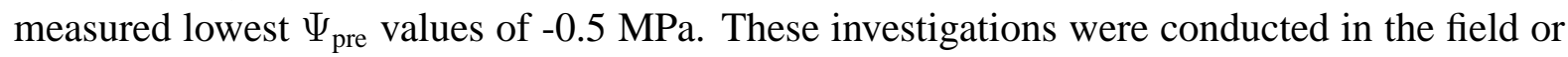
with plants growing in big containers (RANNEY et al. 1991).

In contrast to these findings, FORT et al. (1998) experimented with silver birch saplings in 14 l-containers and measured predawn leaf water potentials below -1.0 MPa after only 2 weeks of drought. The plants had been dehydrated very fast, however, reaching volumetric soil water contents of $1.5 \%$ after 10 days. Studies on other species have shown that the rate of drought development may be an important factor influencing the expression of drought tolerance or avoidance (TURNER and JONES 1980; LÖSCH 2001).

Fast dehydration in combination with root limitation in very small pots might be one reason for very low $\Psi_{\text {pre }}$ as measured in Betula pendula by P̈̈̈̈KKÖNEN et al. (1998a) and PÄ̈̈KKÖNEN et al. (1998b) as well. In the former investigation, one-year-old saplings of B. pendula were planted in 51 -pots and reached predawn leaf water potentials of $-1.3 \mathrm{MPa}$, in the latter, drought experiments were conducted on two-year-old saplings of the same clones in 3 to 5 l-pots and $\Psi_{\text {pre }}$ as low as $-2.65 \mathrm{MPa}$ were measured.

A marked reduction of stomatal conductance in reaction to drought without or with only a small accompanying or preceding drop of predawn leaf water potential has been observed in other tree species like spruce (DIXON et al. 1995; MAIER-MAERCKER 1998), pine (PICON et al. 1996, LEBOURGEOIS et al. 1998), and willow (LIU et al. 2001b) and has been associated with a drought avoiding strategy in response to water shortage (PICON et al. 1996). ARNDT et al. (2001) conducted experiments on Ziziphus rotundifolia, a fruit tree of the Indian arid zone, 
and found that reduced stomatal conductance was the initial response to decreasing soil water content, thus maintaining predawn leaf water potentials, controlling water loss and increasing the intrinsic water use efficiency. Since predawn leaf water potential of droughted plants is maintained by this type of strategy, this parameter might not always be the best measure to quantify the stress they actually experience (LEBOURGEOIS et al. 1998).

Table 5.1.: Chronological order of response of different physiological and biochemical parameters to the water shortage in 1999 and 2000. The clones which reacted first to the stress and the time of their earliest reaction to the drought (in number of weeks after the onset of the drought) are shown. The time when the differences between droughted and well-watered plants first became significant $(P \leq 0.05)$ is given in parentheses. The clones which responded latest to the drought are shown in the right column.

\begin{tabular}{|c|c|c|c|c|}
\hline \multirow[t]{2}{*}{ parameter } & \multicolumn{2}{|c|}{ first reaction } & \multicolumn{2}{|c|}{ latest reaction } \\
\hline & 1999 & & & \\
\hline average daily $g_{\mathrm{sw}}$ at constant VPD & Germ., Aust.1 & 2 (4) weeks & Swed. & 9 (9) weeks \\
\hline$\Psi_{\min }$ & Germ. & 2 (2) weeks & Aust. 2 & 10 (10) weeks \\
\hline$\delta^{13} \mathrm{C}$ value & Germ., Aust.1 & 3 (4-7) weeks & Aust. 2 & 7 (7) weeks \\
\hline photosynthetic WUE & all clones & 3 weeks & & \\
\hline$\Pi_{\mathrm{p}}$ & all clones & 3 weeks & & \\
\hline$\Pi_{0}$ & Germ. & 3 (9) weeks & Swed. & 7 (9) weeks \\
\hline$\epsilon_{\max }[\mathrm{MPa}]$ & Germ., Aust. 2 & 3 weeks & Swed., Aust.1 & 6 weeks \\
\hline$\Psi_{\text {pre }}$ & Germ., Aust. 2 & 4 (7) weeks & Swed. & 10 (12) weeks \\
\hline leaf area based chlorophyll content & Germ. & 4 (7) weeks & Aust.1 & no reaction \\
\hline$A_{\mathrm{amb}}$ & all clones & $8-9(8-9)$ weeks & & \\
\hline & 2000 & & & \\
\hline average daily $g_{\mathrm{sw}}$ at constant VPD & Germ. & 2 (6) weeks & Aust. 2 & 6 (14) weeks \\
\hline$\Psi_{\min }$ & Germ., Swed. & 3 (3) weeks & Aust. 1 and 2 & 9 (9) weeks \\
\hline$\delta^{13} \mathrm{C}$ value & Germ. & 3 (3) weeks & Swed., Aust. 1 and 2 & 9 (9) weeks \\
\hline$\epsilon_{\max }[\mathrm{MPa}]$ & Germ., & 3 weeks & Swed., Aust. 1 and 2 & 7 weeks \\
\hline$\Psi_{\text {pre }}$ & Germ., Swed. & 3 (3) weeks & Aust. 1 and 2 & 9 (9) weeks \\
\hline leaf area based chlorophyll content & Germ., Aust.1 & 4 (4) weeks & Swed., Aust.2 & $6(6)$ weeks \\
\hline photosynthetic WUE & Swed. & 5 (5) weeks & Aust. 2 & 5 weeks \\
\hline$A_{\mathrm{amb}}$ & Aust.1, Swed. & 5 (5) weeks & Aust. 2 & 10 (13) weeks \\
\hline$\Pi_{\mathrm{p}}$ & Swed. & 11 (11) weeks & Germ., Aust. 1 and 2 & 11 weeks \\
\hline$\Pi_{0}$ & Germ., Swed. & 11 (14) weeks & Aust. 1 and 2 & no reaction \\
\hline
\end{tabular}

Different mechanisms of communication between roots and leaves have been proposed to account for reactions of the stomata to drying soils, including changes in the hydraulic conductivity of the xylem (TYREE and SPERRY 1989; LÖSCH and SCHULZE 1994; ALDER et al. 1996) and phytohormones (mainly abscisic acid ABA) being produced in drying roots and transported to the leaves with the xylem sap (ZHANG and DAVIES 1989; TREJO and DAVIES 1991; LOEWENSTEIN and PALLARDY 1998; LIU et al. 2001a), for reviews see LÖSCH and SCHULZE (1994); LÖSCH (2001). FORT et al. (1998) measured a 10-fold increase of ABA in the xylem sap of Betula pendula in reaction to limited water availability. ABA is produced and / or redistributed in leaves as well (TREJO and DAVIES 1991; LIU et al.|2001a).

The early reaction of $\delta^{13} \mathrm{C}$ values of bulk leaf tissue (Fig. 4.11 and 4.12) confirmed the 
fast response of stomatal conductance. According to HUBICK et al. (1989), the carbon isotope composition of plant tissue of $\mathrm{C}_{3}$-plants is largely determined by the ratio of intercellular to atmospheric concentration of $\mathrm{CO}_{2}$ (see equation 3.38), and thus related to the ratio of instantanous rates of $\mathrm{CO}_{2}$ assimilation and stomatal conductance (FARQUHAR and RICHARDS 1984; FARQUHAR et al. 1989; ZIEGLER 1995; JONASSON et al. 1997). Therefore, $\delta^{13} \mathrm{C}$ values of plant tissue can be a regarded as a measure for intrinsic water use efficiency. This relation is often obscured by the fact that most tissues contain large amounts of structural carbon fixed under conditions different from those at the sampling date, e.g. under less limiting conditions (PICON et al. 1996; XU et al.|2000; ARNDT et al. 2001). Since silver birches exhibit indeterminate growth, sprouting new leaves during the whole growth season, their bulk leaf $\delta^{13} \mathrm{C}$ values provide a better measure for preceding WUE and $c_{\mathrm{i}}$ than those of e.g. oaks. Fig. 5.1 shows the significant decline of photosynthetic water use efficiency (calculated from gas exchange measurements) with decreasing (more negative) $\delta^{13} \mathrm{C}$ values in both years of investigation.
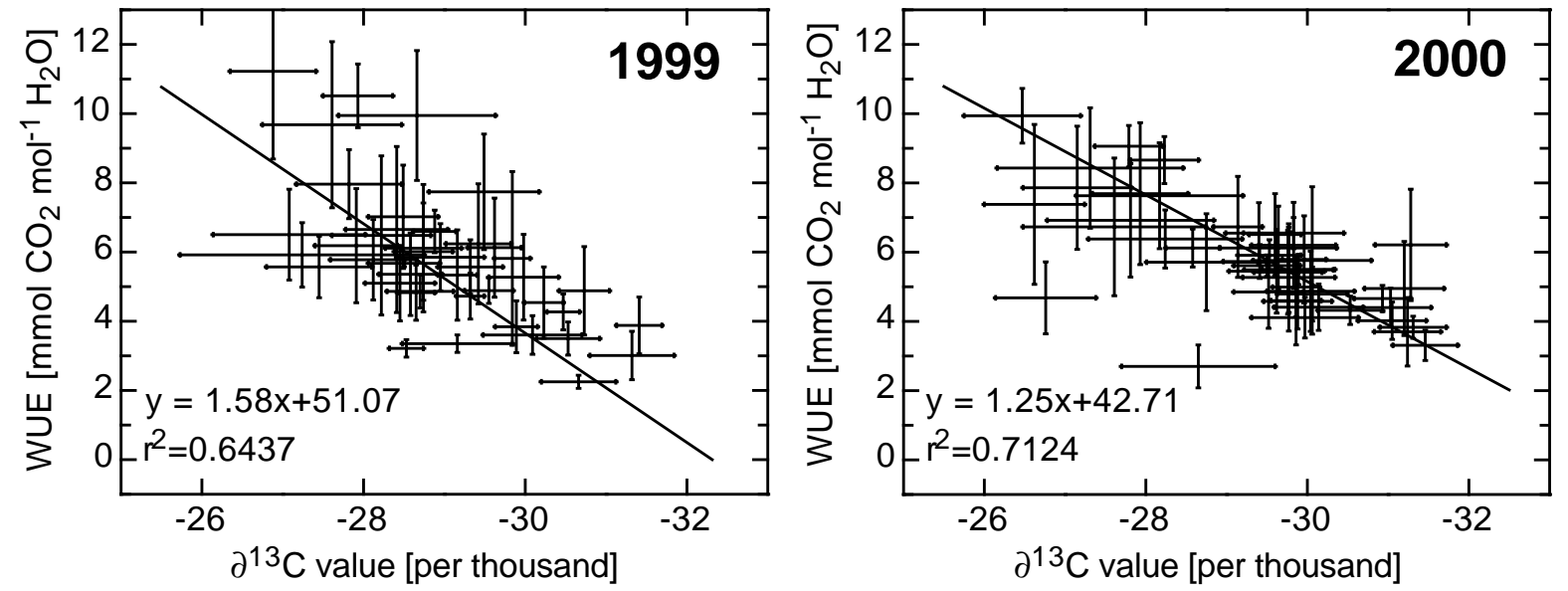

Figure 5.1.: Regressions of photosynthetic water use efficiency against $\delta^{13} \mathrm{C}$ values of bulk leaf tissue of the birches in all treatments 1999 and 2000. The correlations are significant with $P \leq 0.05$.

The $\delta^{13} \mathrm{C}$ values measured in both 1999 and 2000 showed the first response to limited water supply after 3 weeks (Tab. 5.5). Leaf internal $\mathrm{CO}_{2}$ concentrations calculated from these values confirm the stomatal limitation of photosynthesis in the droughted plants as indicated by decreasing values of $c_{\mathrm{i}}$ and increasing WUE calculated from gas exchange measurements (Fig. 4.13 and 4.4). Since leaf internal $\mathrm{CO}_{2}$ concentrations are influenced not only by stomatal conductance to $\mathrm{CO}_{2}$, but by $\mathrm{CO}_{2}$ assimilation as well, these findings and the unaffected photosynthetic capacities ( $\mathrm{Tab} .4 .5$ ) of the plants show that drought stress did not cause marked nonstomatal limitations to $\mathrm{CO}_{2}$ assimilation. These may occur in severely stressed plants (KAISER 1987; CHAVES and PEREIRA 1992; EPRON and DREYER 1993; DICKSON and TOMLINSON 1996; DREYER 1997).

Minima of leaf water potentials measured in the early afternoon $\left(\Psi_{\min }\right)$ were affected rapidly by limited water supply, becoming significantly more negative 2 to 3 weeks after the onset of the drought treatment (Tab. 5.1). The lowest values were reached in August 2000 and ranged from -1.6 $\mathrm{MPa}$ in Bp-Aust.2 to $-1.9 \mathrm{MPa}$ in the German genotype. These values 
are consistent with RANNEY et al. (1991) and BACKES (1996), who measured -1.6 MPa and -1.9 MPa on drought stressed Betula pendula as well.

\subsubsection{Osmotic adjustment}

Both the osmotic potentials at the turgor loss point $\left(\Pi_{\mathrm{p}}\right)$ and at saturation $\left(\Pi_{0}\right)$ showed a tendency to decrease with continuing drought stress in all clones. After about 11 weeks of drought treatment, $\Pi_{0}$ values were lowered by up to $0.34 \mathrm{MPa}$ in 1999 and by up to $0.25 \mathrm{MPa}$ in 2000 (Fig. 4.3), although the decrease was significant only in the German and the Swedish plants. Osmoregulation in reaction to water shortage is more likely to occur if the drought is imposed slowly (ARNDT et al. 2001; LÖSCH 2001), thus the methods used to impose drought in experiments have to be taken into account when comparing osmotic potentials. GEBRE and KUHNS (1993) conducted greenhouse experiments with Populus deltoides, which they dried out fast to predawn leaf water potentials of $-1.0 \mathrm{MPa}$, and measured no osmotic adjustment, but the same clones were capable of osmotic adjustments of -0.2 to $-0.5 \mathrm{MPa}$ in response to moderate water stress, when dehydration was slow (GEBRE et al. 1994). In addition, osmoregulation is supposed to be a very plastic parameter (LÖSCH 2001), exhibiting a high degree of both inter- and intraspecific variation. Osmotic potentials are usually lowered by just a few bar, decreases of more than 1.0 MPa were rarely measured. The adult silver birches investigated by BACKES (1996) lowered $\Pi_{0}$ values by $0.17 \mathrm{MPa}$ in response to a dry period, while RANNEY et al. (1991) found no osmotic adjustment in any of 6 species of birch. EPRON and DREYER (1996) measured an osmotic adjustment of $0.3 \mathrm{MPa}$ in young Quercus petraea, and BACKES (1996) found adjustments of $0.25 \mathrm{MPa}$ in old trees of the same species, while THOMAS (2000) did not detect any osmotic adjustment in either $Q$. petraea or $Q$. pubescens in response to two long drought periods.

The most important anorganic component in osmoregulation of kormophytes is potassium (LÖSCH 2001). In this investigation, potassium contents in leaves of the birch trees were analysed in parallel to the pressure-volume curves (BREIHOLZ, in preparation). The decrease of $\Pi_{0}$ described above was acompanied by an increase of foliar potassium by up to 37 and $76 \%$ in 1999 and 2000, respectively. ARNDT et al. (2001) measured an increase of foliar potassium of $45 \%$, while $\Pi_{0}$ was lowered by $0.42 \mathrm{MPa}$ by Ziziphus rotundifolia in response to drought. GEBRE et al. (1998) examined solute composition in hybrid poplar clones and found that potassium was the main ion, constituting about $30 \%$ of total solutes and $50 \%$ of total ions in drought-stressed plants. XU et al. (2000) investigated the carbon isotope composition of two Pinus hybrids and found discrimination of ${ }^{13} \mathrm{C}$ to decrease (i.e. $\delta^{13} \mathrm{C}$ to become more positive) with increasing concentrations of potassium in the leaves. They did not measure leaf water relations, but the coincidence of a significant increase of foliar potassium with lower discrimination of ${ }^{13} \mathrm{C}$, which is caused by stomatal closure, indicates an osmoregulatory acclimation to drought.

The osmoregulatory function of changes of the mean bulk modulus of tissue elasticity $\epsilon_{\max }$ is controversial. While RANNEY et al. (1991) pointed out that decreasing values of $\epsilon_{\max }$, i.e. increasingly elastic tissues, will maintain positive turgor to lower tissue water potentials, according to $\mathrm{LÖSCH}$ (2001) the mean modulus of elasticity usually increases with increasing turgor potential. LI (1998) found a significant positive correlation between $\epsilon_{\max }$ and the de- 
gree of osmotic adjustment in Eucalyptus microtheca, while WHITE et al. (2000) interpreted a decrease of $\epsilon_{\max }$ values in response to water shortage by Eucalyptus platypus adaptive to drought, although the 3 other species of Eucalyptus in the same investigation increased their bulk modulus of tissue elasticity in response to drier conditions. PITA and PARDOS (2001) investigated drought responses of 6 clones of Eucalyptus globulus and measured highest rates of osmotic adjustment $(0.41 \mathrm{MPa})$ and highest values of $\epsilon_{\max }$ in clones that exhibited the highest leaf expansion rates. NIINEMETS and KOLL (1998) stated that decreasing tissue elasticity renders leaves more resistant to low water potentials and related $\epsilon_{\max }$ to the degree of lignification of cell walls. They pointed out that high $\epsilon_{\max }$ values result in large changes of tissue water potential with only minor changes in symplastic water content, so that the water potential gradient and thus waterflow can be maintained with proportionally less variable cell volume and at lower leaf water deficits. CHARTZOULAKIS et al. (1999) experimented with two cultivars of olive trees and found that both osmotic adjustment and increases in tissue elasticity contributed to turgor maintenance under water stress conditions. On the other hand, THOMAS (2000) pointed out that $\epsilon_{\max }$ may not be an optimal parameter for the determination of tissue elasticity in the assessment of drought adaptation within species, because it is conventionally determined for the range of high turgor (from the linear part of plots of turgor against relative water content), but is also known to change with a decrease in turgor. He found $\epsilon_{\max }$ values to increase with drought in Quercus petraea and Sorbus aria, but to decrease in Fagus sylvatica.

The four clones of silver birch examined in this study increased $\epsilon_{\max }$ values as soon as they decreased the osmotic potentials in 1999, and even before that in 2000 (Tab. 5.1), and they exhibited greater plasticity with regard to $\epsilon_{\max }$ than with regard to the other factors of osmoregulation (Tab. 5.5). Whether this increase can be classified as adaptive osmoregulatory reaction could not be elucidated conclusively. In a drought avoiding species with sensitive regulation of water loss and early stomatal closure, however, a steep decrease of leaf water potential with only small changes in the symplastic water content could well be of adaptive value.

Low tissue osmotic potential does not cause a considerable increase of water extraction from the soil, since there is usually little water left in soils at water potentials below $-1.0 \mathrm{MPa}$, particularly in sandy soils (RANNEY et al. 1991; LÖSCH 2001). Nevertheless, osmoregulation makes it possible to maintain stomatal conductance and $\mathrm{CO}_{2}$ assimilation to some extent, thus keeping metabolic rates high and continuing growth under limiting conditions. This might be of advantage especially in young saplings, which have not yet reached deeper water tables, since osmoregulation can enable them to maintain high root growth rates during establishment (ARNDT et al. 2001; LÖSCH 2001). SPERRY and SALIENDRA (1994) found significantly narrower vessel diameters in the main axis of juvenile (2-3 years old) Betula occidentalis than in adult trees. The young trees maintained hydraulic conductance to a much higher xylem tension than adult xylem, indicating a potential adaptation of the xylem to lower water potentials during establishment.

Whether increased osmoregulation or decreased stomatal conductance is of greater advantage in drought stressed plants depends on the gain of water by tapping of new soil horizons. All four genotypes, and particularly the German and the Swedish ones, exhibited osmotic adjustment to a far greater extent in 1999, when the 451 containers they were planted in were not yet tapped, than in 2000, when the roots had reached the bottom of the pots. Since the 
soil in the containers became gradually moister with depth, fast root growth was worthwhile. This is reflected in the patterns of biomass allocation, which will be discussed below, and can explain the higher values of stomatal conductance and $\mathrm{CO}_{2}$ assimilation and the lower leaf water potentials measured in 1999. If investigations of drought responses of trees are conducted in conditions of either severely limited root growth (e.g. in small pots), or on well-established old grown trees in the field which already have reached the moistest accessible soil horizonts, potentials for osmoregulatory mechanisms may be overlooked.

Another benefit of osmoregulation is the protection of meristematic tissues against dehydration, while older leaves are sacrificed (LÖSCH 2001). This may be of importance especially in Betula pendula, since this species shows a considerable plasticity with regard to its phenology.

\subsubsection{Chlorophyll and nitrogen content of the leaves}

Chlorophyll contents of 3rd and 4th leaves of the birches started to increase 4 weeks after the onset of drought; from early July on, droughted trees of all clones had significantly higher chlorophyll contents per unit leaf area than the well-watered ones (Fig. 4.8, Tab. 5.1). Third and 4th leaves of droughted plants might have been older than those of well watered ones, because growth of new leaves was limited by water shortage (see below), but even older leaves of well-watered trees (5th and 6th) never reached the chlorophyll contents of younger leaves (according to their position on the twig) of droughted plants. Foliar nitrogen contents per unit dry mass of the leaves increased with drought as well (and C:N ratios decreased, Fig. 4.9), but not when calculated based on leaf area (Fig. 4.10). In contrast to these results, MARMANN (1998) measured increasing foliar nitrogen contents with increasing soil moisture in silver birch and ash, and TOGNETTI et al. (1995) and GARCÍA-PLAZAOLA and BECERRIL (2000) dehydrated seedlings of beech and measured a decrease of chlorophyll contents. On the other hand, P̈̈̈̈KKÖNEN et al. (1998a) and P̈̈̈̈KKÖNEN et al. (1998b) reported an increase of foliar chlorophyll and nitrogen and also of rubisco in drought stressed saplings of $B$. pendula. Several factors may influence chlorophyll and nitrogen contents in drought stressed leaves. The nitrogen content of thylakoid membranes may decrease markedly in severe drought stress, though membrane proteines and chlorophyll can be stabilized by the accumulation of polyamines (LÖSCH 2001). Drought stressed leaves contain less starch due to reduced rates of assimilation, thus increased nitrogen contents may be caused by reduced dilution by carbon rather than by increased accumulation of nitrogen (EPRON and DREYER 1996; JONASSON et al. 1997). The increase of specific leaf area measured in all droughted plants (Tab. 4.6) and the unchanged concentrations of nitrogen when calculated on a leaf area basis support the latter hypothesis.

Total leaf areas of the droughted plants were severely reduced in all clones by both increased shedding and reduced growth, thus a shift of nitrogen from more senescent leaves to fewer young ones might be another reason for increased nitrogen contents in drought stressed plants. MARMANN (1998) found no hindrance to the redistribution of nitrogen from senescent leaves of silver birch to younger ones by water shortage. Removal of part of the leaves from a plant is known to increase the supply of nutrients to the remaining leaves (MOONEY 1986), resulting in a stimulation of photosynthetic activity of these leaves. This process in- 
volves an increase in carboxylation efficiency (CE), which was in fact observed in all clones of birch investigated in this study (Tab. 4.5). An increase of $\mathrm{CE}$ is of particular advantage for the maintenance of high rates of $\mathrm{CO}_{2}$ assimilation, when internal concentrations of $\mathrm{CO}_{2}$ are limited by stomatal closure. PÄÄKKÖNEN et al. (1998b) stated that increased chlorophyll and $\mathrm{N}$ contents in leaves of droughted birch with indeterminate growth may be related to the ability of young leaves to compensate for a reduced photosynthetically active foliage area. The droughted birches in this study grew markedly less leaves than the well-watered ones and terminated net increase of leaf numbers earlier (Fig. 4.16). Senescence started earlier as well, with the oldest leaves of the inner crown being senescent in early July in 2000 and net leaf shedding (more leaves were shed than newly grown) starting up to four weeks earlier in the droughted plants than in the well-watered ones.

Early shedding of leaves up to complete defoliation is a phenomenon regularly observed in drought stressed silver birch (BACKES 1996; FORT et al. 1998; MARMANN 1998). In this study, the leaves of three trees, which were accidentally dehydrated to predawn leaf water potentials below $-1.3 \mathrm{MPa}$, wilted and were completely shed. After rewatering to field capacity, all of these trees sprouted new leaves. One reason for the early senescence of drought stressed leaves is photooxidation caused by excessive light in the $\mathrm{CO}_{2}$ limited conditions of stomatal closure (GARCÍA-PLAZAOLA and BECERRIL 2000). Nevertheless, rapid remobilization and redistribution of assimilates for storage and pending regrowth may be the optimal mechanism for coping with drought stress in mesic-type leaves (ARNDT et al. 2001). Both shedding of leaves to reduce the transpiring area and the ability to resprout leaves should then be viewed as a morphological adaptation to severe drought, rather than as the inability to cope with it. Models of KIKUZAWA (1991) predict that short leaf longevity is economic, when the initial photosynthetic rate of the leaf is large, the construction costs are low, and the decrease of net photosynthetic rate with time is large. This hypothesis has been validated by investigations on different trees species (REICH et al. 1991; SCHULTE 1992). JONASSON et al. (1997) showed for Pistacia that phenology of leaves is under the control of drought induced constraints of the carbon balance.

\subsubsection{Morphology of leaves and fine roots}

Not only the number of leaves per plant was reduced by drought, but substantial alterations of morphology occurred as well. According to BERNTSON et al. (1995), within-organ and between-organ allocation of mass have to be viewed independently, because the arrangement of mass within organs can vary substantially, independently of patterns of biomass allocation between roots and shoots. The reduction of both speed of growth and final size of the individual leaves is a phenomenon often observed in relation to water shortage (OSORIO et al. 1998; NIINEMETS and KOLL 1998). Cell expansion is reduced by lowered leaf water potentials to a greater extent than cell division, thus individual cells of leaves are regularly smaller in drought stressed plants ( $\mathrm{LÖSCH} 2001)$. This was reflected by an up to $7 \%$ decrease of size and an up to $13 \%$ increase of density of stomata in leaves of the drought stressed trees in late August 1999 (BREIHOLZ, in preparation). Carbon allocation within plants is regulated by source-sink interaction and developing leaves function as strong sinks. If the growth of leaves is slowed down, the relative sink strength decreases and more assimilate is available for transport to the 
roots (DICKSON and TOMLINSON 1996). MunNS et al. (2000) showed that in response to sudden changes of water relations, leaves of maize and barley reduced growth rates without interference of signals from the roots; the changes in leaf elongation rates could be reversed by placing the roots in a pressure chamber and keeping the xylem sap at atmospheric pressure. After some days, however, pressurization failed to maintain elongation rates, indicating the influence of root signals overriding its effect. Therefore, leaf size is not just passively reduced in droughted plants by lowered turgor pressure, but can serve as an adaptation to regulate allocation of biomass (see below). This might be especially true for Betula pendula, since TAYLOR and DAVIES (1986) suggested that leaf growth of this species is primarily limited by cell wall loosening, which is susceptible to hormones such as ABA, and not by leaf turgor. Since leaf expansion is known to decrease with increasing $\epsilon_{\max }$ (NIINEMETS and KOLL 1998), this parameter has to be considered with regard to its influence on leaf morphology as well as in the context of osmoregulation.

In contrast to other tree species, which react to water shortage with a decrease of specific leaf area (SLA, e.g. Quercus petraea, Q. pubescens, Fagus sylvatica, Sorbus aria (THOMAS 2000), Populus balsamifera (IBRAHIM et al.(1997)), this parameter was significantly increased after two dry summers in all clones of silver birch in this study. Lower specific leaf areas and higher sclerophylly are usually regarded as adaptive to drought stress (ABRAMS 1994; ABRAMS and MOSTOLLER 1995, PITA and PARDOS 2001). Nevertheless, WANG et al.(1998b) claimed that a low allocation of biomass to leaves can be compensated for by a high specific leaf area, and PALMROTH et al. (1999) termed the requirement of less structural carbon for the maintenance of the same leaf area an increase in structural efficiency, which could compensate for smaller carbon gains.

Despite the increase of specific leaf area, total leaf areas of the droughted trees were reduced by up to $49 \%$ after two dry seasons, which markedly reduced the whole plant transpiration in addition to lowering stomatal conductances (BREIHOLZ, in preparation). MEINZER et al. (1992) investigated drought response in Coffea arabica and suggested that the maintenance of nearly constant photosynthetic activity per unit leaf area through a reduction of whole plant leaf area may be the major mode of adjustment to reduced soil water availability. Homeostasis of properties on a unit leaf area basis through reduced rates of leaf expansion may be a common form of adjustment of woody species to water shortage.

Specific fine root area (SRA) was not significantly affected by water shortage, although SRA of the droughted plants tended to be smaller than that of the well-watered ones (Tab. 4.7). Division of the finest roots into diameter classes of $0.2 \mathrm{~mm}$ revealed a shift from the smallest diameters to larger ones in all clones (Fig. 4.15). FITTER (1994) and FITTER (1996) emphasized the enormous plasticity of root architecture in response to belowground heterogeneity. Roots of larger diameter grow faster, are capable of rapidly exploring the soil, and live longer, thus being able to pay back construction costs over a longer period of time (FITTER 1994). On the other hand, finer roots are more effective at filling volumes of soil and represent a smaller overall resource cost. Proliferation of soil with very fine and highly ramified roots has been demonstrated in response to nutrient rich patches in barley (DREW et al. 1975), and HERTEL (1999) showed that SRA of the finest roots (diameter $<1 \mathrm{~mm}$ ) were higher in the comparatively nutrient-rich uppermost organic layer than in lower horizonts of three old-grown beech stands in Germany, although morphological differences of fine roots between the stands were 
only marginal. MAURER and MATYSSEK (1997) investigated the responses of $B$. pendula to different levels of nutrition and found specific root mass (dry mass per root length) of fine roots to decrease in reaction to low nutrient availability. The proportion of finest roots $(<1 \mathrm{~mm})$ in the fine root total increased in comparison with plants growing with unlimiting nutrient supply. Roots exploring untapped soil, however, show a different morphology: they grow for long distances without branching and are of larger diameters (although still below $2 \mathrm{~mm}$, HERTEL, pers. comm.). This kind of root was easily recognizable and abundant in all treatments in this study, but its percental share was higher with regard to the reduced overall fine root biomass of the droughted plants. Besides, HACKE et al. (2000) showed, that small roots are more susceptible to embolism than larger roots, thus a shift to larger diameters within fine roots may help to maintain hydraulic conductance in drought conditions.

Further investigations on the architectural plasticity of root systems in response to different stresses are needed, since belowground plasticity cannot be assessed by allocation of biomass alone (FITTER 1994).

Table 5.2.: Ranking of relative plasticity of different generic groups of parameters measured in the summer of 2000. Absolute plasticity per genotype was quantified as difference between means of the well-watered plants and the droughted plants. Relative plasticity was calculated as percentage of absolute plasticity in relation to the genotype means over both treatments. $00=$ relative plasticity $(r p)<$ $10 \%, 0=r p 10-20 \%,+=r p 20-40 \%,++=r p 40-60 \%,+++=r p 60-80 \%$, and $++++=r p>80 \%$

\begin{tabular}{lllll}
\hline parameter & Bp-Aust.1 & Bp-Aust.2 & Bp-Swed. & Bp-Germ. \\
\hline patterns of root:shoot allocation & 0 & 00 & 0 & 00 \\
chlorophyll and nitrogen contents of the leaves & 0 & 0 & 00 & 0 \\
fine root and leaf morphology & 0 & 0 & 0 & 0 \\
parameters obtained from pressure-volume curves & 0 & 0 & 0 & 0 \\
$\mathrm{CO}_{2}$ gas exchange parameters at saturating $\mathrm{CO}_{2}$ & 0 & 0 & 0 & + \\
$\mathrm{CO}_{2}$ gas exchange parameters at ambient $\mathrm{CO}_{2}$ & ++ & + & + & + \\
leaf water potentials & + & ++ & + & ++ \\
total leaf area & +++ & ++ & ++ & ++ \\
$\mathrm{H}_{2} \mathrm{O}$ gas exchange parameters & ++++ & ++++ & +++ & ++++ \\
\hline
\end{tabular}

\subsubsection{Biomass allocation}

Between-organ allocation exhibited a marked increase of root:shoot and fine root:leaf mass ratios, especially of the German and Swedish trees after the first drought period in 1999. This confirms the hypothesis that osmoregulation kept metabolic rates high during establishment, thus facilitating the fast tapping of unexploited soil. This may be the reason for higher root:shoot mass ratios in the well-watered plants of all clones in 1999 compared to 2000 as well - in the first year of investigation, a greater proportion of biomass was allocated to the roots in both treatments to exploit the soil. Harvests in September 1999 revealed that all plants had reached the bottom of their pots by then. After the second summer, fine root:leaf mass ratios of the droughted plants of all clones were slightly higher than those of the well-watered ones, though these differences were significant only in two clones. Multivariate analyses of 
variance proved the significant influence of the treatment on root:shoot and fine root:leaf mass ratios (Tab. 5.4).

BARTELINK (1998) modelled the partitioning of dry matter in trees and concluded that the availability of soil water and nutrients can be expected to affect partitioning strongly, especially in belowground components. In poor soils, fine root turnover and root:shoot ratio are expected to be high. Previous work with other tree species revealed different responses of allocation patterns to limiting soil conditions. WANG et al. (1998b) examined four populations of Betula papyrifera and found that root:shoot ratios were not affected by water shortage, but increased with limited nutrient availability. MAURER and MATYSSEK (1997) showed an increase of root:shoot in response to low nutrient availability in $B$. pendula as well, although it was not altered by growth in elevated $\mathrm{CO}_{2}$ (KELLOMÄKI and WANG 2001). THOMAS (2000) measured a significantly increased root:shoot ratio in droughted Quercus petraea, but not in Fagus sylvatica, Sorbus aria and Q. pubescens. SOUCH and STEPHENS (1998) found a reduction of root:shoot ratio after two dry years in three hybrid poplar clones, while IBRAHIM et al. (1997), who also worked with hybrid poplar, examined an increase of relative dry matter allocation to the roots in response to drought. The intensity of stress and the plant genotype can strongly influence the response, however, since the poplar in the experiments of SOUCH and STEPHENS (1998) responded with an increase of root:shoot ratio to drought of lower intensity in the first year as well, and TSCHAPLINSKI et al. (1998) found a significant shift of matter allocation to the roots in response to mild drought stress in a drought-resistant clone of hybrid poplar, but less so in a susceptible one. Moderate stress stimulated root growth in Pinus pinaster by loosening of cell walls, while higher stress decreased growth by low turgor pressure (TRIBOULOT et al. 1995). For reviews on the effects of water shortage on allocation patterns see DICKSON and TOMLINSON (1996) and JOSLIN et al. (2000). Surface area ratios of fine roots to leaves were not altered in any of the clones in this study after two years of drought. Changes of the mass ratios were levelled out by both the increase of specific leaf areas and the decrease of specific root areas (see above).

Stomatal limitation of $\mathrm{CO}_{2}$ assimilation and reduction of assimilating area in response to two dry seasons reduced overall biomass in the droughted plants of all clones by 36 to $47 \%$. Reductions of both aboveground and belowground biomasses were highly significant in all clones. Droughted trees exhibited a higher percentage of fine root necromass than the wellwatered ones (Fig. 4.18). This increase was not caused by an increase in root mortality rate, though, but by reduced growth of new roots.

\subsubsection{The drought response of silver birch}

In conclusion, the high plasticity of physiological, morphological, and phenological attributes and allocation in Betula pendula in response to environmental changes is striking.

Among the most sensitive and most plastic reactions to water shortage is the reduction of stomatal conductance, the reduction of water loss by transpiration, and thus the postponement of damaging effects of water shortage. By this, the carbon gain is optimized by an increasing water use efficiency, and marked drops of the leaf water potential are prevented. In addition, silver birch is capable of active osmoregulation and the maintenance of high rates of stomatal conductance, but its use is restricted to circumstances in which the advantages of high 
metabolic rates and growth outweight the disadvantages of higher water losses (i.e. during establishment in unexploited soil). The very plastic phenology of this indeterminately growing species allows for reduction of the whole plant transpiration by reduced leaf area due to senescense and leaf shedding. Leaf area can be regrown in the same season if the water stress ends. This highly plastic phenology has to be classified as an adaptation to severe water shortage, rather than as an indication of high susceptibility to drought.

A marked reduction of biomass in response to drought is not of adaptive value, but a tradeoff of stomatal closure and the reduction of leaf area. A plant response to an environmental stimulus has to be appropriate and enhance fitness to be adaptive (SCHLICHTING 1986). On the other hand, B. pendula is capable of differential reduction of aboveground and belowground biomass and both within- and between-organ allocation respond plastically to environmental changes.

Specific leaf areas increase in response to drought, thus increasing structural efficiency and compensating for lower allocation of biomass to the leaves. Stomatal limitation of $\mathrm{CO}_{2}$ assimilation and the reduction of assimilating leaf area is partly compensated for by an increase of chlorophyll and nitrogen in the remaining leaves due to a passive concentration effect, which increases carboxylation efficiency and helps to maintain photosynthetic properties. There is no hindrance to the redistribution of nitrogen from senescent leaves to younger ones (MARMANN 1998) and permanent sprouting of new leaves allows for the effective recycling of nutrients. Plasticity of fine root architecture in response to nutrient availability has been shown by MAURER and MATYSSEK (1997), and plastic responses to water availability may be possible as well. Between-organ allocation can be altered to some extend in response to both nutrientand water shortage, thus the plastic division of limited biomass according to environmental restraints is possible.

ARNDT et al. (2001) emphasized that species possessing both a drought avoidance mechanism and the ability to acclimate by active osmoregulation would be at an advantage because of increased flexibility in response to changing environmental conditions. Species that respond with a high degree of flexibility can generate appropriate phenotypes in different environments (BAZZAZ 1996). It is this high degree of phenotypic plasticity that enables silver birch to exhibit the widest physiological amplitude of mid-European broad-leafed trees species (ELLENBERG 1996).

\subsection{Similarities and differences between the four genotypes of silver birch}

\subsubsection{Theoretical background on phenotypic plasticity}

Comparison of the four genotypes of European silver birch tested in this study can be done on two levels: first, comparison of clones in the same environment reveals genotypic effects on different traits without potential interference of responses to different environments. Second, a comparison of the responses of genotypes to different environments allows for the estimation of similarities and differences, and potential adaptive values, of their phenotypic plasticity.

Terrestrial plants are sessile, thus they cope with much of the variability in their environ- 
ments by flexibility of response (BAZZAZ 1996). GREGORIUS and KLEINSCHMIT (1999) distinguished between two types of environmental conditions: first, modifying conditions affecting the response, and second, adaptive conditions to which these responses have to be adjusted in order to guarantee survival and reproduction. The response to these conditions has to maintain all biological functions relevant for survival and reproduction. Plasticity on the level of physiology is likely to be accompanied by stability on the level of fitness, thus characters that are more tightly correlated with fitness and reproductive success will display less environmental variance (BELL and LECHOWICZ 1994).

The ability of the carriers of a given genotype to express different phenotypes in response to temporally and spatially varying environmental conditions is termed phenotypic plasticity (GREGORIUS and KLEINSCHMIT 1999). A genotype itself cannot adapt, but codes for the ability of its carriers to adapt. Thus, while genetic variability is a characteristic of a group, i.e. the genotypic composition of a population may be flexible, comprising genotypes adapted to different environments, phenotypic plasticity is a characteristic of the individual (SCHLICHTING 1986). Plants that are able to make broad physiological adjustments to different environments will be able to survive and reproduce successfully across this range of environments (BELL and LECHOWICZ 1994). The amount of environmental variance expressed by plants grown under different conditions is in itself a character under genetic control, thus phenotypic plasticity is inheritable and subjected to evolution. Whether there are genes coding for phenotypic plasticity or plasticity evolves as a by-product of selection on individual traits is subject to controversial debates (VIA 1993; SCHLICHTING and PIGLIUCCI 1993; SCHEINER 1993; VIA 1994).

Four hypotheses explain differences in phenotypic plasticity between genotypes, populations and species:

1. MARSHALL and JAIN (1968) state that adaptation to variable environments is accomplished by either genetic variation or phenotypic plasticity. Species with the lowest heterozygosity, i.e. the least genetic variance, should be most plastic and vice versa.

2. LERNER (1956) also postulates an inverse relation between plasticity and genetic heterozygosity, though it stems from a more negative view on phenotypic plasticity: since inbreeding leads to increased homozygosity and thus developmental instability due to deterious recessives, plasticity will increase.

3. SCHLICHTING and LEVIN (1984) postulate an ecological hypothesis. Since amounts and patterns of response to an environment are shaped by natural selection pressures which vary from one habitat to another, the more divergent the habitats or the ecological tolerances are, the less similar the phenotypic plasticities should be.

4. Since the phenotypic plasticity of a given trait has been shown to be under genetic control, patterns and amounts should vary as a function of the evolutionary relatedness of the compared species simply as a byproduct of divergent evolution (SCHLICHTING and LEVIN 1984).

SCHLICHTING and LEVIN (1984) tested these hypotheses with three species of Phlox of differential relatedness, heterozygosity, and habitats. They found a great diversity of response 
to different environmental variables and suggested that the similarity of patterns of plasticity might be determined to some extent by relatedness, while the amount is influenced by ecology and possibly heterozygosity.

BELL and LECHOWICZ (1994) approached the concept of phenotypic plasticity from the environment, suggesting environmental variance as a good measure for plasticity, taking up the ecological hypothesis of SCHLICHTING and LEVIN (1984). They stated that there is substantial environmental variance at the spatial scale of plant dispersal, thus selection will act on plasticity even within local populations of plants. Since environmental variance increases with distance, species that disperse their propagules farther will be more plastic.

The genetic basis for phenotypic plasticity may be found in regulatory gene loci, which turn on or off structural genes in response to environmental stimuli, or in the expression of different alleles in different environments (WU 1998). SCHLICHTING (1986) emphazised that the concept of phenotypic integration is important, because random and undirected changes of one character in relation to another might result in a reduction of plant fitness. Therefore, selection should act on the interrelationship of traits as well. Changes in amounts of epistasis and dominance were reported in response to different treatments. Such changes in the functioning of regulatory and modifier genes might alter the pleiotropic relationships between traits.

\subsubsection{Microenvironmental plasticity}

The use of clonal material provides an effective tool to reduce variability among replicates within treatments relative to the variability among treatments (OSORIO et al. 1998). By the exact replication of a given genotype in different environments, it is possible to study its norm of reaction, i.e. its inherent capacity for phenotypic plasticity (WU 1998). Significant clonal variation in the plastic reactions and susceptibility of Betula pendula has been detected in response to different levels of ozone (HOLOPAINEN and KÄRENLAMPI 1997), or ozone and water availability (PÄÄKKÖNEN et al. 1998a), to different temperatures during growth of the pollen tube (PASONEN et al. 2000), and to mammalian and insect herbivores (JIA et al. 1997; ROUSI et al. 1997; MUTIKAINEN et al. 2000).

Nevertheless, variation is observed between different individuals of the same genotype in the same treatment as well. Geneticists usually distinguish between predictable macroenvironment and unpredictable microenvironment when discussing the sources of environmental variability. The internal coincidences of development and conditions immediately external to the organism represent examples of the microenvironment. This type of plasticity is supposed to be under low genetic control (WU 1998).

Microenvironmental plasticity caused by circumstances within the plant and immediately external the plant cannot be differenciated from methodical inaccuracies and from each other. Tab. 5.3 shows coefficients of variation (percentage of standard deviation) of different parameters. Variation coefficients ranged from $2 \%$ in $\delta^{13} \mathrm{C}$ values to more than $50 \%$ with regard to the daily means of stomatal conductance. Different methodical pecularities have to be considered when comparing variation of different parameters within genotypes and treatments. For example, measurements of gas exchange were conducted from 10 o'clock in the morning to late afternoon, thus the average values comprise the diurnal courses of these parameters. Variaton coefficients are especially high with regard to characters of the $\mathrm{H}_{2} \mathrm{O}$ gas exchange, which 
respond very fast to changes in the environment, thus coefficients of variation can reflect a character's speed of response to environmental changes. Some parameters exhibit higher variation within the droughted plants of one genotype than within the well-watered ones, reflecting the higher impact of small differences in soil water content when water is limiting in comparison to ample water supply.

Table 5.3.: Microenvironmental plasticity as quantified by the coefficient of variation of 18 parameters measured in 2000. Variation coefficients are calculated as percental standard deviation of average value. Average variation coefficients of all clones in each treatment are shown.

\begin{tabular}{llll}
\hline parameter & W99/W00 & D99/W00 & D99/D00 \\
\hline foliar $\delta^{13} \mathrm{C}$ value & 2 & 2 & 3 \\
osmotic potential at the turgor loss point $\Pi_{\mathrm{p}}$ & 7 & 6 & 7 \\
specific leaf area & 6 & 6 & 8 \\
leaf area based $A_{\max }$ & 12 & 6 & 9 \\
foliar C/N ratio & 9 & 9 & 11 \\
osmotic potential at saturation $\Pi_{0}$ & 9 & 11 & 10 \\
leaf area based chlorophyll content & 10 & 11 & 10 \\
leaf area based nitrogen content & 9 & 10 & 12 \\
root:shoot mass ratio & 14 & 11 & 10 \\
leaf size & 9 & 8 & 20 \\
minimum leaf water potential $\Psi_{\min }$ & 14 & 13 & 15 \\
total leaf area & 14 & 18 & 17 \\
carboxylation efficiency CE & 17 & 11 & 23 \\
fine root:leaf mass ratio & 20 & 17 & 14 \\
specific fine root surface area SRA & 19 & 22 & 20 \\
average daily net photosynthesis $A_{\text {amb }}$ & 14 & 15 & 35 \\
average daily stomatal conductance average daily $g_{\mathrm{sw}}$ & 27 & 29 & 51 \\
\hline
\end{tabular}

\subsubsection{Comparison of the four genotypes of silver birch}

Differences between sites and habitats belong to the macroenvironment. In this study, phenotypic response across the contrasting treatments (difference between average values of wellwatered and droughted plants, relative values calculated as percentage of the average over both treatments) is referred to as phenotypic plasticity.

Significant variation was detected between the genotypes of Betula pendula with regard to morphological, biochemical, and physiological traits and the plasticity of their responses to water shortage. Tab. 5.4 summarizes the results of multivariate analyses of variance of several features and reveals significant influences of the tree's genotype on 14 of 16 listed traits. Particular features of the leaves made it possible to distinguish the clones at first sight: leaves of Bp-Aust. 2 and the German clone were distinctly larger and of a lighter green than those of the other Austrian and the Swedish genotype. Their chlorophyll contents underlined the differences in colour, being up to $38 \%$ lower in Bp-Aust.2 and Bp-Germ. than in BpAust.1 and Bp-Swed.. Specific leaf areas differed as well, with the German genotype exhibiting significantly higher values than the other clones in both years and in all treatments - with regard 
to this feature, similarities were greatest between the German and the Swedish plants on the one hand, and the two Austrian clones on the other. GARCíA-PLAZAOLA and BECERRIL (2000) studied three Spanish provenances of Fagus sylvatica from climatically different origins and found the most conspicious differences in morphological characters as well.

Plasticity was highest in all clones with regard to those parameters involved in environmental tracking, especially stomatal conductance and thus transpiration (Tab. 5.5). In the well watered treatments, highest stomatal conductances were reached by the German and the Swedish clone in both years. With regard to the drought treatments, stomatal conductance after 11 weeks of water shortage was higher in the Swedish and the German clone than in the Austrian plants in 1999, while the differences were less pronounced in 2000. The German plants and Bp-Aust.1 exhibited the greatest plasticity of stomatal conductance and transpiration, i.e. the greatest differences between well watered and drought stressed plants (Tab. A.3). Consequently, similarities with regard to the maximum stomatal conductance were most pronounced between the Swedish and the German plants, originating from drier habitats, while with regard to the amount of plasticity, Bp-Germ. resembled Bp-Aust.1. Since stomatal closure affected net-photosynthesis to a greater extent in Bp-Aust.1, though, plasticity of the photosynthetic water use efficiency was greater in the German plants. The $\delta^{13} \mathrm{C}$ values of bulk leaf tissue confirmed significantly lower water use efficiencies of the well watered German trees in comparison to the other genotypes caused by high stomatal conductances.

Not only did the German genotype exhibit the highest rates of stomatal conductance per unit leaf area in 2000, but it displayed the largest leaf areas as well. These were significantly larger than those of the other clones in both the well watered and the drought stressed treatment, causing higher rates of transpiration. In contrast to these results, MÄKELÄ et al. (1996) hypothesized that plants from drier habitats should pursue a more conservative water use strategy than those from moister habitats, predicting a decrease of stomatal conductance with a decrease of the frequency of rainfall from model calculations. However, one of the bases of their model was the absence of competition for water between plants, based on the assumption that root systems of forest trees only partly overlap. HERTEL (1999) and LEUSCHNER et al. (2001) provided evidence that this assumption is not true, and COWAN (1982) pointed out that competition for water would alter optimum strategies: evolutionary stable optimisation strategies should lead to higher initial rates of transpiration that decrease more rapidly than in the absence of competition. Therefore, high stomatal conductances of the German genotype in favourable conditions in combination with fast and plastic responses of the stomata to water shortage can be interpreted as a highly competitive strategy. TILMAN (1980) interpreted the ability to rapidly use and deplete limited resources, thus preventing other plants from using them, as competitive ability. He assumed competition to be highest on those sites where the respective resources are limiting.

Indications for a more prodigal water use strategy of provenances from drier habitats in comparison with those from moister ones when grown at ample water supply have been reported for Fagus sylvatica (TOGNETTI et al.|1995: GARCÍA-PLAZAOLA and BECERRIL 2000), Pinus sylvestris (PALMROTH et al.1999), Castanea sativa (VILLANI et al.1992), Parkia biglobosa, a leguminous tree of African Savanna (TEKLEHAIMANOT et al.]1998), and different species of Eucalyptus (LI 1998; PITA and PARDOS 2001). ZHANG et al. (1997) concluded 
from their investigations of drought responses of three Pinus ponderosa provenances, that the prodigal and highly plastic strategy of the population from the driest origin was advantageous in dealing with environmental stress. In a natural plant community, their drought avoidance mechanism would confer a competitive advantage by optimizing carbon gain under favourable conditions, and minimize water loss when water was limiting. However, contrasting results were obtained as well (WANG et al. 1998a; LI et al. 2000).

Both the osmotic potentials at saturation and at the turgor loss point of the Austrian clones showed tendencies to lower (more negative) values, although conditions at their place of origin were moister than at the sites in eastern Germany and Sweden. Nevertheless, Bp-Swed. and Bp-Germ. exhibited a markedly greater capacity for osmotic adjustment than both Austrian clones in 1999, which was reflected by increases of foliar potassium by 31 and $37 \%$, respectively, while it only increased by $17 \%$ in Bp-Aust. 1 and not at all in Bp-Aust.2 (BREIHOLZ, in preparation). Leaves of the well-watered German and Swedish plants were more elastic than those of the Austrian genotypes in both years of investigation and showed a more plastic response to the drought in 2000. LI (1998) investigated different provenances of Eucalyptus microtheca and found no significant differences in osmotic potentials at saturation of the well watered treatments, but a markedly higher capacity to osmotically adjust in the droughted trees from drier sites in northwestern Australia. These provenances also exhibited significantly greater ratios of bulk moduli of tissue elasticity of the droughted plants to those of the wellwatered ones, thus a greater increase, i.e. plasticity, of this parameter. Comparison of this ratio for the investigated birch clones shows markedly higher values for the German and Swedish plants, also indicating a higher capacity for osmotic adjustment in these clones. These findings support the hypothesis of both LI (1998) and TUOMELA (1997), who also investigated drought responses of Eucalyptus microtheca, that drought adaptation is related more to the degree of osmotic adjustment than to the absolute values of osmotic potential.

Responses of most physiological parameters differed only gradually between the clones, revealing significant influences of both treatment and genotype on the respective parameter, but no interaction between genotype and treatment. Phenotypic plasticity consists of both a direction and an amount of response, and SCHLICHTING and LEVIN (1984) suggested from their investigations on different species of Phlox, that the direction and pattern of plastic responses might be shaped by the degree of relatedness between the species. Since all clones investigated in this study were of the same species, similar patterns of reaction are not surprising. JASIENSKI et al. (1997) analysed within-species variation in expression of phenotypic plasticity in Abutilon theophrastii on gradients of light, temperature, moisture, and nutrients, and found that overall similarity of ecological responses was very high, especially on the nutrient and moisture gradients. ROUPSARD et al. (1998) investigated responses of several physiological and morphological parameters of 7 provenances of the panafrican leguminous tree Faiherbia albida to drought. Significant effects of both treatment and genotype were found, but treatment $x$ genotype did not have a significant influence on any of the parameters.

A significant influence of the interrelation of genotype and treatment (genotype $x$ treatment) on a parameter indicates that there is not only plasticity of this character in response to a treatment, but that differences exist between the genotypes for their plastic responses (SCHLICHTING 1986). Visualization of the reaction norms of the genotypes can demonstrate these differences (VIA 1994). Fig. 5.2 shows such norms of reaction for three parameters, for 

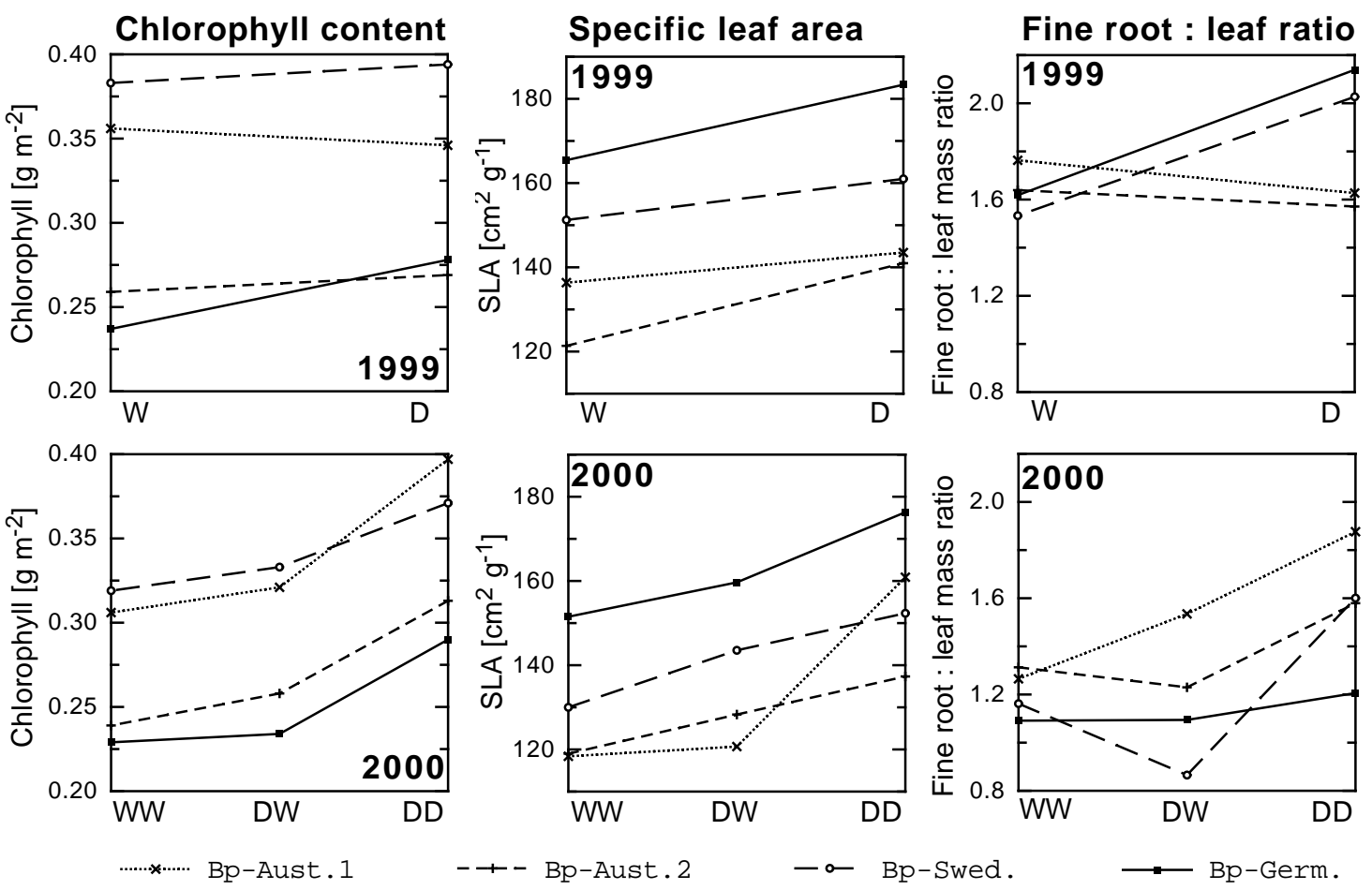

Figure 5.2.: Reaction norms of chlorophyll contents, specific leaf areas, and fine root:leaf mass ratios in 1999 and 2000. W and D denote average values for the well-watered and droughted treatments in 1999, while WW, DW, and DD represent the well-watered, drought-and-recovery, and droughted treatments, respectively, in 2000. For number of samples, see the respective tables in the appendix.

which a significant genotype $x$ treatment influence was calculated (Tab. 5.4). The influence of the genotype on foliar chlorophyll contents is evident, grouping Bp-Aust.1 and Bp-Swed. on the one hand, and Bp-Aust. 2 and Bp-Germ. on the other one. The treatment of the plants significantly influenced their foliar chlorophyll content, although in 1999 only the droughted German and Swedish plants markedly increased it. In 2000, chlorophyll contents were increased in the leaves of all drought stressed plants, but not to the same extent.

Specific leaf areas were highest in the German and Swedish plants, and increased in response to water shortage in all clones. In 1999, there were no significant differences between the genotypes with regard to this reaction, thus no treatment $\mathrm{x}$ genotype influence was detected. In 2000, however, Bp-Aust. 1 exhibited a norm of reaction different from those of the other clones. As with regard to foliar chloropyll concentrations, the specific leaf area of BpAust.1 showed no significant response to water shortage in 1999, but responded to a greater extent than those of the other clones in the second year of drought.

Reaction norms of fine root:leaf mass ratios for 1999 (Fig. 5.2) exhibit pronounced differences in allocation patterns between the droughted German and Swedish plants on one side and the Austrian ones on the other. While this ratio decreased in the drought stressed Austrian plants, it markedly increased in Bp-Germ. and Bp-Swed. in this phase of establishment, enabling them to tap the moister depths of their pots fast. As with regard to the chlorophyll content and specific leaf area described above, fine root:leaf ratios of Bp-Aust. 1 responded only in 
Table 5.4.: Significance of the influence of the treatment, the genotype, and the procuct of treatment $\mathrm{x}$ genotype on the variance of different parameters as obtained from multivariate analyses of variance (Appendix B). Asterisks indicate a significant influence $(P \leq 0.05)$ of the factor.

\begin{tabular}{lccc}
\hline parameter & Treatment & Genotype & Treatment x Genotype \\
\hline average stomatal conductance $\left(g_{\mathrm{sw}}\right)$ & $*$ & $*$ & \\
intercellular $\mathrm{CO}_{2}$ concentration $\left(\mathrm{c}_{\mathrm{i}}\right)$ & $*$ & $*$ & \\
photosynthetic water use efficiency $(\mathrm{WUE})$ & $*$ & $*$ & \\
leaf area based net-photosynthesis $\left(A_{\mathrm{amb}}\right)$ & $*$ & & \\
leaf area based photosynthetic capacity $\left(A_{\max }\right)$ & & & \\
chlorophyll based photosynthetic capacity $\left(A_{\max }\right)$ & $*$ & $*$ & \\
carboxylation efficiency $(\mathrm{CE})$ & $*$ & & \\
saturating $\mathrm{CO}_{2}$ concentration $\left(\mathrm{CO}_{2 s a t}\right)$ & $*$ & & $*$ \\
bulk modulus of tissue elasticity $\left(\epsilon_{\max }\right)$ & & $*$ & $*$ \\
foliar $\delta^{13} \mathrm{C}$ value & $*$ & $*$ & $*$ \\
leaf area based chlorophyll content & $*$ & $*$ & $*$ \\
specific leaf area (SLA) & $*$ & $*$ & $*$ \\
specific fine root surface area $(\mathrm{SRA})$ & $*$ & $*$ & $*$ \\
total leaf area & $*$ & $*$ & $*$ \\
total fine root surface area & & $*$ & \\
fine root:leaf area ratio & $*$ & $*$ & \\
fine root:leaf mass ratio & $*$ & $*$ & \\
root:shoot mass ratio & & & \\
&
\end{tabular}

the second drought period. Conspicious is the reaction of patterns of allocation of the Swedish plants in the drought-and-recovery treatment 2000. After a net increase of dry mass allocation to the fine roots during the drought period in 1999, they allocated relatively more dry matter to the leaves in the wet summer 2000, thus compensating for reduction of assimilating surfaces in the previous year. In September 2000, the drought-and-recovery treated trees had even greater leaf areas and aboveground dry masses than those plants that had been well-watered for two summers.

After two dry summers, the overall biomasses of the German and Swedish plants were reduced by 40 and $36 \%$, respectively, while the droughted Austrian clones were $47 \%$ (BpAust.1) and $45 \%$ (Bp-Aust.2) smaller than those regularly watered to field capacity. These numbers reflect the effect of a more prodigal water use strategy, since any experimental drought design that keeps soil water at a target level favours such strategies: plants with higher transpirations are irrigated with greater amounts of water. In a cyclic drought stress design, plants with higher rates of transpiration would have used the available water earlier, and subsequently would have reduced stomatal conductance to a minimum earlier, thus limiting their biomass production to a greater extent. Both kinds of experimental design induce artificial effects, since, especially in forest trees, growth in limited and fast drying rooting space without competition does not occur in nature, either.

In conclusion, genotypic differences between the four birch clones were detected with regard to physiological, biochemical, and morphological characters. 
With regard to specific leaf areas, similarities were greatest between the two Austrian clones, thus reflecting the greater genetic similarity as calculated from the analysis of 6 isoenzymes, and the spatial vicinity of their places of origin. However, foliar chlorophyll contents, leaf sizes and photosynthetic capacities were most similar between Bp-Aust.1 and Bp-Swed. on the one hand, and Bp-Aust.2 and Bp-Germ. on the other.

Plasticity of many characters was highest in the German genotype and Bp-Aust.1, which therefore exhibited similarities although both genetic and spatial distances between them and their places of origin are greater than between other genotypes. The smallest amount of heterozygosity in this investigation was measured in Bp-Aust.2, which exhibited the smallest amount of plasticity in many of the analysed characters. On the other hand, the German genotype was heterozygot for 3 of the 6 investigated isozymes, thus exhibiting the highest degree of heterozygosity, but also responded most plastic in many characters. However, the analysis of 6 enzyme systems is by far not enough to draw conclusions about genetic similarities and to relate them to phenotypes. JASIENSKI et al. (1997) attempted to study the underlying genetic basis of phenotypic plasticity within genotypes of Abutilon theophrasti by analysing 400 RAPD loci and concluded from their results that satisfactory sampling of genome similarity via RAPD analysis in higher organisms would require thousands of bands. WANG (1996) tried to correlate growth vigour with heterozygosity in fast- and slow-growing families and three generations of selfing of Betula pendula. They found no differences in allozyme variability between the family groups of differential growth and stem volume was not correlated to the degree of heterozygosity. Allozyme variability was only reduced in advancing generations of selfing, in which decreasing heterozygosity was related to decreasing growth.

Analysis of the water use strategies of the clones supported the ecological hypothesis of SCHLICHTING and LEVIN (1984) as a factor influencing phenotypic plasticity. With regard to capacities of stomatal conductance, the response of patterns of allocation, and the capacity for osmotic adjustment (which is known to be heritable, LÖSCH 2001), the results of this study suggest a more prodigal and more plastic water use strategy for the German and the Swedish genotypes than for the Austrian ones, especially for Bp-Aust.2. Precipitation at the places of origin of the German and Swedish trees is less than half the amount than at the place of origin of the Austrian plants. Since competition for water is highest on sites where water is limiting (TILMAN 1980), and a prodigal water use strategy exhibits high competitive ability for water (THOMPSON 1987; ZHANG et al. 1997), these genotypes seem to be better adapted to drier sites than the Austrian ones. 
Table 5.5.: Ranking of the relative plasticity of 40 physiological, biochemical, morphological, production, and allocation parameters measured in the summer of 2000. For definition of relative plasticity see Tab. 5.2 $00=$ relative plasticity $(r p)<10 \%, 0=r p 10-20 \%,+=r p 20-40 \%,++=r p 40-60 \%,+++$ $=r p 60-80 \%$, and $++++=r p>80 \%$

\begin{tabular}{|c|c|c|c|c|}
\hline parameter & Bp-Aust.1 & Bp-Aust.2 & Bp-Swed. & Bp-Germ. \\
\hline leaf area based nitrogen content $\left[\mathrm{g} \mathrm{m}^{-2}\right]$ & 00 & 00 & 00 & 00 \\
\hline$\Pi_{0}[\mathrm{MPa}]$ & 00 & 00 & 00 & 00 \\
\hline$\Pi_{\mathrm{p}}[\mathrm{MPa}]$ & 0 & 00 & 00 & 00 \\
\hline total fine root necromass $[\mathrm{g}]$ & 00 & 00 & 0 & 00 \\
\hline root:shoot mass ratio $\left[\mathrm{g} \mathrm{g}^{-1}\right]$ & 0 & 00 & 00 & 00 \\
\hline fine root:leaf area ratio $\left[\mathrm{cm}^{2} \mathrm{~cm}^{-2}\right]$ & 0 & 00 & 00 & 00 \\
\hline specific fine root surface area $\left[\mathrm{cm}^{2} \mathrm{~g}^{-1}\right]$ & 00 & 00 & 0 & 0 \\
\hline$\delta^{13} \mathrm{C}$ value $[\% o]$ & 0 & 00 & 00 & 0 \\
\hline leaf area based $A_{\max }\left[\mu \mathrm{mol} \mathrm{m}^{-2} \mathrm{~s}^{-1}\right]$ & 0 & 00 & 00 & 0 \\
\hline chlorophyll content based $A_{\max }\left[\mu \mathrm{mol} \mathrm{g} \mathrm{chl.}{ }^{-1} \mathrm{~s}^{-1}\right]$ & 0 & 0 & 0 & 00 \\
\hline tree height $[\mathrm{cm}]$ & 0 & 0 & 00 & + \\
\hline specific leaf area $\left[\mathrm{cm}^{2} \mathrm{~g}^{-1}\right]$ & + & 0 & 0 & 0 \\
\hline fine root:leaf mass ratio $\left[\mathrm{g} \mathrm{g}^{-1}\right]$ & + & 0 & 0 & 0 \\
\hline leaf size $\left[\mathrm{cm}^{2}\right]$ & + & + & 00 & 0 \\
\hline number of root tips per $\mathrm{g}$ DW & 00 & 0 & + & + \\
\hline $\mathrm{C} / \mathrm{N}$ ratio $\left[\mathrm{g} \mathrm{g}^{-1}\right]$ & + & + & 00 & 0 \\
\hline $\mathrm{CO}_{2 \text { sat }}[\mathrm{ppm}]$ & 00 & 0 & + & + \\
\hline$\epsilon_{\max }[\mathrm{MPa}]$ & 00 & 0 & + & + \\
\hline dry weight based nitrogen content [\% DW] & + & + & 00 & 0 \\
\hline$c_{\mathrm{i}}[\mathrm{ppm}]$ & + & 0 & 0 & + \\
\hline $\mathrm{CE}\left[\mu \mathrm{mol} \mathrm{m}^{-2} \mathrm{~s}^{-1} \mathrm{ppm}^{-1}\right]$ & 00 & 0 & + & ++ \\
\hline leaf area based chlorophyll content $\left[\mathrm{g} \mathrm{m}^{-2}\right]$ & + & + & 0 & + \\
\hline$A_{\mathrm{amb}}\left[\mu \mathrm{mol} \mathrm{m}^{-2} \mathrm{~s}^{-1}\right]$ & + & + & + & + \\
\hline Potassium content $\left[\mathrm{mmol} \mathrm{kg}^{-1}\right]$ & + & 0 & + & ++ \\
\hline$\Psi_{\min }[\mathrm{MPa}]$ & + & ++ & + & ++ \\
\hline relative fine root necromass [\% of total fine root dry mass] & ++ & ++ & ++ & + \\
\hline total root dry mass $[\mathrm{g}]$ & ++ & ++ & + & ++ \\
\hline total fine root dry mass $[\mathrm{g}]$ & ++ & ++ & + & ++ \\
\hline total fine root surface area $\left[\mathrm{cm}^{2}\right]$ & ++ & ++ & + & ++ \\
\hline photosynthetic WUE $\left[\mu \mathrm{mol} \mathrm{mmol}^{-1}\right]$ & +++ & + & + & +++ \\
\hline$\Psi_{\text {pre }}[\mathrm{MPa}]$ & ++ & ++ & + & +++ \\
\hline total shoot dry mass $[\mathrm{g}]$ & +++ & ++ & ++ & ++ \\
\hline total leaf area $\left[\mathrm{cm}^{2}\right]$ & +++ & ++ & ++ & ++ \\
\hline living fine root biomass $[\mathrm{g}]$ & +++ & +++ & + & +++ \\
\hline daily maximum of $g_{\text {sw-max }}\left[\mathrm{mmol} \mathrm{m}^{-2} \mathrm{~s}^{-1}\right]$ & ++++ & +++ & ++ & +++ \\
\hline total leaf dry mass [g] & ++++ & ++ & + & +++ \\
\hline total plant dry mass $[\mathrm{g}]$ & ++++ & ++++ & +++ & +++ \\
\hline average daily $g_{\mathrm{sw}-\operatorname{mean}}\left[\mathrm{mmol} \mathrm{m}^{-2} \mathrm{~s}^{-1}\right]$ & ++++ & ++++ & ++++ & ++++ \\
\hline daily maximum of $E_{\max }\left[\mathrm{mmol} \mathrm{m}^{-2} \mathrm{~s}^{-1}\right]$ & ++++ & ++++ & ++++ & ++++ \\
\hline average daily $E_{\text {mean }}\left[\mathrm{mmol} \mathrm{m}^{-2} \mathrm{~s}^{-1}\right]$ & ++++ & ++++ & ++++ & ++++ \\
\hline
\end{tabular}




\section{Summary}

Young trees of four clones of Betula pendula from origins with different amounts of precipitation were subjected to prolonged drought periods (12 to 14 weeks with soil water contents below 3 vol\%) in two subsequent summers.

The aims of this study were: (1) to investigate the drought response of silver birch in a multi-level approach and to elucidate the basis of the particularly wide physiological amplitude of this species and (2) to analyse variation in drought responses of different genotypes in order to assess phenotypic plasticities of the genotypes and to identify potential genotypic differences with regard to their adaptability to drought.

Responses of different physiological, biochemical, and morphological parameters to water shortage were analysed. $\mathrm{CO}_{2}$ and $\mathrm{H}_{2} \mathrm{O}$ gas exchange were investigated under ambient and elevated $\mathrm{CO}_{2}$ concentration to assess responses of stomatal conductance and the photosynthetic apparatus. Leaf water status and osmotic adjustment were analysed with the pressure-chamber technique and pressure volume curves. Analysis of foliar chlorophyll and nitrogen contents revealed biochemical responses to drought, while the investigation of bulk leaf tissue carbon isotopic composition yielded information about water use efficiencies. Finally, harvests of the trees and measurement of root and leaf surface areas showed responses of within-organ and between-organ allocation.

The following results were obtained:

1. Reduction of stomatal conductance was the first and most plastic response of silver birch to water shortage, thus postponing damaging effects of drought and effectively maintaining predawn leaf water potentials; non-stomatal limitations of photosynthesis were not detected.

2. Silver birch appeared to be capable of osmotic adjustment, which was mainly used during the phase of establishment in the first year of investigation, when deeper soil horizonts with higher water contents had not yet been explored.

3. Marked responses of total leaf area and the especially plastic phenology of this species have to be classified as adaptations to drought.

4. Both within-organ and between-organ allocation of biomass responded to drought.

5. Genotypes from drier locations displayed higher degrees of osmotic adjustment than those from origins with better water supply, although their osmotic potentials were not lower under ample water supply.

6. Genotypes from drier locations reached higher stomatal conductances under both well watered and drought stressed conditions. 
7. Particularly the German genotype, which originated from a stand prone to summer drought, displayed a more prodigal water use strategy than the Austrian genotypes from origins with higher amounts of precipitation. This prodigal strategy in combination with effective mechanisms of both drought avoidance and tolerance is classified as highly competitive and adapted to habitats with edaphic summer droughts.

In conclusion, all investigated clones of silver birch reached the high rates of stomatal conductance and net assimilation typical for early-successional trees. Genotypes from all origins responded to water shortage by marked mechanisms of drought avoidance on all levels of plant performance; highest degrees of phenotypic plasticity were observed with regard to $\mathrm{H}_{2} \mathrm{O}$ and $\mathrm{CO}_{2}$ gas exchange and leaf area. The extent of response, however, appeared to be partly affected by adaptations to places of origin, with the genotypes from drier locations displaying a tendency for more prodigal water use strategies. 


\section{A. Plasticity}

Table A.1.: Relative plasticity [\%] of the four clones with regard to the to the water status parameters as measured with the pressure chamber and calculated from pressure-volume curves. The parameters shown are the minimum and maximum of the leaf water potential ( $\Psi_{\min }$ and $\left.\Psi_{\text {pre }}\right)$, the osmotic potentials as saturation and at the turgor loss point $\left(\Pi_{0}\right.$ and $\left.\Pi_{\mathrm{p}}\right)$, and the modulus of elasticity $\left(\epsilon_{\max }\right)$. The values of $\Psi$ were averaged over 4 dates of measurement from early June to late August of both1999 and 2000, those of the osmotic potentials and $\epsilon_{\max }$ were averaged over 3 dates from early July to late August. Asterisks indicate significant differences $(P \leq 0.05)$ between the W99W00- and the D99D00-treatment in all measurements, $(*)$ show such significant differences in only part of the measurements.

\begin{tabular}{lllllllll}
\hline parameter & Aust.1 & Aust.2 & Swed. & Germ. & Aust.1 & Aust.2 & Swed. & Germ. \\
\hline & 1999 & & & & 2000 & & & \\
\hline$\Psi_{\text {pre }}$ & $42(*)$ & $33(*)$ & $19(*)$ & $32(*)$ & $47(*)$ & $54(*)$ & $34(*)$ & $61 *$ \\
$\Psi_{\min }$ & $12(*)$ & $16(*)$ & $15(*)$ & $14(*)$ & $31(*)$ & $42(*)$ & $29(*)$ & $42 *$ \\
$\Pi_{0}$ & $19(*)$ & 11 & $14(*)$ & $14(*)$ & 14 & 4 & $7(*)$ & $10(*)$ \\
$\Pi_{\mathrm{p}}$ & 7 & 14 & $15(*)$ & $19 *$ & 8 & 5 & $8(*)$ & 3 \\
$\epsilon_{\max }$ & $31 *$ & $34(*)$ & $40(*)$ & 24 & 10 & 12 & 24 & 23 \\
\hline
\end{tabular}

Table A.2.: Relative plasticity [\%] of the four clones with regard to the water exchange parameters as calculated from measurements with the LI-1600 steady-state porometer. $g_{\text {sw-max }}$ and $g_{\text {sw-mean }}$ are the maximal stomatal conductance to water vapour measured in the morning (7:00 to 9:00 solar time) and the daily means of stomatal conductance, while $\mathrm{E}_{\max }$ and $\mathrm{E}_{\text {mean }}$ represent the respective rates of transpiration. The values were averaged over 3 measurement dates in August 2000. Asterisks indicate significant differences $(P \leq 0.05)$ between the W99W00- and the D99D00-treatment in all measurements, $(*)$ show such significant differences in only part of the measurements

\begin{tabular}{lllll}
\hline parameter & Bp-Aust.1 & Bp-Aust.2 & Bp-Swed. & Bp-Germ. \\
\hline$g_{\text {sw-max }}\left[\mathrm{mmol} \mathrm{m}^{-2} \mathrm{~s}^{-1}\right]$ & $92 *$ & $75\left(^{*}\right)$ & $56 *$ & $62\left(^{*}\right)$ \\
$g_{\text {sw-mean }}\left[\mathrm{mmol} \mathrm{m}^{-2} \mathrm{~s}^{-1}\right]$ & $104 *$ & $101^{*}$ & $80^{*}$ & $93 *$ \\
$E_{\max }\left[\mathrm{mmol} \mathrm{m}^{-2} \mathrm{~s}^{-1}\right]$ & $89 *$ & $108\left(^{*}\right)$ & $104 *$ & $88\left(^{*}\right)$ \\
$E_{\operatorname{mean}}\left[\mathrm{mmol} \mathrm{m}^{-2} \mathrm{~s}^{-1}\right]$ & $103 *$ & $108 *$ & $87 *$ & $98 *$ \\
\hline
\end{tabular}


Table A.3.: Relative plasticity [\%] of the four clones with regard to the daily means of gas-exchange parameters as calculated from measurements with the LI-6400 system. The parameters shown are net photosynthesis $\left(A_{\mathrm{amb}}\right)$, stomatal conductance $\left(g_{\mathrm{sw}}\right)$, transpiration $(E)$, leaf internal $\mathrm{CO}_{2}$ concentration $\left(c_{\mathrm{i}}\right)$, and photosynthetic water use efficiency WUE. $\left(c_{\mathrm{a}}=360 \mathrm{ppm}\right.$, PPFD $=1500-0 \mu$ mol photons $\mathrm{m}^{-2} \mathrm{~s}^{-1}, T_{\text {leaf }}=22{ }^{\circ} \mathrm{C}$ and VPD $=1 \mathrm{kPa}$ ). The values were averaged over 5 dates of measurement from early June to late August of each 1999 and 2000. Asterisks indicate significant differences $(P \leq$ 0.05) between the W99W00- and the D99D00-treatment in all measurements, $\left(^{*}\right)$ show such significant differences in only part of the measurements

\begin{tabular}{|c|c|c|c|c|c|c|c|c|}
\hline parameter & Aust.1 & Aust.2 & Swed. & Germ. & Aust.1 & Aust.2 & Swed. & Germ. \\
\hline & 1999 & & & & 2000 & & & \\
\hline$A_{\mathrm{amb}}\left[\mu \mathrm{mol} \mathrm{m}^{-2} \mathrm{~s}^{-1}\right]$ & $43(*)$ & $32(*)$ & $23(*)$ & $25(*)$ & $38(*)$ & $24(*)$ & $37(*)$ & $22(*)$ \\
\hline$g_{\mathrm{sw}}\left[\mathrm{mmol} \mathrm{m}^{-2} \mathrm{~s}^{-1}\right]$ & $81 *$ & $57(*)$ & $59(*)$ & $93 *$ & $98 *$ & $61(*)$ & $78 *$ & $97 *$ \\
\hline$E\left[\mathrm{mmol} \mathrm{m}^{-2} \mathrm{~s}^{-1}\right]$ & $73 *$ & $51(*)$ & $49(*)$ & $81 *$ & $89 *$ & $55(*)$ & $71 *$ & $86 *$ \\
\hline$c_{\mathrm{i}}[\mathrm{ppm}]$ & $20(*)$ & $9(*)$ & $11(*)$ & $22 *$ & $29 *$ & $18(*)$ & $19 *$ & $33 *$ \\
\hline WUE $\left[\mu \mathrm{mol} \mathrm{mmol}{ }^{-1}\right]$ & $40(*)$ & $20(*)$ & $28(*)$ & $63 *$ & $63 *$ & $33(*)$ & $38 *$ & $69 *$ \\
\hline
\end{tabular}

Table A.4.: Relative plasticity [\%] of the four clones with regard to the gas-exchange parameters calculated from $\mathrm{CO}_{2}$ response curves in early August 1999 and 2000. Relative plasticities of photosynthetic capacity $\left(A_{\max }\right)$ per leaf area and per gram chlorophyll, carboxylation efficiency $(\mathrm{CE})$, and saturating $\mathrm{CO}_{2}$ concentration $\left(\mathrm{CO}_{2 \text { sat }}\right)$ are shown. Asterisks indicate significant differences $(P \leq 0.05)$ between the W99W00- and the D99D00-treatment.

\begin{tabular}{lllllllll}
\hline parameter & Aust.1 & Aust.2 & Swed. & Germ. & Aust.1 & Aust.2 & Swed. & Germ. \\
\hline & 1999 & & & \multicolumn{7}{c}{2000} \\
\hline$A_{\max }\left[\mu \mathrm{mol} \mathrm{m}^{-2} \mathrm{~s}^{-1}\right]$ & 7 & 9 & 10 & 16 & 15 & 3 & 5 & 14 \\
$A_{\max }\left[\mu \mathrm{mol} \mathrm{g} \mathrm{chl.}^{-1} \mathrm{~s}^{-1}\right]$ & 11 & $20 *$ & $20 *$ & 13 & $15 *$ & $16 *$ & 20 & 6 \\
$\mathrm{CE}\left[\mu \mathrm{mol} \mathrm{m}^{-2} \mathrm{~s}^{-1} \mathrm{ppm}^{-1}\right]$ & 19 & 0 & 5 & 13 & 2 & 18 & 26 & $50 *$ \\
$\mathrm{CO}_{2 \text { sat }}[\mathrm{ppm}]$ & 9 & 8 & 12 & 2 & 10 & 14 & 29 & 26 \\
\hline
\end{tabular}

Table A.5.: Relative plasticity [\%] of the four clones with regard to the nitrogen and chlorophyll contents and the carbon isotope composition of their leaves. Plasticities of three sampling dates ( 5 dates for the chlorophyll measurements) in July and August of both 1999 and 2000 were averaged. Asterisks indicate significant differences $(P \leq 0.05)$ between the W99W00- and the D99D00-treatment.

\begin{tabular}{|c|c|c|c|c|c|c|c|c|}
\hline parameter & Aust.1 & Aust.2 & Swed. & Germ. & Aust.1 & Aust.2 & Swed. & Germ. \\
\hline & 1999 & & & & 2000 & & & \\
\hline$\delta^{13} C[\% o]$ & $8 *$ & $6 *$ & $5(*)$ & $7 *$ & $11 *$ & $8 *$ & $6 *$ & $11 *$ \\
\hline $\mathrm{N}$-content $[\%$ of DW] & 1 & 2 & $8(*)$ & $10(*)$ & $31 *$ & $23 *$ & 8 & $17 *$ \\
\hline $\mathrm{N}$-content $\left[\mathrm{g} \mathrm{m}^{-2}\right]$ & 4 & $12 *$ & $2(*)$ & 1 & 1 & 9 & 8 & 3 \\
\hline $\mathrm{C} / \mathrm{N}$ ratio $\left[\mathrm{g} \mathrm{g}^{-1}\right]$ & 5 & 3 & $8(*)$ & $10(*)$ & $28 *$ & $23 *$ & $8(*)$ & $17 *$ \\
\hline chlorophyll content $\left[\mathrm{g} \mathrm{m}^{-2}\right]$ & 3 & $4(*)$ & $3(*)$ & $18(*)$ & $28 *$ & $28 *$ & $16 *$ & $22 *$ \\
\hline
\end{tabular}


Table A.6.: Relative plasticity [\%] of the four clones with regard to the morphology of the third and fourth leaves (counted from the terminal bud of a twig). Asterisks indicate significant differences $(P \leq$ 0.05) between the W99W00- and the D99D00-treatment.

\begin{tabular}{lllllllll}
\hline parameter & Aust.1 & Aust.2 & Swed. & Germ. & Aust.1 & Aust.2 & Swed. & Germ. \\
\hline & 1999 & & & & 2000 & & & \\
\hline average leaf size $\left[\mathrm{cm}^{2}\right]$ & 3 & 2 & 20 & 14 & $22 *$ & 21 & 6 & $16 *$ \\
specific leaf area $\left[\mathrm{cm}^{2} \mathrm{~g}^{-1}\right]$ & 5 & $15 *$ & 8 & $10 *$ & $30 *$ & $14 *$ & $19 *$ & $16 *$ \\
\hline
\end{tabular}

Table A.7.: Relative plasticity [\%] of the four clones with regard to the morphology of their fine roots 2000. Asterisks indicate significant differences $(P \leq 0.05)$ between the W99W00- and the D99D00treatment.

\begin{tabular}{lllll}
\hline parameter & Aust.1 & Aust.2 & Swed. & Germ. \\
\hline root tips per mg DW & 10 & 17 & 40 & 32 \\
specific surface area $\left[\mathrm{cm}^{2} \mathrm{~g}^{-1}\right.$ ] & 4 & 2 & 12 & 17 \\
fine root biomass [g DW] & $63 *$ & $64 *$ & $37 *$ & $68 *$ \\
fine root necromass [g DW] & 5 & 1 & 20 & 8 \\
percentage of necromass & $52 *$ & $46 *$ & $53 *$ & $39 *$ \\
\hline
\end{tabular}

Table A.8.: Relative plasticity [\%] of the four clones with regard to pattern of allocation in 2000. Asterisks indicate significant differences $(P \leq 0.05)$ between the W99W00- and the D99D00-treatment.

\begin{tabular}{lllll}
\hline parameter & Bp-Aust.1 & Bp-Aust.2 & Bp-Swed. & Bp-Germ. \\
\hline tree height [cm] & 12 & 14 & 10 & 24 \\
total biomass [g DW] & $94 *$ & $89 *$ & $72 *$ & $80 *$ \\
aboveground biomass [g DW] & $66 *$ & $54 *$ & $45 *$ & $50 *$ \\
belowground biomass [g DW] & $56 *$ & $60 *$ & $37 *$ & $50 *$ \\
leaf mass [g DW] & $81 *$ & $58 *$ & $39 *$ & $61 *$ \\
total leaf area [cm ${ }^{2}$ ] & $64 *$ & $50 *$ & $43 *$ & $48 *$ \\
fine root mass [g DW] & $49 *$ & $44 *$ & 23 & $47 *$ \\
total fine root area [ cm ${ }^{2}$ ] & $53 *$ & 46 & $34 *$ & $54 *$ \\
root:shoot mass ratio & 12 & 5 & 8 & 0 \\
fine root:leaf mass ratio & $37 *$ & 15 & $18 *$ & 14 \\
fine root:leaf area ratio & 12 & 4 & 9 & 8 \\
\hline
\end{tabular}




\section{B. Multivariate analyses of variance}

Table B.1.: Multivariate analysis of variance of the moduli of elasticity of bulk leaf tissue $\left(\epsilon_{\max }\right)$. Influences of the factors clone and treatment were tested with a repeated measurements glm design. Samples of 4 trees of each treatment and clone were analysed on 4 dates. The results of the univariate test of hypotheses for within subject effects are shown with $P>F$ adjusted with the Greenhouse-Geisser $\epsilon$.

\begin{tabular}{lcrrrrrrr}
\hline source & DF & Type III SS & F value & $\operatorname{Pr}>F$ & DF & Type III SS & F value & $\operatorname{Pr}>F$ \\
\hline & 1999 & & & \multicolumn{7}{c}{2000} \\
\hline date & 3 & 22.5625 & 3.70 & 0.0224 & 3 & 617.7327 & 43.72 & $<0.0001$ \\
date*treatment & 3 & 9.3931 & 1.54 & 0.2206 & 6 & 43.8534 & 1.55 & 0.1755 \\
date*clone & 9 & 22.0115 & 1.20 & 0.3195 & 9 & 155.9565 & 3.68 & 0.0008 \\
date*treatment*clone & 9 & 15.9280 & 0.87 & 0.5477 & 18 & 22.2921 & 0.26 & 0.9983 \\
error (date) & 48 & 97.4689 & & & 93 & 437.9631 & & \\
\hline
\end{tabular}

Table B.2.: Multivariate analysis of variance of the maxima of stomatal conductance measured in 2000 . Influences of the factors clone and treatment were tested with a repeated measurements glm design. Measurements on 6 leaves of different trees per treatment and clone on 4 dates were analysed. The results of the univariate test of hypotheses for within subject effects are shown with $P>F$ adjusted with the Greenhouse-Geisser $\epsilon$.

\begin{tabular}{lrrrr}
\hline source & DF & Type III SS & F value & $P r>$ F \\
\hline date & 3 & 794579 & 92.90 & $<0.0001$ \\
date*treatment & 3 & 93856 & 10.97 & $<0.0001$ \\
date*clone & 9 & 110644 & 4.31 & 0.0004 \\
date*treatment*clone & 9 & 30697 & 1.20 & 0.3127 \\
error (date) & 120 & 342126 & & \\
\hline
\end{tabular}


Table B.3.: Multivariate analysis of variance of gas exchange parameters obtained from $\mathrm{CO}_{2}$ response curves measured in August 1999 and 2000. Analyses are based on measurements on 5 (1999) of 4 (2000) leaves of different trees per treatment and clone. Results of two-way ANOVA on the effects of the clone and the treatment as well as their interrelation are shown.

\begin{tabular}{|c|c|c|c|c|c|c|c|c|}
\hline source & $\mathrm{DF}$ & Type III SS & F value & $\operatorname{Pr}>F$ & DF & Type III SS & $F$ value & $\operatorname{Pr}>F$ \\
\hline & \multicolumn{4}{|c|}{$A_{\max }\left[\mu \mathrm{mol} \mathrm{m}^{-2} \mathrm{~s}^{-1}\right] 1999$} & \multicolumn{4}{|c|}{$A_{\max }\left[\mu \mathrm{mol} \mathrm{m}^{-2} \mathrm{~s}^{-1}\right] 2000$} \\
\hline model & 7 & 270.60 & 5.77 & 0.0002 & 11 & 45.48 & 1.82 & 0.0874 \\
\hline error & 32 & 214.29 & & & 36 & 81.94 & & \\
\hline clone & 3 & 216.23 & 10.76 & $<0.0001$ & 3 & 18.68 & 2.74 & 0.0578 \\
\hline treatment & 1 & 6.46 & 0.97 & 0.3333 & 2 & 5.01 & 1.10 & 0.3439 \\
\hline \multirow[t]{2}{*}{ clone*treatment } & 3 & 47.91 & 2.38 & 0.0875 & 6 & 21.80 & 1.60 & 0.1766 \\
\hline & \multicolumn{4}{|c|}{$A_{\max }\left[\mu \mathrm{mol} \mathrm{g} \mathrm{chl.}{ }^{-1} \mathrm{~s}^{-1}\right] 1999$} & \multicolumn{4}{|c|}{$A_{\max }\left[\mu \mathrm{mol} \mathrm{g} \mathrm{chl.}{ }^{-1} \mathrm{~s}^{-1}\right] 2000$} \\
\hline model & 7 & 2263 & 6.31 & 0.0001 & 11 & 3279 & 15.41 & $<0.0001$ \\
\hline error & 32 & 1639 & & & 36 & 696 & & \\
\hline clone & 3 & 963 & 6.26 & 0.0018 & 3 & 2639 & 45.48 & $<0.0001$ \\
\hline treatment & 1 & 1205 & 23.51 & $<0.0001$ & 2 & 398 & 10.28 & 0.0003 \\
\hline \multirow{2}{*}{ clone*treatment } & 3 & 95 & 0.62 & 0.6068 & 6 & 252 & 2.09 & 0.0790 \\
\hline & \multicolumn{4}{|c|}{$\mathrm{CE}\left[\mu \mathrm{mol} \mathrm{m}{ }^{-2} \mathrm{~s}^{-1} \mathrm{ppm}^{-1}\right] 1999$} & \multicolumn{4}{|c|}{$\mathrm{CE}\left[\mu \mathrm{mol} \mathrm{m}^{-2} \mathrm{~s}^{-1} \mathrm{ppm}^{-1}\right] 2000$} \\
\hline model & 7 & 0.0153 & 15.08 & $<0.0001$ & 11 & 0.0053 & 3.04 & 0.0058 \\
\hline error & 32 & 0.0046 & & & 36 & 0.0057 & & \\
\hline clone & 3 & 0.0145 & 33.53 & $<0.0001$ & 3 & 0.0013 & 2.66 & 0.0626 \\
\hline treatment & 1 & 0.0000 & 0.00 & 0.9656 & 2 & 0.0027 & 8.61 & 0.0009 \\
\hline \multirow[t]{2}{*}{ clone*treatment } & 3 & 0.0007 & 1.65 & 0.1969 & 6 & 0.0013 & 1.36 & 0.2555 \\
\hline & \multicolumn{4}{|c|}{$\mathrm{CO}_{\text {2sat }}[\mathrm{ppm}] 1999$} & \multicolumn{4}{|c|}{$\mathrm{CO}_{2 \text { sat }}[\mathrm{ppm}] 2000$} \\
\hline model & 7 & 231757 & 11.11 & $<0.0001$ & 11 & 136463 & 3.08 & 0.0052 \\
\hline error & 32 & 95356 & & & 36 & 144778 & & \\
\hline clone & 3 & 211371 & 23.64 & $<0.0001$ & 3 & 33086 & 2.74 & 0.0573 \\
\hline treatme & 1 & 533 & 0.18 & 0.6753 & 2 & 43952 & 10.93 & 0.0002 \\
\hline clone*treatment & 3 & 19853 & 2.22 & 0.1049 & 6 & 2579 & 0.64 & 0.6965 \\
\hline
\end{tabular}


Table B.4.: Multivariate analysis of variance of some leaf gas exchange parameters measured under constant low VPD in 1999 and 2000. Influences of the factors clone and treatment were tested with a repeated measurements glm design. Measurements on 5 leaves of different trees per treatment and clone on 6 dates were analysed. Results of the univariate test of hypotheses for within-subject-effects are shown with $P>F$ adjusted with the Greenhouse-Geisser $\epsilon$.

\begin{tabular}{|c|c|c|c|c|c|c|c|c|}
\hline source & $\mathrm{DF}$ & Type III SS & F value & $\operatorname{Pr}>\mathrm{F}$ & DF & Type III SS & F value & $\operatorname{Pr}>F$ \\
\hline & \multicolumn{4}{|c|}{$g_{\mathrm{sw}}\left[\mathrm{mmol} \mathrm{m}^{-2} \mathrm{~s}^{-1}\right] 1999$} & \multicolumn{4}{|c|}{$g_{\mathrm{sw}}\left[\mathrm{mmol} \mathrm{m}^{-2} \mathrm{~s}^{-1}\right] 2000$} \\
\hline date & 5 & 3.6311 & 63.05 & $<0.0001$ & 5 & 2.1558 & 72.70 & $<0.0001$ \\
\hline date*treatment & 5 & 0.7016 & 12.18 & $<0.0001$ & 10 & 0.2573 & 4.34 & 0.0003 \\
\hline date*clone & 15 & 0.6399 & 3.70 & 0.0001 & 15 & 0.4222 & 4.75 & $<0.0001$ \\
\hline date*treatment*clone & 15 & 0.1079 & 0.62 & 0.8098 & 30 & 0.2204 & 1.24 & 0.2332 \\
\hline \multirow[t]{2}{*}{ error (date) } & 160 & 1.8430 & & & 180 & 1.0675 & & \\
\hline & \multicolumn{4}{|c|}{$A_{\mathrm{amb}}\left[\mu \mathrm{mol} \mathrm{m}^{-2} \mathrm{~s}^{-1}\right] 1999$} & \multicolumn{4}{|c|}{$A_{\text {amb }}\left[\mu \mathrm{mol} \mathrm{m}^{-2} \mathrm{~s}^{-1}\right] 2000$} \\
\hline date & 5 & 1826 & 70.66 & $<0.0001$ & 5 & 1733 & 62.23 & $<0.0001$ \\
\hline date*treatment & 5 & 457 & 17.69 & $<0.0001$ & 10 & 220 & 3.95 & 0.0005 \\
\hline date*clc & 15 & 380 & 4.91 & $<0.0001$ & 15 & 107 & 1.28 & 0.2443 \\
\hline nt*clone & 15 & 137 & 1.77 & 0.0722 & 30 & 128 & 0.77 & 0.7612 \\
\hline \multirow[t]{2}{*}{ error (date } & 160 & 827 & & & 180 & 1002 & & \\
\hline & \multicolumn{4}{|c|}{$c_{\mathrm{i}}[\mathrm{ppm}] 1999$} & \multicolumn{4}{|c|}{$c_{\mathrm{i}}[\mathrm{ppm}] 2000$} \\
\hline date & 5 & 89065 & 32.13 & $<0.0001$ & 5 & 44418 & 20.67 & $<0.0001$ \\
\hline date*treatment & 5 & 47625 & 17.18 & $<0.0001$ & 10 & 32894 & 7.66 & $<0.0001$ \\
\hline date*clone & 15 & 50600 & 6.08 & $<0.0001$ & 15 & 35086 & 5.44 & $<0.0001$ \\
\hline date*treatment*clone & 15 & 8909 & 1.07 & 0.3901 & 30 & 13892 & 1.08 & 0.3781 \\
\hline \multirow[t]{2}{*}{ error (date) } & 160 & 88704 & & & 180 & 77346 & & \\
\hline & \multicolumn{4}{|c|}{ WUE $\left[\mu \mathrm{mol} \mathrm{mmol}^{-1}\right] 1999$} & \multicolumn{4}{|c|}{ WUE $\left[\mu \mathrm{mol} \mathrm{mmol}^{-1}\right] 2000$} \\
\hline date & 5 & 243.18 & 29.20 & $<0.0001$ & 5 & 78.85 & 10.76 & $<0.0001$ \\
\hline date*treatment & 5 & 157.97 & 18.97 & $<0.0001$ & 10 & 103.70 & 7.08 & $<0.0001$ \\
\hline date*clone & 15 & 141.56 & 5.67 & $<0.0001$ & 15 & 138.69 & 6.31 & $<0.0001$ \\
\hline date*treatment*clone & 15 & 28.75 & 1.15 & 0.3162 & 30 & 43.41 & 0.99 & 0.4845 \\
\hline error (date) & 160 & 266.52 & & & 180 & 263.81 & & \\
\hline
\end{tabular}

Table B.5.: Multivariate analysis of variance of $\delta 13 \mathrm{C}$ values of bulk leaf tissue. Influences of the factors clone and treatment were tested with a repeated measurements glm design. Samples of 4 trees of each treatment and clone were analysed on 4 dates. Results of the univariate test of hypotheses for withinsubject-effects are shown with $P>F$ adjusted with the Greenhouse-Geisser $\epsilon$.

\begin{tabular}{lcrrrrrrr}
\hline source & DF & Type III SS & F value & $\operatorname{Pr}>F$ & DF & Type III SS & F value & $\operatorname{Pr}>F$ \\
\hline & 1999 & & & \multicolumn{7}{c}{2000} \\
\hline date & 3 & 8.9268 & 10.64 & $<0.0001$ & 3 & 18.8980 & 17.42 & $<0.0001$ \\
date*treatment & 3 & 66.8211 & 79.64 & $<0.0001$ & 6 & 109.3228 & 50.40 & $<0.0001$ \\
date*clone & 9 & 18.5534 & 7.37 & $<0.0001$ & 9 & 12.3234 & 3.79 & 0.0002 \\
date*treatment*clone & 9 & 8.9238 & 3.55 & 0.0004 & 18 & 8.6164 & 1.32 & 0.1712 \\
error (date) & 216 & 60.4123 & & & 324 & 117.1365 & & \\
\hline
\end{tabular}


Table B.6.: Multivariate analysis of variance of foliar chlorophyll contents $\left[\mathrm{g} \mathrm{m}^{-2}\right]$. Influences of the factors clone and treatment were tested with a repeated measurements glm design. In 199910 leaves of each treatment and clone of different trees were examined on 6 dates, while in 20006 leaves each were examined on 5 dates. The results of the univariate test of hypotheses for within-subject-effects are shown with $P>F$ adjusted with the Greenhouse-Geisser $\epsilon$.

\begin{tabular}{lrrrrrrrr}
\hline source & DF & Type III SS & F value & $P r>F$ & DF & Type III SS & F value & $P r>F$ \\
\hline & 1999 & & & & 2000 & & & \\
\hline date & 5 & 0.3503 & 118.47 & $<0.0001$ & 4 & 0.1660 & 52.87 & $<0.0001$ \\
date*treatment & 5 & 0.0221 & 7.49 & $<0.0001$ & 8 & 0.0311 & 4.95 & 0.0002 \\
date*clone & 15 & 0.1357 & 15.30 & $<0.0001$ & 12 & 0.0021 & 2.72 & 0.0073 \\
date*treatment*clone & 15 & 0.0188 & 2.12 & 0.0197 & 24 & 0.0472 & 2.50 & 0.0015 \\
error (date) & 360 & 0.2129 & & & 528 & 0.4145 & & \\
\hline
\end{tabular}

Table B.7.: Multivariate analysis of variance of specific and total leaf areas as calculated from harvests in August 1999 and 2000. Results of two-way ANOVA on the effects of the clone and the treatment as well as their interrelation are shown.

\begin{tabular}{lrrrrrrrr}
\hline source & DF & Type III SS & $\mathrm{F}$ value & $P r>F$ & DF & Type III SS & F value & $P r>F$ \\
\hline & \multicolumn{7}{c}{ Specific leaf area $\left[\mathrm{cm}^{2} \mathrm{~g}^{-1}\right] 1999$} & \multicolumn{5}{c}{ Specific leaf area $\left[\mathrm{cm}^{2} \mathrm{~g}^{-1}\right]$} & 2000 \\
\hline model & 7 & 10542 & 14.71 & $<0.0001$ & 11 & 23648 & 24.39 & $<0.0001$ \\
error & 24 & 2458 & & & 60 & 5290 & & \\
clone & 3 & 8740 & 28.45 & $<0.0001$ & 3 & 12333 & 46.63 & $<0.0001$ \\
treatment & 1 & 1595 & 15.58 & 0.0006 & 2 & 9184 & 52.09 & $<0.0001$ \\
clone*treatment & 3 & 207 & 0.67 & 0.5771 & 6 & 2131 & 4.03 & 0.0019 \\
\hline \multicolumn{7}{r}{} & Total leaf area $\left[\mathrm{cm}^{2}\right] 1999$ & \multicolumn{5}{c}{ Total leaf area $\left[\mathrm{cm}^{2}\right]$} & 2000 & \\
\hline model & 7 & 1482969 & 211853 & $<0.0001$ & 11 & 86223129 & 17.35 & $<0.0001$ \\
error & 24 & 430214 & & & 60 & 27101823 & & \\
clone & 3 & 829676 & 15.43 & $<0.0001$ & 3 & 21181131 & 15.63 & $<0.0001$ \\
treatment & 1 & 454116 & 25.33 & $<0.0001$ & 2 & 55264784 & 61.17 & $<0.0001$ \\
clone*treatment & 3 & 199176 & 3.70 & 0.0254 & 6 & 9777213 & 3.61 & 0.004 \\
\hline
\end{tabular}


Table B.8.: Multivariate analysis of variance of specific and total fine root areas and fine root:leaf area ratios as calculated from the harvests of 6 trees of each treatment and clone in August 2000. Results of two-way ANOVA on the effects of the clone and the treatment as well as their interrelation are shown.

\begin{tabular}{lrrrrrrrr}
\hline source & DF & Type III SS & F value & $\operatorname{Pr}>F$ & DF & Type III SS & F value & $P r>F$ \\
\hline \multicolumn{7}{c}{ Specific fine root surface area $\left[\mathrm{cm}^{2} \mathrm{~g}^{-1}\right]$} & \multicolumn{1}{l}{ Total fine root surface } & area $\left[\mathrm{cm}^{2}\right]$ \\
\hline model & 11 & 302193 & 2.76 & 0.0066 & 11 & 1389197409 & 5.07 & $<0.0001$ \\
error & 54 & 538287 & & & 58 & 1443690818 & & \\
clone & 3 & 113219 & 3.79 & 0.0154 & 3 & 403153891 & 5.40 & 0.0024 \\
treatment & 2 & 52238 & 2.62 & 0.0820 & 2 & 817001955 & 16.41 & $<0.0001$ \\
clone*treatment & 6 & 119516 & 2.00 & 0.0819 & 6 & 172830037 & 1.16 & 0.3417 \\
\hline \multicolumn{7}{c}{ fine root:leaf area ratio } \\
\hline model & 11 & 83.03 & 7.55 & 0.0002 & & & & \\
error & 58 & 109.78 & & & & & & \\
clone & 3 & 75.20 & 13.24 & $<0.0001$ & & & & \\
treatment & 2 & 1.23 & 0.33 & 0.7234 & & & & \\
clone*treatment & 6 & 6.98 & 0.61 & 0.7174 & & & & \\
\hline
\end{tabular}

Table B.9.: Multivariate analysis of variance of root:shoot and fine root:leaf mass ratios as calculated from harvests of 4 trees of each treatment and clone in August 1999 and and 6 trees each in August 2000. Results of two-way ANOVA on the effects of the clone and the treatment as well as their interrelation are shown.

\begin{tabular}{|c|c|c|c|c|c|c|c|c|}
\hline source & $\mathrm{DF}$ & Type III SS & F value & $\operatorname{Pr}>F$ & $\mathrm{DF}$ & Type III SS & F value & $\operatorname{Pr}>F$ \\
\hline & \multicolumn{4}{|c|}{ root:shoot ratio 1999} & \multicolumn{4}{|c|}{ root:shoot ratio 2000} \\
\hline model & 7 & 1.4569 & 10.07 & $<0.0001$ & 11 & 0.5686 & 3.84 & 0.0003 \\
\hline error & 24 & 0.4961 & & & 60 & 0.8085 & & \\
\hline clone & 3 & 1.1858 & 19.12 & $<0.0001$ & 3 & 0.1647 & 4.08 & 0.0106 \\
\hline treatment & 1 & 0.1252 & 6.06 & 0.0214 & 2 & 0.1044 & 3.88 & 0.0261 \\
\hline \multirow[t]{2}{*}{ clone*treatment } & 3 & 0.1459 & 2.35 & 0.0974 & 6 & 0.2993 & 3.70 & 0.0034 \\
\hline & \multicolumn{4}{|c|}{ fine root:leaf mass ratio 1999} & \multicolumn{4}{|c|}{ fine root:leaf mass ratio 2000} \\
\hline model & 7 & 1.4056 & 3.86 & 0.0060 & 11 & 5.1655 & 7.74 & $<0.0001$ \\
\hline error & 24 & 1.2471 & & & 60 & 3.6420 & & \\
\hline clone & 3 & 0.3286 & 2.11 & 0.1258 & 3 & 1.9457 & 10.68 & $<0.0001$ \\
\hline treatment & 1 & 0.3290 & 6.33 & 0.0190 & 2 & 2.2124 & 18.22 & $<0.0001$ \\
\hline clone*treatment & 3 & 0.7480 & 4.80 & 0.0093 & 6 & 1.0074 & 2.77 & 0.0193 \\
\hline
\end{tabular}




\section{Bibliography}

Abrams, M. D. \& S. A. Mostoller (1995). Gas exchange, leaf structure and nitrogen in contrasting successional tree species growing in open and understory sites during a drought, Tree Physiology 15: 361-370.

ABRAMS, M. D. (1994). Genotypic and phenotypic variation of stress adaptions in temperate tree species: a review of several case studies, Tree Physiology 14: 833-842.

Alder, N. N., J. S. Sperry \& W. T. Pockman (1996). Root and stem xylem embolism, stomatal conductance, and leaf turgor in Acer grandidentatum populations along a soil moisture gradient, Oecologia 105: 293-301.

Arndt, S. K., S. C. Clifford, W. WaneK, H. G. Jones \& M. Popp (2001). Physiological and morphological adaptations of the fruit tree Ziziphus rotundifolia in response to progressive drought stress, Tree Physiology 21: 705-715.

BACKES, K. (1996). Der Wasserhaushalt vier verschiedener Baumarten der Heide-WaldSukzession, $\mathrm{PhD}$ thesis, Universität Göttingen, Göttingen.

BARtelink, H. H. (1998). A model of dry matter partitioning in trees, Tree Physiology 18: $91-101$.

BAzZAz, F. A. (1979). The physiological ecology of plant succession, Annual Review of Ecology and Systematics 10: 351-371.

BAZZAZ, F. A. (1996). Plants in changing environments, Cambridge University Press.

BeLL, G. \& M. J. LECHOWICZ (1994). Spatial heterogeneity at small scales and how plants respond to it, in M. M. CALDWELL \& R. P. PEARCY (eds), Exploitation of environmental heterogeneity by plants, Academic Press, Inc., San Diego, pp. 391-414.

Berntson, G. M., E. J. FARnsworth \& F. A. BAZZAZ (1995). Allocation, within and between organs, and the dynamics of root length changes in two birch species, Oecologia 101: 439-447.

Braun, H. J. (1970). Funktionelle Histologie der sekundären Sproßachse. I. Das Holz, Gebrüder Borntraeger, Berlin, Stuttgart.

BUCK, A. L. (1981). New equations for computing vapour pressure and enhancement factor, Journal of Applied Meteorology 20: 1527-1532. 
Chartzoulakis, K., A. Patakas \& A. Bosabalidis (1999). Comparative study on gas exchange, water relations and leaf anatomy of two olive cultivars grown under well-irrigated and drought conditions, Zeitschrift für Naturforschung 54c: 688-692.

Chaves, M. M. \& J. S. Pereira (1992). Water stress, $\mathrm{CO}_{2}$ and climate change, Journal of Experimental Botany 43(253): 1131-1139.

Cheliak, W. M. \& J. A. Pitel (1984). Techniques for starch gel electrophoresis of enzymes from forest tree species, Information report $\pi-x-42$.

CowAN, I. R. (1982). Water use and optimization of carbon assimilation, in O. L. LANGE, P. S. Nobel, C. B. OsMond \& H. ZIEGLER (eds), Encyclopedia of plant physiology 2. Physiological plant ecology, Vol. 12, pp. 589-630.

Dickson, R. E. \& P. T. TOMLinson (1996). Oak growth, development and carbon metabolism in response to water stress, Annales des Sciences Forrestieres 53: 181-196.

Dixon, M., D. LE Thiec \& J. P. GARrec (1995). The growth and gas exchange response of soil-planted Norway spruce [Picea abies (L.) Karst.] and red oak (Quercus rubra L.) exposed to elevated $\mathrm{CO}_{2}$ and naturally occurring drought, New Phytologist 129: 265-273.

Drew, M. C., L. R. SAKer \& T. W. Ashley (1975). Nutrient supply and the growth of the seminal root system in barley. I. The effect of nitrate concentration on the growth of axes and laterals, Journal of Experimental Botany 24: 1189-1202.

Dreyer, E. (1997). Photosynthesis and drought in forest trees, in E. REnNenberG, W. EsCHRICH \& H. ZIEGLER (eds), Trees - contributions to modern tree physiology, Backhuys Publishers, Leiden, pp. 215-238.

Ellenberg, H. (1996). Vegetation Mitteleuropas und der Alpen, Ulmer Verlag, Stuttgart.

Epron, D. \& E. Dreyer (1993). Photosynthesis of oak leaves under water stress: maintenance of high photochemical efficiency of photosystem II and occurrence of non-uniform $\mathrm{CO}_{2}$ assimilation, Tree Physiology 13: 107-117.

EPRON, D. \& E. DREYER (1996). Starch and soluble carbohydrates in leaves of water-stressed oak saplings, Annales des Sciences Forrestieres 53: 263-268.

Farquhar, G. D., K. T. Hubick, A. G. Condon \& R. A. Richards (1989). Carbon isotope fractionation and plant water-use efficiency, in P. W. RUNDEL, J. R. EHLERINGER \& K. A. NAGY (eds), Stable isotopes in ecological research, Springer Verlag, New York Berlin Heidelberg, pp. 21-40.

FARQUHAR, G. D. \& R. A. RichaRdS (1984). Isotopic composition of plant carbon correlates with water-use efficiency of wheat genotypes, Australian Journal of Plant Physiology 11: 539-552. 
FERET, P. P. \& F. BERGMANn (1976). Gel electrophoresis of proteins and enzymes, in J. P. MiksCHE (ed.), Modern methods in forest genetics, Springer Verlag, New York Berlin Heidelberg, p. 49.77.

Fischer, M., M. V. KLEUnEn \& B. SChmid (2000). Genetic allee effects on performance, plasticity and developmental stability in a clonal plant, Ecology Letters 3: 530-539.

FitTER, A. H. (1994). Architecture and biomass allocation as components of the plastic response of root systems to soil heterogeneity, in M. M. CALDWELL \& R. P. PEARCY (eds), Exploitation of environmental heterogeneity by plants, Academic Press, Inc., San Diego, pp. 305-323.

FitTER, A. H. (1996). Characteristics and functions of root systems, in Y. WAISEL, A. ESHEL \& U. KAFKAFI (eds), Plant roots: the hidden half, Dekker, New York, pp. 1-20.

Fort, C., F. Muller, P. LAbel, A. Granier \& E. Dreyer (1998). Stomatal conductance, growth and root signaling in Betula pendula seedlings subjected to partial soil drying, Tree Physiology 18: 769-776.

García-Plazaola, J. I. \& J. M. Becerril (2000). Effects of drought on photoprotective mechanisms in European beech (Fagus sylvatica L.) seedlings from different provenances, Trees 14: 485-490.

Gebre, G. M., M. R. Kuhns \& J. R. Brandle (1994). Organic solute accumulation and dehydration tolerance in three water stressed Populus deltoides clones, Tree Physiology 14: $575-587$.

Gebre, G. M. \& M. R. Kuhns (1993). Effects of water stress preconditioning on gas exchange and water relations of Populus deltoides clones, Canadian Journal of Forest Research 23: $1291-1297$.

Gebre, G. M., T. J. Tschaplinski, G. A. Tuskan \& D. E. Todd (1998). Clonal and seasonal differences in leaf osmotic potential and organic solutes of five hybrid poplar clones grown under field conditions, Tree Physiology 18: 645-652.

Gregorius, H.-R. \& J. R. G. Kleinschmit (1999). The environmental dichotomy of adaption and the role of genetic diversity, Silvae Genetica 48(3-4): 193-199.

Gregorius, H.-R. (1974). Genetischer Abstand zwischen Populationen I. Zur Konzeption der genetischen Abstandsmessung, Silvae Genetica 23: 22-27.

Greve, A., C. Leuschner \& W. U. Kriebitzsch (1992). Ökophysiologische Untersuchungen in einem Heide-Anflugwald auf armen Sanden in der Lüneburger Heide. I. $\mathrm{CO}_{2}$ Gaswechsel von Betula pendula und Pinus sylvestris unter natürlichen Bedingungen, Verhandlungen der Gesellschaft für Ökologie 21: 143-147.

Hacke, U. G., J. S. Sperry \& J. Pittermann (2000). Drought experience and cavitation resistance in six shrubs from the Great Basin, Utah, Basic and Applied Ecology 1: 31-41. 
HAGEMEIER, M. (2001). Funktionale Kronenarchitektur mitteleuropäischer Baumarten am Beispiel von Hängebirke, Waldkiefer, Traubeneiche, Hainbuche, Winterlinde und Rotbuche, $\mathrm{PhD}$ thesis, Universität Göttingen, Göttingen.

HeGi, G. (1981). Illustrierte Flora von Mitteleuropa, Vol. 3, Parey, Berlin.

Hertel, D. (1999). Das Feinwurzelsystem von Rein- und Mischbeständen der Rotbuche: Struktur, Dynamik und interspezifische Konkurrenz, PhD thesis, Universität Gesamthochschule Kassel. Vol. 317 of Dissertationes Botanicae, J. Cramer, Berlin Stuttgart.

Holopainen, T. \& L. KÄRENLAmPi (1997). Variation in ozone sensitivity among clones of Betula pendula and Betula pubescens, Environmental Pollution 95(1): 37-44.

Hubick, K. T., R. Shorter \& G. D. Farquhar (1989). Heritability and genotype x environment interactions of carbon isotope discrimination and transpiration efficiency in peanut (Arachis hypogea L.), Australian Journal of Plant Physiology 16: 799-813.

Ibrahim, L., M. F. Proe \& A. D. CAMeron (1997). Main effects of nitrogen supply and drought stress upon whole-plant carbon allocation in poplar, Canadian Journal of Forest Research 27: 1413-1419.

Jasienski, M., F. J. Ayala \& F. A. BAzZAZ (1997). Phenotypic plasticity and similarity of DNA among genotypes of an annual plant, Heredity 78: 176-181.

Jassby, A. D. \& T. PlatT (1976). Mathematical formulation of the relationship between photosynthesis and light for phytoplancton, Limnology and Oceanography 21: 540-547.

JiA, J., P. Niemelä, M. Rousi \& S. HÄrkÖNEN (1997). Selective browsing of moose (Alces alces) on birch (Betula pendula) clones, Scandinavian Journal of Forest Research 12: $33-40$.

Jonasson, S., H. Medrano \& J. Flexas (1997). Variation in leaf longevity of Pistacia lentiscus and its relationship to sex and drought stress inferred from leaf $\delta^{13} C$, Functional Ecology 11: 282-289.

Joslin, J. D., M. H. Wolfe \& P. J. HANSON (2000). Effects of altered water regimes on forest root systems, New Phytologist 147: 117-129.

KAISER, W. M. (1987). Effects of water deficit on photosynthetic capacity, Physiologia Plantarum 71: 142-149.

KELLOMÄKI, S. \& K.-Y. WANG (2001). Growth and resource use of birch seedlings under elevated carbon dioxide and temperature, Annals of Botany 87: 669-682.

KiKUZAWA, K. (1991). A cost - benefit analysis of leaf habit and leaf longevity of trees and their geographical pattern, The American Naturalist 138(5): 1250-1263.

Kleinschmit, J. (1998). Die Birke - Standortansprüche und Möglichkeiten der züchterischen Verbesserung, Forst und Holz 53(4): 99-104. 
Koide, R. Z., R. H. Robichaux, S. R. Morse \& C. M. Smith (1989). Plant water status, hydraulic resistance and capacitance, in R. W. PEARCY, J. R. Ehleringer, H. A. MoOney \& P. W. Rundel (eds), Plant physiological ecology, field methods and instrumentation, Chapman and Hall, London, New York, pp. 161-184.

KÖStler, J. N., E. BrÜCKNer \& H. BibelRiether (1968). Die Wurzeln der WaldbäumeUntersuchungen zur Morphologie der Waldbäume in Mitteleuropa, Verlag Paul Parey, Hamburg, Berlin.

Lebourgeois, F., G. Lévy, G. Aussenac, B. Clerc \& F. Willm (1998). Influence of soil drying on leaf water potential, photosynthesis, stomatal conductance and growth in two black pine varieties, Annales des Sciences Forrestieres 55: 287-299.

Lerner, I. M. (1956). Genetic homeostasis, Dover Publication Inc., New York.

Leuschner, C., D. Hertel, H. Coners \& V. Büttner (2001). Root competition between beech and oak: a hypothesis, Oecologia 126: 276-284.

LEUSCHNER, C. (1992). Ökophysiologische Untersuchungen in einem Heide-Anflugwald auf armen Sanden in der Lüneburger Heide. II. Blatt-Wasserstatus von Betula pendula und Pinus sylvestris im Jahresverlauf, Verhandlungen der Gesellschaft für Ökologie 21: 155-158.

Li, C., F. Berninger, J. Koskela \& E. Sonninen (2000). Drought responses of Eucalyptus microtheca provenances depend on seasonality of rainfall in their place of origin, Australian Journal of Plant Physiology 27: 231-238.

LI, C. (1998). Some aspects of leaf water relations in four provenances of Eucalyptus microtheca seedlings, Forest Ecology and Management 111: 303-308.

Liengsiri, C., C. Piewluang \& T. J. B. Boyle (1990). Starch gel electrophoresis of tropical trees, Asean Canada Forest Tree Seed Centre, Muak Lek, Saraburi.

LiU, L., A. J. S. McDonald, I. Stadenberg \& W. J. Davies (2001a). Abscisic acid in leaves and roots of willow: significance for stomatal conductance, Tree Physiology 21: 759_ 764.

LiU, L., A. J. S. McDonald, I. Stadenberg \& W. J. Davies (2001b). Stomatal and leaf growth responses to partial drying of root tips in willow, Tree Physiology 21: 765-770.

Loewenstein, N. J. \& S. G. Pallardy (1998). Drought tolerance, xylem sap abscisic acid and stomatal conductance during soil drying: a comparison of young plants of four temperate deciduous angiosperms, Tree Physiology 18: 421-430.

LÖSCH, R. \& E.-D. SCHULZE (1994). Internal coordination of plant responses to drought and evaporational demand, in E.-D. Schulze \& M. M. CALDWEll (eds), Ecological Studies: Ecophysiology and Photosynthesis, number 100, Springer Verlag, New York Berlin Heidelberg, pp. 185-204. 
Lösch, R. (2001). Wasserhaushalt der Pflanzen, Quelle \& Meyer Verlag, Wiebelsheim.

MAIER-MAERCKER, U. (1998). Dynamics of change in stomatal response and water status of Picea abies during a persistent drought period: a contribution to the traditional view of plant water relations, Tree Physiology 18: 211-222.

MÄKelä, A., F. BERninger \& P. HARI (1996). Optimal control of gas exchange during drought: theoretical analysis, Annals of Botany 77: 461-467.

Marmann, P. (1998). Der interne Stickstoffkreislauf von Esche (Fraxinus excelsior) und Birke (Betula pendula) bei unterschielicher Wasserversorgung, $\mathrm{PhD}$ thesis, Universität Bayreuth.

Marshall, D. M. \& S. K. Jain (1968). Phenotypic plasticity of Avena fatua and A. barbata, The American Naturalist 102: 457-467.

MAURER, S. \& R. MATYSSEK (1997). Nutrition and the ozone sensitivity of birch (Betula pendula): II. Carbon balance, water-use efficiency and nutritional status of the whole plant, Trees 12: 11-20.

Meinzer, F. C., N. Z. SAliendra \& C. H. Crisosto (1992). Carbon isotope discrimination and gas exchange in Coffea arabica during adjustment to different soil moisture regimes, Australian Journal of Plant Physiology 19: 171-184.

Mooney, H. A. (1986). Photosynthesis, in M. J. Crawley (ed.), Plant Ecology, Blackwell Scientific Publication, Oxford, pp. 345-373.

Moran, R. \& D. Porath (1980). Chlorophyll determination in intact tissues using N,NDimethylformamide, Plant Physiology 65: 478-479.

MORAN, R. (1982). Formulae for determination of chlorophyllous pigments extracted with N,N-Dimethylformamide, Plant Physiology 69: 1376-1381.

Müller, M. J. (1996). Handbuch ausgewählter Klimastationen der Erde, Forschungsstelle Bodenerosion der Universität Trier, Trier.

Munns, R., J. B. Passioura, J. Guo, O. Chazen \& G. R. Cramer (2000). Water relations and leaf expansion: importance of time scale, Journal of Experimental Botany 51(350): 1495-1504.

Mutikainen, P., M. Walls, J. Ovaska, M. Keinänen, R. Julkunen-Tiitto \& E. VAPAAVUORI (2000). Herbivore resistance in Betula pendula: Effect of fertilization; defoliation; and plant genotype, Ecology 81(1): 49-65.

NiInemets, Ü. \& O. Koll (1998). Stoichiometry of foliar carbon constituents varies along light gradients in temperate woody canopies: implications for foliage morphological plasticity, Tree Physiology 18: 467-479. 
Osorio, J., M. L. Osorio, M. M. Chaves \& J. S. Pereira (1998). Water deficits are more important in delaying growth than in changing patterns of carbon allocation in Eucalyptus globulus, Tree Physiology 18: 363-373.

PÄÄKKÖnen, E., J. VAhala, M. Pohjola, T. Holopainen \& L. KÄREnlampi (1998a). Physiological, stomatal and ultrastructural ozone responses in birch (Betula pendula Roth) are modified by water stress , Plant, Cell and Environment 21: 671-684.

P̈̈̈̈KKÖNen, E., M. S. GÜnthardt-Georg \& T. Holopainen (1998b). Responses of leaf processes in a sensitive birch (Betula pendula Roth) clone to ozone combined with drought, Annals of Botany 82: 49-59.

Palmroth, S., E. Berninger, E. NikinmaA, J. Lloyd, P. Pulkkinen \& P. Hari (1999). Structural adaptation rather than water conservation was observed in Scots pine over a range of wet to dry climates, Oecologia 121: 302-309.

PASOnen, H.-L., M. KÄPYLÄ \& P. PULKKINEN (2000). Effects of temperature and pollination site on pollen performance in Betula pendula Roth - evidence for genotype-environment interactions, Theoretical and Applied Genetics 100: 1108-1112.

PiCON, C., J. M. Guehl \& A. FERHi (1996). Leaf gas exchange and carbon isotope composition responses to drought in a drought-avoiding (Pinus pinaster) and a droughttolerant (Quercus petraea) species under present and elevated atmospheric $\mathrm{CO}_{2}$ concentrations, Plant, Cell and Environment 19: 182-190.

Pita, P. \& J. A. PARdos (2001). Growth, leaf morphology, water use and tissue water relations of Eucalyptus globulus clones in response to water deficit, Tree Physiology 21: 599_ 607.

Prentice, I. C., P. J. Bartlein \& T. WebB (1991). Vegetation and climate change in eastern North America since the last glacial maximum, Ecology 72: 2038-2056.

PRentiCE, I. C. (1993). Climate change - process and production, Nature 363: 209-210.

RANney, T. G., R. W. BIR \& W. A. SKROCH (1991). Comparative drought resistance among six species of birch (Betula): influence of mild water stress on water relations and leaf gas exchange, Tree Physiology 8: 351-360.

Reich, P. B., C. Uhl, M. B. Walters \& D. S. Ellsworth (1991). Leaf lifespan as a determinant of leaf structure and function among 23 amazonian tree species, Oecologia 86: $16-24$.

REINEKING, A., R. LANGEL \& J. SCHIKOWSKI (1993). ${ }^{15} \mathrm{~N},{ }^{13}$ C-on-line measurement with an elemental analyser (Carlo Erba, NA 1500), a modified trapping box and a gas isotope mass spectrometer (Finnigan, MAT 251), Isotopenpraxis Environmental Health Studies 29: $169-174$. 
Roupsard, O., H. I. Joly \& E. Dreyer (1998). Variability of initial growth, water-use efficiency and carbon isotope discrimination in seedlings of Faidherbia albida (Del.) A. Chev., a multipurpose tree of semi-arid Africa. Provenance and drought effects, Annales des Sciences Forrestieres 55: 329-348.

Rousi, M., J. Tahvanainen, H. Henttonen, D. A. Herms \& I. Uotila (1997). Clonal variation in susceptibility of white birch (Betula spp.) to mammalian and insect herbivores, Forest Science 43(3): 396-402.

SCHEINER, S. M. (1993). Plasticity as a selectable trait: reply to Via, The American Naturalist 142(2): 371-373.

Schlichting, C. D. \& D. A. Levin (1984). Phenotypic plasticity of annual phlox: tests of some hypotheses, American Journal of Botany 71(2): 252-260.

Schlichting, C. D. \& M. Pigliucci (1993). Control of phenotypic plasticity via regulatory genes, The American Naturalist 142(2): 366-370.

Schlichting, C. D. (1986). The evolution of phenotypic plasticity in plants, Annual Review of Ecology and Systematics 17: 667-693.

SCHMUCKER, T. (1942). Die Baumarten der Nördlich-gemäßigten Zone und ihre Verbreitung, in KÖSTLER (ed.), Schriftenreihe der Internationalen Forstzentrale, Vol. 4, Centre Internationale de Sylviculture.

Scholander, P. F., H. T. Hammel, E. D. Bradstreet \& E. A. Hemmingsen (1965). Sap pressure in vascular plants, Science 148: 339-346.

Schulte, M. (1992). Saisonale und interanuelle Variabilität des $\mathrm{CO}_{2}$-Gaswechsels von Buchen (Fagus sylvatica L.) - Bestimmung von C-Bilanzen mit Hilfe eines empirischen Modells, $\mathrm{PhD}$ thesis, Universität Göttingen, Göttingen.

SitTe, P., H. Ziegler, F. EHRENDORFER \& A. BRESINSKY (1991). Lehrbuch der Botanik, Gustav Fischer Verlag, Stuttgart, Jena, New York.

Sokal, R. R. \& F. J. Rohlf (1981). Biometry, W.H. Freeman, San Francisco.

Souch, C. A. \& W. STEPhEns (1998). Growth, productivity and water use in three hybrid poplar clones, Tree Physiology 18: 829-835.

SPERRY, J. S. \& N. Z. S ALIENDRA (1994). Intra- and inter-plant variation in xylem cavitation in Betual occidentalis, Plant, Cell and Environment 17: 1233-1241.

TAYLOR, G. \& W. J. DAVIES (1986). Yield turgor of growing leaves of Betula and Acer, New Phytologist 104: 347-353.

Teklehaimanot, Z., J. LAnek \& H. F. Tomlinson (1998). Provenance variation in morphology and leaflet anatomy of Parkia biglobosa and its relation to drought tolerance, Trees 13: 96-102. 
Thomas, F. M. (2000). Growth and water relations of four deciduous tree species Fagus sylvatica L., Quercus petraea [Matt.] Liebl., Q. pubescens Willd., Sorbus aria [L.] Cr.) occurring at Central-European tree-line sites on shallow calcarous soils: physiological reactions of seedlings to severe drought, Flora 195: 104-115.

Thompson, K. (1987). The ressource ratio hypothesis and the meaning of competion, Functional Ecology 1: 297-315.

Tilman, D. (1980). Resources: a graphical-mechanistic approach to competition and predation, The American Naturalist 116: 362-393.

Tognetti, R., J. D. Johnson \& M. Michelozzi (1995). The response of European beech (Fagus sylvatica) seedlings from two Italian populations to drought and recovery, Trees 9: 348-354.

Trejo, C. L. \& W. J. DAVIES (1991). Drought induced closure of Phaseolus vulgaris L. stomata precedes leaf water deficit and any increase in xylem ABA concentration, Journal of Experimental Botany 42(245): 1507-1515.

Triboulot, M. B., J. Pritchard \& D. Tomos (1995). Stimulation and inhibition of pine root growth by osmotic stress, New Phytologist 130: 169-175.

Tschaplinski, T. J., G. A. Tuskan, G. M. Gebre \& D. E. Todd (1998). Drought resistance of two hybrid Populus clones grown in a large-scale plantation, Tree Physiology 18: $653-658$.

TuOMela, K. (1997). Physiological and morphological responses of Eucalyptus microtheca provenances to water availability in tropical drylands, $\mathrm{PhD}$ thesis, University of Helsinki.

TURNER, N. C. \& M. M. JONES (1980). Turgor maintenance by osmotic adjustment: a review and evaluation, in N. C. TURNER \& P. J. KRAMER (eds), Adaptation of plants to water and high temperature stress, John Wiley and Sons, London, pp. 87-103.

TyReE, M. T. \& H. T. HAMmel (1972). The measurement of the turgor pressure and the water relations of plants by the pressure-bomb technique, Journal of Experimental Botany 23: $267-282$.

Tyree, M. T. \& J. S. SPERRY (1989). Vulnerability of xylem to cavitation and embolism, Annual Review of Plant Physiology and Molecular Biology 40: 19-38.

Tyree, M. T. \& P. G. Jarvis (1982). Water in tissues and cells, in O. L. LAnge, P. S. Nobel, C. B. Osmond \& H. ZIEGler (eds), Encyclopedia of plant physiology 2. Physiological plant ecology, Springer Verlag, New York Berlin Heidelberg, pp. 36-77.

VIA, S. (1993). Adaptive phenotypic plasticity: target or by-product of selection in a variable environment, The American Naturalist 142(2): 352-365. 
VIA, S. (1994). The evolution of phenotypic plasticity: what do we really know?, in L. A. REAL (ed.), Ecological genetics, Princeton University Press,, pp. 35-57.

Villani, F., M. PigliucCi, M. Lauteri \& M. Cherubini (1992). Congruence between genetic, morphometric, and physiological data on differentiation of Turkish chestnut (Castanea sativa), Genome 35: 251-256.

von Caemmerer, S. \& G. D. Farquhar (1981). Some relationships between the biochemistry of photosynthesis and the gas exchange of leaves, Planta 153: 376-387.

WAnG, J. R., C. D. B. HAwkins \& T. Letchford (1998a). Photosynthesis, water and nitrogen use efficiencies of four paper birch (Betula papyrifera) populations grown under different soil moisture and nutrient regimes, Forest Ecology and Management 112: 233-244.

Wang, J. R., C. D. B. Hawkins \& T. LetchFord (1998b). Relative growth rate and biomass allocation of paper birch (Betula papyrifera) polations under different soil moisture and nutrient regimes, Canadian Journal of Forest Research 28: 44-55.

WANG, T. L. (1996). Allozyme variation in populations, full-sib families and selfed lines in Betula pendula Roth, Theoretical and Applied Genetics 92: 1052-1058.

White, D. A., N. C. Turner \& J. H. Galbraith (2000). Leaf water relations and stomatal behavior of four allopatric Eucalyptus species planted in Mediterranean southwestern Australia, Tree Physiology 20: 1157-1165.

Witterungs Report Daten (1999/2000). Deutscher Wetterdienst.

WU, R. (1998). The detection of plasticity genes in heterogeneous environments, Evolution 52(4): 967-977.

Xu, Z. H., P. G. Saffigna, G. D. Farquhar, J. A. Simpson, R. J. Haines, S. Walker, D. O. Osborne \& D. Guinto (2000). Carbon isotope discrimination and oxygen isotope composition in clones of the $F_{1}$ hybrid between slash pine and Caribbean pine in relation to tree growth, water-use efficiency and foliar nutrient concentration, Tree Physiology 20: $1209-1217$.

ZHANG, J. \& W. J. DAVIES (1989). Abscisic acid produced in dehydrating roots may enable the plant to measure the water status of the soil, Plant, Cell and Environment 12: 73-81.

Zhang, J. W., Z. Feng, G. M. GregG \& C. M. Schumann (1997). Carbon isotopic composition, gas exchange, and growth of three populations of ponderosa pine differing in drought tolerance, Tree Physiology 17: 461-466.

ZIEgler, H. (1995). Stable isotopes in plant physiology and ecology, Progress in Botany 56: $1-24$. 


\section{Acknowledgement}

My thanks go first to Prof. Christoph Leuschner for all the support he has given me during my studies.

My work would not have been half as enjoyable without my colleagues and friends Lars, Heinz, Florian, Dietrich, Ralf, Tom, Marc, Dirk, and all the others in Kassel and Göttingen. Special thanks to Sabine for all the work with the trees, and in particular to Dietrich, whose advice I could always count on.

This work has been supported by the DFG through grants No. LE 762/3-1 and LE 762/3-2. 


\section{Lebenslauf}

Name

Geburtsdatum

Geburtsort

Eltern

Staatsangehörigkeit

Familienstand
Stella Theresia Aspelmeier, geb. Landwehr

03. 10. 1968

Verl

Elisabeth und Günter Landwehr

deutsch

verheiratet

1975 - 1979 Besuch der Grundschule in Verl-Kaunitz

1979 - 1988 Besuch des Gymnasiums Verl

Juni 1988 Abitur am Gymnasium Verl

Sept. 1988 - Mai 1990 Ausbildung zur Industriekauffrau bei der Claas OHG, Harsewinkel

Mai 1990 Abschlußprüfung zur Industriekauffrau vor der Industrie- und Handelskammer

Jan. 1989 - Nov. 1989 Vorbereitung zur Wirtschaftsenglischprüfung "English for Business" an der Berlitz Schule Gütersloh

Nov. 1989 Abschlußprüfung "English for Business" vor der britischen Industrie- und Handelskammer

Mai 1990 - Aug. 1990 Beschäftigung als Industriekauffrau bei der Claas OHG, Harsewinkel

Okt. 1990 bis Juli 1992 Grundstudium der Biologie an der Georg-August Universität Göttingen

Juli 1992 Vordiplom Biologie an der Universität Göttingen

Okt. 1992 - Juni 1993 Weiterführung des Studiums an der University of Edinburgh, Großbritannien

Okt. 1993 - Sept. 1997 Weiterführung des Studiums an der Universität Göttingen

Aug. und Sept. 1994 Praktikum zur Photosynthese antarktischer Flechten am Zentrum für Mündungs- und Küstenökologie des Niederländischen Institutes für Ökologie in Yerseke

Juni 1995 - Sept. 1995 Beschäftigung als studentische Hilfskraft am Lehrstuhl für Geobotanik der Universität Göttingen und Teilnahme an einem einmonatigen Forschungsprojekt des Lehrstuhls in List/Sylt

Sept. 1997 Diplom im Fach Biologie an der Universität Göttingen

ab Nov. 1997 Promotion in der Arbeitsgruppe von Prof. Christoph Leuschner, bis Oktober 2000 an der Gesamthochschule Kassel, dann an der Universität Göttingen 